\title{
Educators' Perceptions of Preparation and Practice for Teaching Algebra I to Students with Mathematical Learning Disabilities
}

\author{
Sararose DeVore Lynch \\ West Virginia University
}

Follow this and additional works at: https://researchrepository.wvu.edu/etd

\section{Recommended Citation}

Lynch, Sararose DeVore, "Educators' Perceptions of Preparation and Practice for Teaching Algebra I to Students with Mathematical Learning Disabilities" (2011). Graduate Theses, Dissertations, and Problem Reports. 3101.

https://researchrepository.wvu.edu/etd/3101

This Dissertation is protected by copyright and/or related rights. It has been brought to you by the The Research Repository @ WVU with permission from the rights-holder(s). You are free to use this Dissertation in any way that is permitted by the copyright and related rights legislation that applies to your use. For other uses you must obtain permission from the rights-holder(s) directly, unless additional rights are indicated by a Creative Commons license in the record and/ or on the work itself. This Dissertation has been accepted for inclusion in WVU Graduate Theses, Dissertations, and Problem Reports collection by an authorized administrator of The Research Repository @ WVU.

For more information, please contact researchrepository@mail.wvu.edu. 
Educators' Perceptions of Preparation and Practice for Teaching Algebra I to Students with Mathematical Learning Disabilities

Sararose DeVore Lynch

B.S. West Virginia Wesleyan, 2004

M.S. West Virginia University, 2006

Dissertation submitted to the College of Human Resources and Education

at West Virginia University

in partial fulfillment of the requirements

for the degree of

Doctor of Education

in

Curriculum and Instruction

Approved by

Johnna Bolyard, Ph.D., Chairperson

Ann Richards, Ph.D.

Patricia Obenauf, Ed.D.

Sarah Selmer, Ed.D.

Reagan Curtis, Ph.D.

Department of Curriculum \& Instruction/Literacy Studies

Morgantown, West Virginia

2011

Keywords: Algebra I Teacher Preparation, Teacher Perceptions, Mathematical Learning

Disabilities, Algebra I Instructional Practices

Copyright 2011 Sararose D. Lynch 


\begin{abstract}
Educators' Perceptions of Preparation and Practice for Teaching Algebra I to Students with Mathematical Learning Disabilities
\end{abstract}

Sararose D. Lynch

The purpose of this mixed methods study was to describe the current state of Algebra I instruction for students with mathematical learning disabilities (MLD) in West Virginia and teachers' preparation for this practice, as perceived by teachers. Further, this study examined the extent teachers' instructional practices for teaching students with MLD Algebra I aligned with best practices recommended in the research literature. Fifty-seven educators from West Virginia who taught Algebra I to students with Mathematical Learning Disabilities completed the Survey of Instructional Practices Implemented by Algebra I General and Special Educators When Educating Students with a MLD. In addition, a subset of five survey respondents participated in a telephone interview. Descriptive analyses were performed on the quantitative data, and correlations and relations were examined comparing teachers on demographic variables. The qualitative data analyses included conventional content analysis of the literature and open-ended survey responses, and directed content analysis of the interview transcripts. The results from this study described the varied current state of Algebra I instruction for students with MLD and teachers preparation for teaching Algebra I to students with MLD in West Virginia. Algebra I and Algebra Support educators reported the use of five literature recommended practices for Algebra I instruction to students with MLD during typical classroom instruction: (a) the use of technology, (b) cognitive instructional strategies, (c) explicit instruction, (d) graphic organizers, and (e) peer assisted learning. However, Algebra I and Algebra Support educators reported not using manipulatives or CRA as part of their typical classroom instruction. Further, correlations existed between specific educator characteristics and manipulative use. 


\section{DEDICATION}

I dedicate this work to my family who supported me through this whole process. Jeremy, I thank you for your unyielding and unconditional support throughout the years of my Ed.D education. To my daughter, Isabelle, I love you and your arrival motivated me to finish my dissertation in the timeliest manner possible. Joe Smith and Toni DeVore, my parents, I want to thank you for the love of education you instilled in me and for always believing in me. Your accomplishments and service to others as educators inspired me to become an educator. Appreciation goes out to my friend Cresta Kowalski for being my sounding board at times and watching Isabelle during those last few months of my dissertation writing. The devotion and support of my family made the completion of this dissertation possible. 


\section{ACKNOWLEDGEMENTS}

I would like to express my sincere gratitude to the members of my Dissertation Committee, Dr. Johnna Bolyard, Dr. Ann Richards, Dr. Sarah Selmer, Dr. Pat Obenauf, and Dr. Reagan Curtis. Thank you for your willingness to support me through my doctoral program. Dr. Johnna Bolyard, I thank you for your never-ending belief in my abilities and continual encouragement to always strive for excellence. As my mentor, I thank you for providing me with numerous opportunities to grow professionally as an educator and a researcher. Through our collaborative projects, you taught me what it truly means to be a reflective and informed practitioner and for that I will always be grateful. Dr. Ann Richards, thank you for convincing me that I should pursue a doctoral degree.

I am especially grateful to Lou Maynus, the WVDE Mathematics Coordinator, and Dr. Laura Pyzdrowski for giving me insight and access to the WVDE expectations and professional development for teaching Algebra I to students with MLD. I also want to thank the teachers who participated in this study. 
TABLE OF CONTENTS

Page

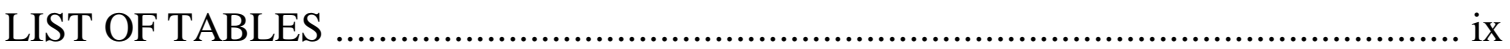

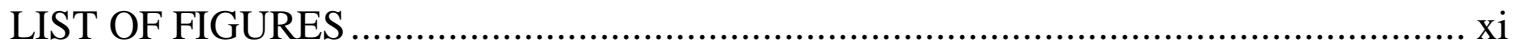

CHAPTER 1: INTRODUCTION ....................................................................

Purpose Statement .............................................................................

Policies Surrounding Mathematics Instruction in the United States .........................

Trends in Assessment Data .............................................................................2

Implications of NCLB ......................................................................... 3

Implications of IDEA (2004) ............................................................... 4

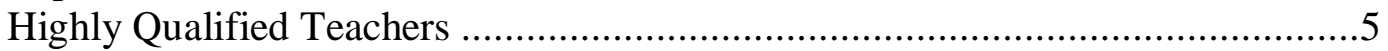

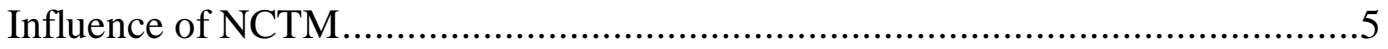

Current State of Algebra I Instruction in the United States ................................6

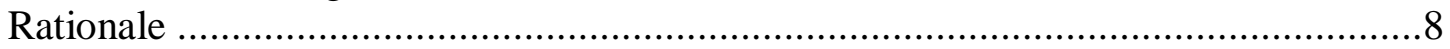

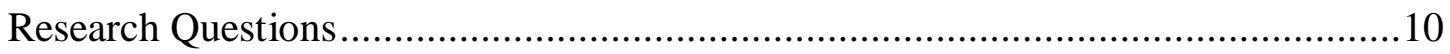

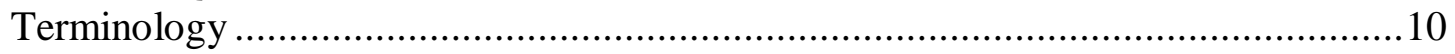

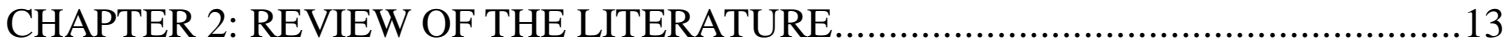

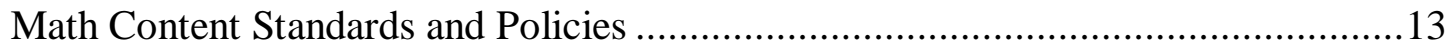

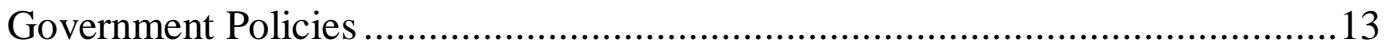

NCTM Principles, Standards, and Focal Points ............................................... 14

Influence of NCTM Principles and Standards .......................................... 16

Algebra I Content Standards and Policies ......................................................16

Algebra I Content Standards and Policies in West Virginia .............................18

Common Core State Standards ............................................................19

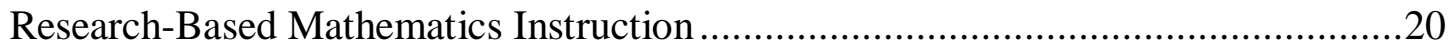

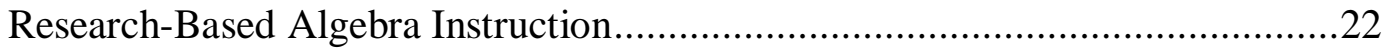

Teaching and Learning for Students with Mathematical Learning Disabilities..........23

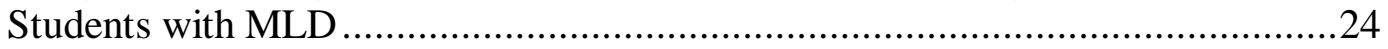

Effective Instructional Strategies for Students with MLD ................................26

Implementation of Effective Instructional Strategies .....................................30

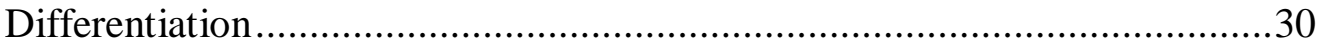

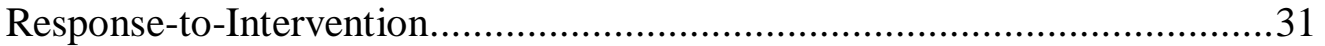

Effective Strategies for Teaching Algebra I to Students with MLD .....................32

Implementation Issues When Instructing Students with MLD ..............................36

Mathematics Instructional Issues for Students with MLD ...............................37

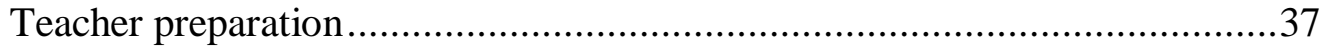

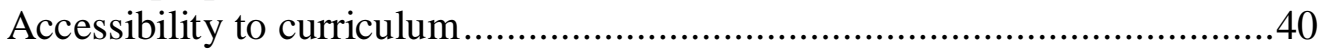

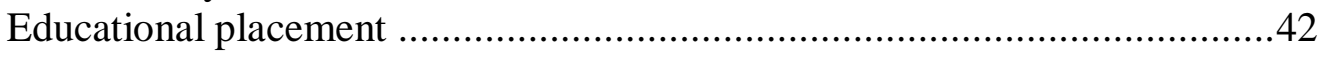

Algebra I Implementation Issues for Instruction of Students with MLD ............43

Algebra I Implementation Issues for Instruction of Students with MLD in

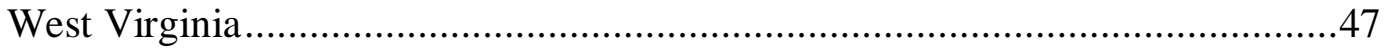

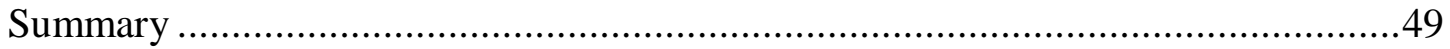

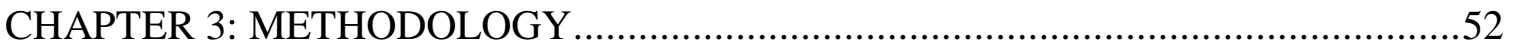




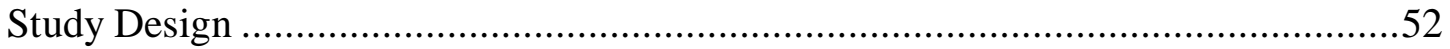

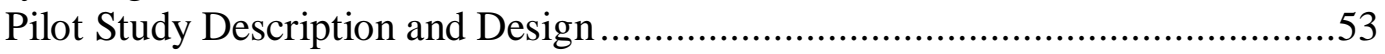

Pilot study findings that informed the state-wide study ............................ 58

Participants and Setting ....................................................................................59

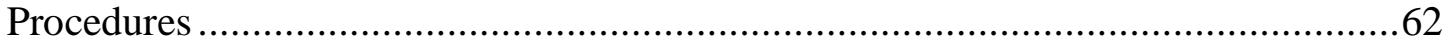

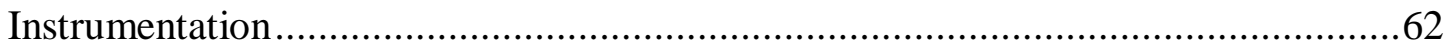

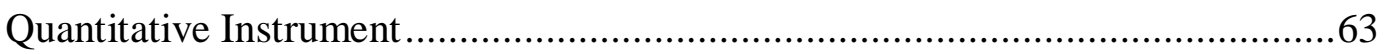

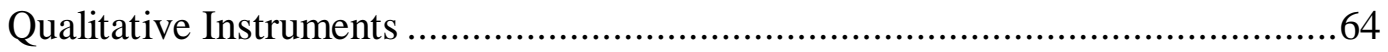

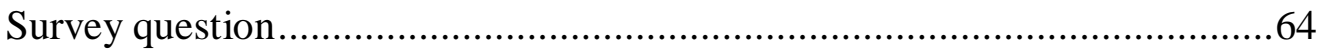

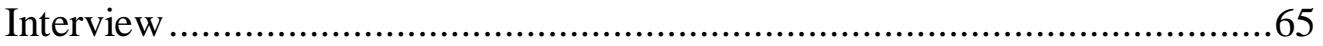

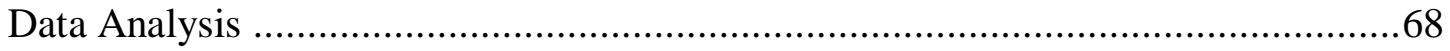

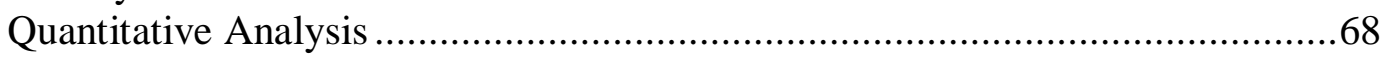

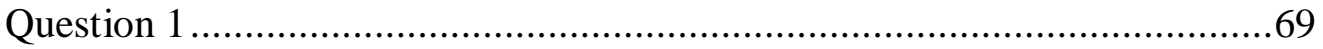

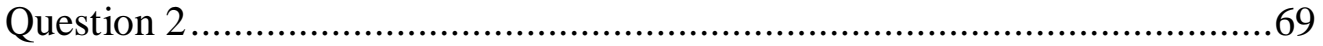

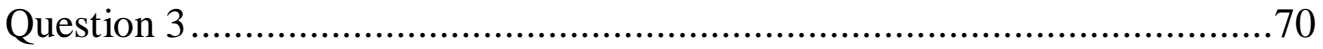

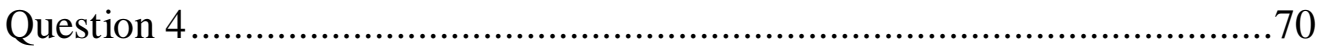

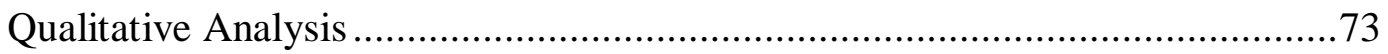

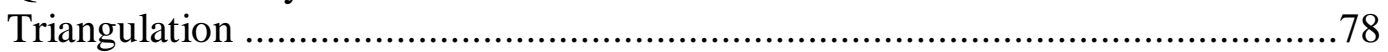

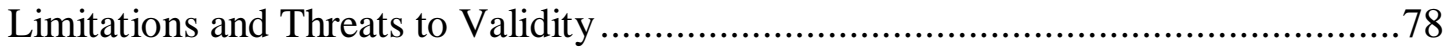

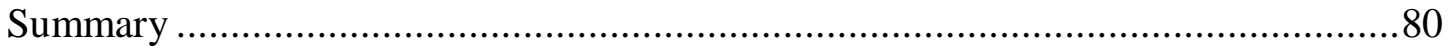

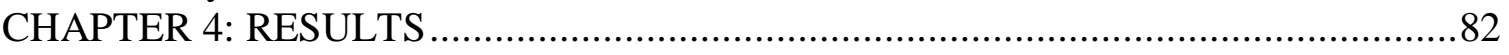

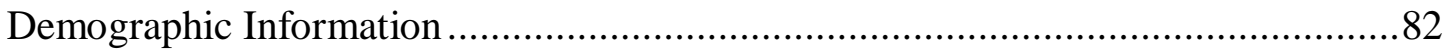

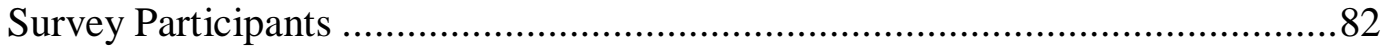

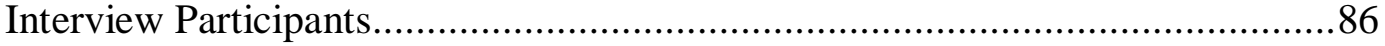

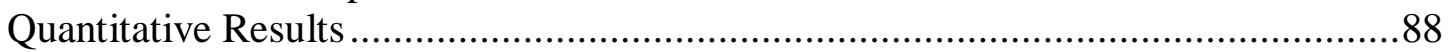

Educational and Professional Development Opportunities ..................................8

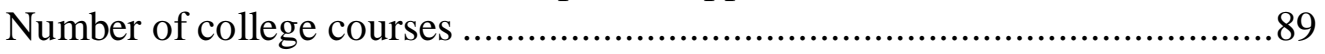

Amount of professional development offerings …………............................99

Format of professional development offerings ..............................................95

Perceptions Regarding Educational and Professional Development Opportunities

Description of perceptions based on preparedness .....................................99

Implemented Practices and Alignment to Literature Recommended Practices ..102

Reported use of literature recommended instructional practices ...................102

Perceived Issues Surrounding the Algebra I Instruction of Students with MLD 108

Perceptions of how effectively students with MLD were taught Algebra I ..108

Perceptions of issues when teaching Algebra I to students with MLD ..........109

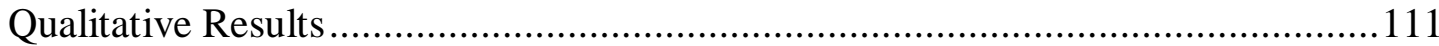

Educational and Professional Development Opportunities .................................114

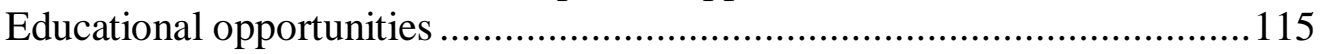

Professional development opportunities......................................................116

Perceptions Regarding Educational and Professional Development Opportunities

.

Perceptions of higher education teacher preparation ...................................120 
Perceptions of professional development teacher preparation 121 Implemented Practices and Alignment to Literature Recommended Practices ..121

Survey and interview results on CRA and manipulative use 125

Perceived Issues Surrounding the Algebra I Instruction of Students with MLD 127

Varied classroom instructional environments..................................... 128

Inclusive classrom instructional issues................................................. 130

Challenging student characteristics .................................................... 133

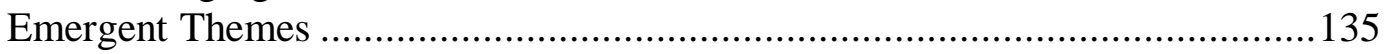

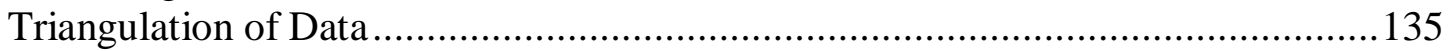

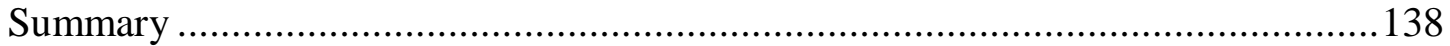

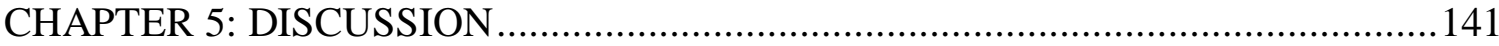

Current State of Algebra I Instruction for Students with MLD and Teachers'

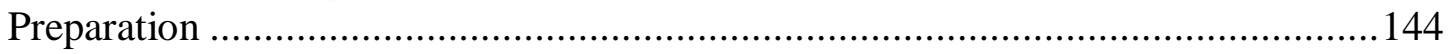

Varied State of Educational and Professional Development Opportunities

Addressing Algebra I Instruction for Students with MLD ..............................144

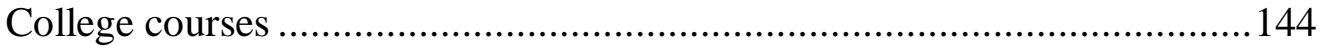

Professional development ......................................................... 146

Perceptions Regarding Educational and Professional Development Experiences in

Regards to Preparedness to Implement Instructional Practices ........................ 147

The influence of instruction in pedagogical strategies to strengthen the

mathematics learning of students ........................................................... 148

Reported Instructional Practices Alignment to Recommended Practices ........... 149

Perceptions Regarding Professional Development Experiences and the Use of

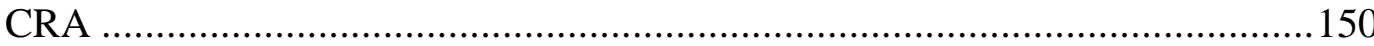

Perceived Issues Regarding the Instruction of Algebra I to Students with MLD151

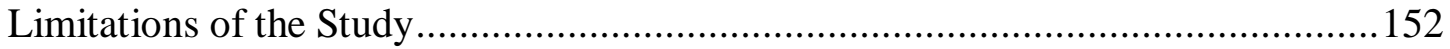

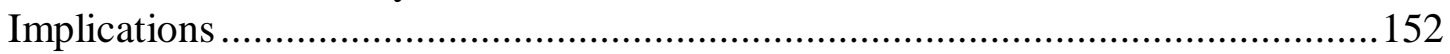

Implications for Research.............................................................. 153

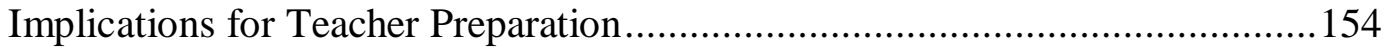

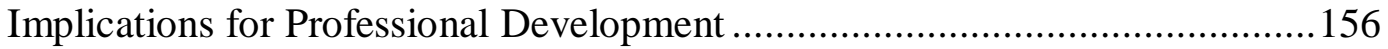

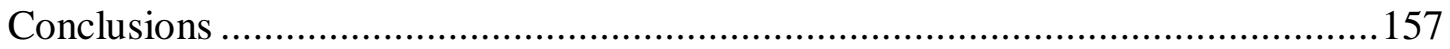

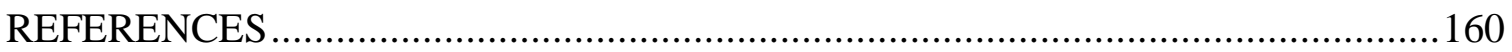

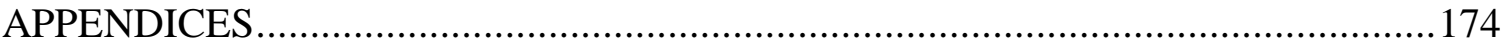

Appendix A: Email Message Inviting Teachers to Complete the Survey of

Instructional Practices Implemented by Algebra I General and Special Educators

When Educating Students with a MLD ................................................... 175

Appendix B: Cover Letter to Teachers Who Complete the Survey of Instructional

Practices Implemented by Algebra I General and Special Educators When Educating

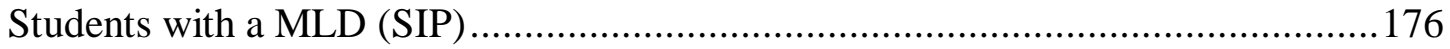

Appendix C: Survey of Instructional Practices Implemented by Algebra I General and Special Educators When Educating Students With a MLD (SIP)......................... 177

Appendix D: Interview Cover Letter ...................................................... 185

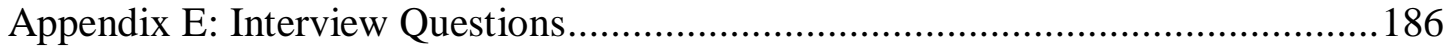

Appendix F: Coding Chart for Cross Interview Analysis .................................... 188 
Appendix G: Crosstabulation of "Highly Qualified" in Mathematics and Number of College Courses Addressing MLD....

Appendix H: Crosstabulation of "Highly Qualified" in Special Education and Number of College Courses Addressing MLD

Appendix I: Crosstabulation of RESA of Employment Compared to Hours of

Professional Development Addressing Students with MLD .....................................191

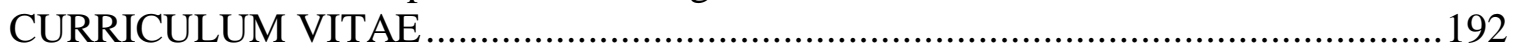




\section{LIST OF TABLES}

Tables

Page

Table 1. Pilot Study Interview Questions .57

Table 2. Description of Additional Interview Questions .......................................67

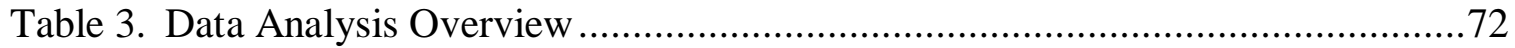

Table 4. Themes of Best Practices and Perceived Issues When Teaching Students

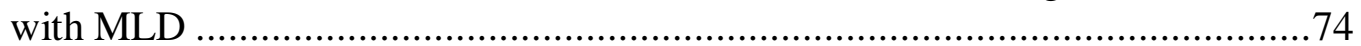

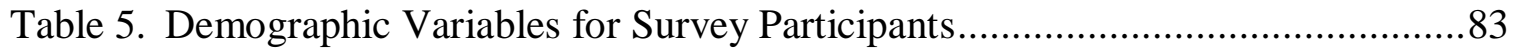

Table 6. Demographic Variables of the Follow-Up Interview Participants ...................86

Table 7. Crosstabulation of Certification and Number of College Courses

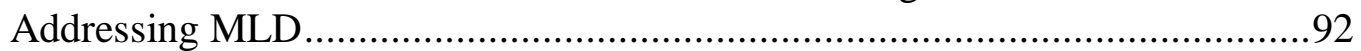

Table 8. Format of Attended Professional Development Sessions That Address Students With MLD ....

Table 9. Significant Chi-square Results Between Types of Professional Development Sessions and Demographic Characteristics....

Table 10.Level of Preparedness to Use Specific Practices When Teaching Students with MLD

Table 11.Frequency of Utilized Literature Recommended Instructional Practices by Participants When Teaching Students with MLD.

Table 12.Significant Chi-square Results between Types of Utilized Instructional Practices and Demographic Characteristics.

Table 13.Teachers' Perceptions of Issues When Teaching Algebra I to Students with MLD .

Table 14.Thematic Category Codes Used for Directed Content Analysis of Interview Transcripts

Table 15. Codes Used to Analyze Participants' Perceived Issues When Teaching Students with MLD

Table 16. Interview Responses Regarding Educational Opportunities for Teaching Algebra I to Students with MLD.

Table 17.Interview Responses Regarding Professional Development Opportunities for Teaching Algebra I to Students with MLD ....

Table 18.Survey and Interview Responses Regarding Perceptions of Educational and Professional Development Experiences That Addressed Teaching Algebra I to Students with MLD

Table 19. Best Practices for Teaching Algebra I to Students with MLD Alignment with Literature Recommendations

Table 20.Responses Regarding the use of CRA/Graduated Instructional Sequence When Teaching Algebra I to Students with MLD

Table 21. Responses Regarding the Theme of Issues With Varied Algebra I Classroom Instructional Environment for Students with MLD. 
Table 22.Responses Regarding the Theme of Issues With the Inclusive Algebra I Classroom for Students with MLD

Table 23.Responses Reguarding the Theme of Issues of Challenging Student Characteristics When Teaching Algebra I to Students with MLD .134 


\section{LIST OF FIGURES}

Figure

Page

Figure 1. Number of College Courses That Addressed Students with MLD-Special Educators vs. General Educators ..............................................................89 


\section{CHAPTER 1: INTRODUCTION}

If there is a heaven for school subjects, algebra will never go there. It is the one subject in the curriculum that has kept children from finishing high school, from developing their special interests and from enjoying much of their home study work. It has caused more family rows, more tears, and more heartaches, and more sleepless nights than any other school subject.

\section{Purpose Statement}

-Anonymous editorial writer [ca. 1936]

The purpose of this study was to describe the current state of Algebra I instruction for students with mathematical learning disabilities (MLD) in West Virginia and teachers' preparation for this practice, as perceived by teachers. Further, this study examined the extent teachers' instructional practices for teaching students with MLD Algebra I aligned with best practices recommended in the research literature. Results from this study could influence the development of future professional development offerings, state and county supported programs, and resources that address the challenges faced in today's Algebra I classrooms.

\section{Policies Surrounding Mathematics Instruction in the United States}

Reforms to secondary public education in the United States occurred continuously over the past decade because of the Individuals with Disabilities Education Act (IDEA) of 2004 and the No Child Left Behind Act (NCLB) of 2001. Mandates from these acts require schools to make the general education curriculum more accessible for students with disabilities, while requiring these students to meet higher standards based on content proficiency. These changes in curriculum directly and immediately impact both the largest group of students receiving special education services, those with specific learning disabilities (SLD), and the teachers who instruct these students (National Center for Education Statistics [NCES], 2010). 


\section{Trends in Assessment Data}

Prior to NCLB (2002), other policies and reports called for large-scale assessment for accountability in the United States. With the launch of Sputnik in 1957 and the release of the Nation At Risk report in 1983, the United States entered into a global competition for the highest achieving students in mathematics and science (Urban \& Wagnor, 2009). In 1999 data from the Trends in International Mathematics and Science Study (TIMSS), the most commonly utilized tool for making international comparisons of student achievement (Lange, 2007), ranked mathematics achievement of eighth-grade students from the United States 19 out of 38 countries (NCES, 2009). Similarly, in the 2003 TIMSS data the United States ranked 15 out of 45 countries in eighth-grade mathematics achievement (NCES, 2009). According to the 2007 TIMSS data, the United States ranked ninth out of 45 countries, but continued to fall behind international competitors in Asia and Europe (NCES, 2009).

Within the United States, the National Assessment of Educational Progress (NAEP) is administered to monitor student achievement in fourth, eighth, and twelfth grades. Over the last two decades of the $20^{\text {th }}$ century, the NAEP results highlighted shortcomings in the United States' public school mathematics efforts with regard to the gap between the achievement of students without disabilities and students receiving special education services (Kieran, 2007). Based on the NAEP results of the late 1980s, secondary students from the United States appeared to have some knowledge of basic algebraic concepts and skills, but students were not able to apply that knowledge in problem-solving situations, nor did they seem to understand many of the fundamental algebraic concepts and skills (Kieran, 1992). In 2009, the NAEP results reported a higher percentage of eighth-grade students with disabilities performing at/or above Basic and at/or above Proficient than in all previous NAEP assessments (NCES, 2009). However, these 
students still scored significantly lower than students without disabilities. This gap in achievement between students with disabilities and their non-disabled peers is commonly referred to as the general education-special education achievement gap. This gap applies not only to results of the NAEP, but many state assessments as well (Loveless, 2008).

\section{Implications of NCLB}

In response to the mathematics achievement trends present in the results from both NAEP and TIMSS, the government signed into law the NCLB act in 2001. NCLB (2002) mandates focus on the following four pillars: (1) stronger accountability for results, (2) more freedom for states and communities, (3) research-based programs and practices, and (4) expanded parental options. Additionally, NCLB (2002) mandates high content standards and academic proficiency for all students as measured by adequate yearly progress (AYP). The requirements for AYP apply to state education associations (SEA), local education associations (LEA), schools, and individual subgroups of students as specified by race, income, and special education services received. The intent of NCLB (2002) is not only to enable U.S. students to become academically competitive on an international level, but to also advance the achievement of all students by holding schools accountable for the academic proficiency of all students, including students with disabilities (Ferrini-Mundy \& Floden, 2007). In order to advance the achievement of all students, NCLB (2002) requires students with disabilities to be educated with their non-disabled peers when appropriate. This requirement increases access to the general education curriculum for at risk student populations in the United States. The United States appears to be on track with the inclusion of students with disabilities, as measured by the NCLB Survey (Eckes \& Swando, 2009; Education Commission of the States, 2005). However, an 
achievement gap still exists in the United States. Across the nation, many schools fail to make AYP because of the students with disabilities subgroup (Eckes \& Swando, 2009).

\section{Implications of IDEA (2004)}

The primary policy addressing the education of students with disabilities is IDEA (2004). This act ensures that students with disabilities receive a free and appropriate public education within the least restrictive environment (LRE). IDEA (2004) requires that instructional strategies and interventions for students with SLD be legally based on the services, accommodations, and modifications documented in the students' Individualized Education Program (IEP). An administrator, special educator, general educator, and a student's guardian develop a student's IEP to provide specially designed instruction, at no cost to parents, and to meet the specific needs of a student with a disability (IDEA, 2004; National Center for Learning Disabilties[NCLD], 2008). Specially designed instruction is the adaptation of the content, methodology, or delivery of instruction to attend to the specific needs of the student that result from the child's disability. The intent of this specially designed instruction is to ensure access to the general education curriculum, in order to offer an opportunity to achieve the educational standards of their SEA (IDEA, 2004; NCLD, 2008). Typically, inclusive classrooms with general education peers provide instruction for the majority of students with the primary identification of SLD, while the minority of this population is students in a self-contained classroom (NCES, 2009). This shift from educating students with SLD in a self-contained classroom to inclusion has resulted in many teachers, general and special educators, being required to teach and utilize unfamiliar content and instructional practices (Brodesky, Gross, McTigue \& Tierney, 2004; Maccini \& Gagnon, 2002, 2006). 


\section{Highly Qualified Teachers}

In an educational era driven by legislation such as NCLB (2002) and IDEA (2004), a focus on creating "highly qualified" teachers who are well educated about the subject matter they are teaching is at the forefront of education across the United States. A combination of mandates from both acts changed the requirements for both general and special education teacher preparation programs nationwide (U.S. Department of Education [ED], 2007). In mathematics, the National Council of Teachers of Mathematics (NCTM) provides suggestions for the mathematics content all public school students should learn. These suggestions directly influence the required mathematics content coursework for "highly qualified" teachers. While these requirements may support the development of teachers' knowledge of subject-matter content, recent studies found that even teachers who are "highly" educated about the subject matter they are teaching are not necessarily "highly" educated in instructional strategies needed to reach all students (DeSimone \& Parmer, 2006; Maccini \& Gagnon 2002).

\section{Influence of NCTM}

Although federal legislation is main source of curricular and instructional changes in American public schools, professional organizations also have a strong influence on these changes. NCTM has influenced mathematics curriculum and instruction in United States public schools since 1980 (NCTM, 1989, 2000, 2006, 2009). In 2000, NCTM recommended six Principles for school mathematics: equity, curriculum, teaching, learning, assessment, and technology. The Equity Principle addresses the needs of students with SLD. This Principle calls for mathematics instruction with strong support and high expectations for all students. It emphasizes that all students should not be treated in the same manner but should have access to the same challenging curriculum. Low expectations should no longer exist for low achieving 
students, especially those with disabilities, because low expectations coupled with tracking are characteristics of many mathematics classes that have traditionally not offered significant mathematical substance to struggling students. The Equity Principle concludes by emphasizing that all students can learn when offered access to high-quality mathematics instruction. Such instruction should be the norm instead of the exception (NCTM, 2000). NCLB (2002) and IDEA (2004) support the suggested curriculum and instruction outlined in the Equity Principle (NCTM, 2000; ED, 2007).

\section{Current State of Algebra I Instruction in the United States}

For almost a century, algebra was a major source of failure in high school for many U.S. students (Kilpatrick \& Izsak, 2008). Thus, the creation of the NCTM $(1989,2000)$ Standards, specifically the recommendation for curriculum and instruction surrounding algebra, received increased attention (Kilpatrick \& Izsak, 2008; Moses \& Cobb, 2001). The Standards aim to make school mathematics, including Algebra I, accessible to all students though the integration of algebraic concepts into a comprehensive curriculum prior to a standalone high school course (NCTM, 1989, 2000; Kilpatrick \& Izsak, 2008). In 1994, NCTM's board of directors released a position statement regarding the need for algebra to be taught to all students. Research indicates that an individual's success in college and the workforce is connected to the type of mathematics courses taken in high school (American Diploma Project Network, 2009); the desire to provide opportunities for future economic success for all students influenced NCTM's position statement (Kilpatrick \& Izsak, 2008). This position statement sparked a national debate that is ongoing today (Fennell, 2008; Kilpatrick \& Izsak, 2008; National Research Council, 2001 Pennsylvania Council of Teachers of Mathematics, 2009). This debate centers on the resulting curriculum initiative, "Algebra for All”, created in response to the 1994 NCTM position statement. The 
"Algebra for All" initiative swept across the U.S. in recent years and resulted in changes to many states' graduation requirements. In 2009, 22 states required students to pass an Algebra I course before graduating. By 2015 that number is projected to increase to 29 (American Diploma Project Network, 2009). NCLB and IDEA, as well as NCTM, influenced the nationwide curricular trend, "Algebra For All", a trend that includes students with MLD who typically take Algebra I in an inclusive setting where they struggle (Allensworth, Nomi, Montgomery \& Lee, 2009; Loveless, 2009; Steele \& Steele, 2003).

The majority of studies on Algebra I instruction for students with MLD primarily focused on one of the following themes: teachers' algebra content knowledge, teachers' beliefs about inclusion and perception of teaching students with disabilities, student learning, and the best practices utilized when instructing secondary students with MLD (DeSimone \& Parmar, 2006; Gagnon \& Maccini, 2001; Kieran, 2007; Lusk, Thompson \& Daane, 2008; Maccini \& Gagnon, 2000, 2002, 2006; Witzel, Riccomini \& Schneider, 2008; Witzel, Smith \& Brownell, 2001). Kieran (2007) identified research that suggested teachers' knowledge of students' actual algebraic thinking is limited and that many students can reason beyond teachers' expectations. Kieran called for more research surrounding this issue because if expectations of students are low, due to teachers' inability to elicit algebraic understanding, then students will continue to fail. This directly affects students with MLD because teachers of these students often have low expectations of their ability to learn higher level mathematics concepts (NCTM, 2000). In addition to developing teachers' knowledge of how to elicit mathematical communication, Maccini and Gagnon (2006) identified a need for further development of pre-service and inservice teachers' understanding of instructional methods that facilitate meaningful instruction for all students. Other researchers supported this need and suggested future research should address 
the learning and teaching of algebra concepts in order to identify and recommend effective algebra instructional practices (Chazan, 2008; Kieran, 2007; Maccini \& Gagnon, 2006). To begin this research based recommendation process regarding effective algebra instructional practices, research needs to identify currently implemented Algebra I instructional practices for students with MLD, and how educators developed a knowledge base for these practices.

\section{Rationale}

The performance of students with disabilities in West Virginia on large-scale assessments (i.e. the state assessment, Westest II and NAEP) follows the national trend of students with disabilities performing much lower than their general education peers. On the 2008-09 West Virginia NCLB report card, that collectively assessed all students enrolled in West Virginia public schools and took Westest II, the subgroup of students with disabilities failed to make AYP in mathematics (West Virginia Education Information System [WVEIS], 2010). On the 2008-09 Westest II, only $29.7 \%$ of all assessed students with disabilities obtained mastery or above in mathematics (WVEIS, 2010). A review of mathematics scores for the special education subgroup for each of West Virginia's 55 counties revealed that the highest scoring county recorded $44.8 \%$ of students with disabilities tested reaching the mastery or above level; the lowest recorded only $14.0 \%$ of students with disabilities tested reaching the mastery or above level (WVEIS, 2010). The 2009 NAEP eighth-grade mathematics results for the special education subgroup were very similar to the Westest II results, with only $22.4 \%$ of the special education subgroup scoring above the basic level (WVEIS, 2010). The $8^{\text {th }}$ grade NAEP assessment tests concepts that are required for algebraic thinking. Some educators believe the results of this assessment can be an indicator of how students may perform in a traditional Algebra I course (Loveless, 2008). Student performance on both of these assessments raises the 
question about the type of instructional practices and classroom assessments utilized for students with disabilities included in the general education environment.

Nationally, limited research exists about the instructional practices educators' are implementing for students with MLD in Algebra I classrooms and how their knowledge base of these practices developed. In West Virginia, no published research about this topic has occurred. The only current research of mathematics curriculum and instruction in West Virginia is a comparison study titled "The Final Report of the National Mathematics Advisory Panel” How is West Virginia Stacking Up? (West Virginia Department of Education [WVDE], 2009). The study by the WVDE addressed limited aspects of algebra instruction in West Virginia and compared them to the National Mathematics Advisory Panel (NMAP) recommendations. Specifically, this study investigated the alignment of the WVDE mathematics education framework to recommendations by the NMAP. It did not address Algebra I teachers' perceptions of teaching students with MLD or utilized practices.

Thus, the question is what type of learning environment and instructional practices do Algebra I teachers utilize for students with MLD in West Virginia? Further, what opportunities have educators had to develop a knowledge base needed for this type of instruction? Given the fact that Algebra I is a graduation requirement in West Virginia and faced with the reality that students with MLD continue to fall short of AYP benchmarks and NAEP proficiency standards, it is essential to address these questions.

This study addressed these questions by utilizing a mixed methods design to examine educators' perceptions regarding Algebra I instruction for students with MLD in West Virginia and how they developed a knowledge base for this practice. Quantitative research, in the form of a survey, provided descriptive statistics of the current state of Algebra I instruction for students 
with MLD, based on educators' perceptions. Participant interviews supported, explained, and supplemented the survey results to determine a relationship between instructional practices, educators' opportunities to expand their knowledge/practice of teaching students with MLD, and their backgrounds. A primary goal of education across the United States is to provide instruction that facilitates learning for all students. This study was designed to contribute to that goal.

\section{Research Questions}

1. What opportunities have Algebra I/Algebra Support educators from West Virginia had to develop knowledge for teaching students with MLD?

2. What are West Virginia's Algebra I/Algebra Support educators' perceptions regarding how beneficial their educational experiences and opportunities were in helping them develop a knowledge for teaching students with MLD?

3. How do West Virginia's Algebra I/Algebra Support educators' instructional practices for students with MLD align with the recommended best practices to utilize for students with MLD?

a. How do teachers' characteristics (gender, experience, etc.) influence their alignment of their instructional practices with best practices?

4. What are West Virginia's Algebra I/Algebra Support educators' perceived issues with regard to the instruction of algebra to students with MLD?

\section{Terminology}

Algebra Support- According to the WVDE, this course should provide interventions for the "atrisk" students that include re-teaching/pre-teaching targeted concepts or skills and provide additional practice. It is recommened that many different instructional practices such as explicit 
instruction, formative assessment, and peer-assisted learning be utilized. This course should coincide with an Algebra I course.

Cognitive Instruction/Assault Strategy- This strategy combines multisensory instruction with a cognitive approach. Key steps in this strategy include guidance with prompts as needed, rehearsing steps or procedures in writing and orally, helping students stay actively involved in instruction while being focused, providing models and then helping students create their own models.

Explict Instruction-This type of instruction involves a teacher demonstrating step by step specific strategies for solving various problem types and students using this plan to think their way through a solution. Directly modeling specific and general problem solving strategies and specific learning strategies using multisensory techniques is a key element of explict instruction. Inclusive Classroom- There is no federal definition of an inclusive classroom, but for the purpose of this study, it is used to describe a classroom where students with disabilities are educated with their nondisabled peers. Students with disabilities are placed in an inclusive classroom with appropriate aids and supports if it is considered their least restrictive learning environment. $L R E$ - Least restrictive environment; According to IDEA (2004) it is the "maximum extent appropriate," when children with disabilities are educated with children without disabilities, and that special classes, separate schooling, or other removal of children with disabilities from regular education environments occur only when the nature or severity of the disability is such that education in regular classes with the use of supplementary aids and services cannot be achieved satisfactorily. 
$M L D$ - Mathematical learning disability; Students with a specific learning disability in mathematics and are characterized as having cognitive deficits when learning and understanding mathematics are identified as MLD.

$R T I$ - Response to Intervention; This is a general process by which educators use objective student-performance data to determine when additional instruction and/or interventions are needed for struggling students. This process is also used in the identification of students with a specific learning disability.

$S L D$ - Specific Learning Disability 


\section{CHAPTER 2: REVIEW OF LITURATURE}

The purpose of this chapter is to review literature associated with the topic of the study and to frame the need for additional research on this topic. The chapter is organized into four main sections. The first section describes educational policies and mathematical content standards that drive mathematics curriculum and instruction in the U.S., and more specifically, Algebra I instruction in West Virginia. The next section begins with a broad review of the theoretical and empirical research literature on research-based mathematics instruction in the U.S. This section concludes by focusing on Algebra I instruction. The next section examines research literature on teaching and learning for students with MLD. In this section, MLD is first defined then characteristics of students with MLD are identified. Following that, effective mathematics teaching strategies for students with MLD are identified, and then effective strategies for teaching Algebra I to students with MLD are identified and described in detail. The focus of the final section is empirical research about the implementation issues surrounding mathematics instruction, especially Algebra I, to students with MLD across the U.S. The literature review concludes with a summary of the existing relevant research for this study and implications for Algebra I instruction of students with MLD in West Virginia.

\section{Math Content Standards and Policies}

The structure of the education system in the United States is based on federal and state mandates. These mandates drive what curricula and instructional practices public educators utilize, which directly affect students' learning.

\section{Government Policies}

National education legislation passed from the 1960s through the early 2000s impacted curricular and instructional recommendations made by NCTM. Specifically, for mathematics 
this legislation influenced the content taught and instructional practices nationwide in mathematics classrooms. IDEA (2004) and NCLB (2001), previously the Elementary and Secondary Education Act, are two major pieces of legislation that impacted NCTM recommendations. Mandates from these acts made the general education curriculum more accessible for students with special needs, while requiring these students to meet higher standards based on content proficiency. Further, these acts mandate teachers be accountable for their knowledge base of the content they are teaching as well as instructional strategies to meet all students' needs. NCLB (2001) and IDEA (2004) directly influenced mathematics instruction in U.S. public schools and U.S. teacher preparation programs by requiring institutions to revise their mathematics programs to meet the regulations outlined by both acts.

\section{NCTM Principles, Standards, and Focal Points}

In 1980, NCTM published An Agenda for Action, which outlined professional actions recommended for school mathematics programs nationwide. This publication provided ten recommendations of action for K-12 mathematics programs focusing on the fundamentals of problem solving. In 1989 Curriculum and Evaluation Standards for School Mathematics followed in which NCTM expanded on the previous recommendations by providing suggestions for mathematics teaching and learning, categorizing them in subgroups of K-grade 4, grades 5-8, and grades 9-12. This publication was a foundation and motivator for many states to reconsider their mathematics standards. Finally, in 2000, NCTM released the Principles and Standards for School Mathematics. This document clarified and elaborated on the 1989 NCTM standards.

The 2000 Principles and Standards are organized into different subgroups by grade

bands: pre-K-grade 2, grades 3-5, grades 6-8, and grades 9-12. The six recommended Principles for school mathematics are equity, curriculum, teaching, learning, assessment and technology. 
The Standards are separated into content standards and process standards. These Content and Process Standards are to be addressed with different emphasis across all grade bands. The Content Standards include number and operations, algebra, geometry, measurement, and data analysis and probability. The purpose of the Content standards is to identify up to seven specific content learning expectations for each of the four grade bands (NCTM, 2000). The Process Standards are problem solving, reasoning and proof, communication, connections, and representations. The purpose of the Process Standards is to describe, using examples, what the Standard ought to look like in a grade band and what the teachers' responsibility should be in achieving the Standard (NCTM, 2000). Process Standards describe ways through which students should learn the content. According to NCTM, implementing these Principles and Standards as recommended, should result in a high-quality mathematics education for all students (NCTM, 2000).

In 2005, NCTM and the Association of State Supervisors of Mathematics released the report, Standards and Curriculum-View by the Nation (DeRidder, 2007). It addressed the concerns regarding the many mathematical concepts that U.S. students were expected to learn in such a short amount of time (Fennell, 2006). Many educators felt that students were expected to be exposed to so many concepts so fast, that they were given no time to develop a deep understanding of how to apply these newly learned concepts. In response to this report, NCTM created Curriculum Focal Points to identify the key concepts students should learn in order to develop a deep mathematical understanding and connections. The Curriculum Focal Points for Prekindergarten through Grade 8 Mathematics: A Quest for Coherence extends the descriptions given by the Principles and Standards and gives "targets" for each grade level (NCTM, 2006). Following work at the prekindergarten through eighth grade level, NCTM developed targets for 
high school curriculum. Focus in High School Mathematics:Reasoning and Sense Making is the first in a series of publications by NCTM that intends to emphasize the need for reasoning opportunities in five specific content areas of high school mathematics curriculum (NCTM, 2009). These include: numbers and measurements, algebraic symbols, functions, geometry, and probability and statistics.

\section{Influence of NCTM Principles and Standards}

NCTM Principles and Standards are often utilized as curriculum development tools by states when developing and mapping out effective curriculum (Thurlow, 2000; WVDE, 2006). According to Thurlow (2000), over 40 states developed mathematics state standards which mirror the recommended Standards set by NCTM. There is evidence that students in school districts which implemented curriculum based on the Standards outscored students from districts where the Standards were not the driving force behind the mathematics curriculum (Reys, Reys, Lapan, Holliday, \& Wasman, 2003). NCTM has not only published and influenced content standards adopted by numerous states but they have also released publications and provided free online instructional material for teachers to utilize while providing NCLB (2001) and IDEA (2004) required researched-based instruction. Little research exists regarding the influence of curriculum development based on NCTM Curriculum Focal Points.

\section{Algebra I Content Standards and Policies}

During the 1970s and 1980s, algebra was a major source of failure in high school for many U.S. students (Kilpatrick \& Izsak, 2008). As a result, the Standard's (1989, 2000) recommendation for curriculum and instruction surrounding algebra emphasized making instruction of algebraic concepts more accessible for all students (Moses \& Cobb, 2001). In 1994, NCTM's board of directors released a position statement about the need for algebra to be 
taught to all students. This position statement influenced the creation of the "Algebra for All" initiative which has been highly debated nationwide for more than a decade (Fennell, 2008; Kilpatrick \& Izsak, 2008; National Research Council, 2001; Pennsylvania Council of Teachers of Mathematics, 2009). This debate over "Algebra for All” encouraged educators, administrators, and curriculum developers to analyze what content should be taught in an Algebra I course and for what purpose the completion of an Algebra I course is required. Throughout this debate, the majority of mathematics educators acknowledged the importance of education, specifically Algebra I, in future economic opportunities of their students but they disagreed on how to prepare all students for Algebra (Kilpatrick \& Izsak, 2008). Many mathematics curriculum designers and school districts started to integrate algebra concepts into elementary and middle school curricula, while other curriculum designers and school districts did not. The NCTM $(1989,2000)$ recommendations of making algebra accessible to all students by integrating it into comprehensive elementary and middle school curriculums, earlier than in one high school course, is supported by both the National Research Council (2001) and the NMAP (2008). School districts and mathematics educators struggle with how to present these concepts to students with MLD well into the twenty-first century, almost 20 years after the inception of "Algebra for All".

The "Algebra for All" initiative swept over America and deemed Algebra I a necessity for all students to pass before graduating, or in order to, graduate from high school (Diversity in Mathematics Education Center for Learning and Teaching, 2007). Research indicates that an individual's success in college and the workforce is connected to the type of mathematics courses taken in high school (American Diploma Project Network, 2009). This post-secondary success is one of the main reasons behind the push for all students to complete an Algebra I 
course (Chazan, 2008; National Research Council 2001). Both the National Research Council (2001) and the NMAP (2008) suggest that more students nationwide enroll in a traditional Algebra I course in $8^{\text {th }}$ grade to ensure success in post-secondary education endeavors. Recommendations by these groups coupled with the requirements of NCLB (2001) and IDEA (2004) influenced the rise in the number of students with disabilities nationwide, specifically MLD, who take higher level mathematics course such as Algebra I before graduating from high school (NCES, 2010).

\section{Algebra I Content Standards and Policies in West Virginia}

WVDE (2008) Policy 2510 states a student must earn four units of mathematics with a minimum of one Algebra credit to graduate with a diploma. This requirement of only one Algebra credit does not support the NMAP expectation of all students to proceed successfully at least through the content of Algebra II prior to high school graduation (WVDE, 2009). WVDE Policy 2520.2 outlines the required mathematics content standards and objectives (CSO's) which should drive instruction throughout all mathematics courses in West Virginia public schools (WVDE, 2006). Algebra I CSO's are descriptively addressed in this policy and are grounded in the NCTM Principles and Standards. An introduction to the Algebra I CSOs states:

Algebra I objectives provide the gateway to all higher mathematics courses. An emphasis on conceptual development and multiple representations will be used to draw generalizations and to serve as a tool for solving real-world problems. Algeblocks may be used to bridge the gap from the concrete to the abstract. Available technology such as calculators, computers, and interactive utilities are to be used as tools to enhance learning. The West Virginia Standards for $21^{\text {st }}$ Century Learning include the following components: $21^{\text {st }}$ Century Content Standards and Objectives and $21^{\text {st }}$ Century Learning Skills and Technology Tools. All West Virginia teachers are responsible for classroom instruction that integrates learning skills, technology tools and content standards and objectives (WVDE, 2006, p.65). 
This policy coupled with West Virginia's $21^{\text {st }}$ Century Teaching Initiative documents and resources support many of the NMAP's suggestions on how to incorporate more conceptual skills as well as problem solving skills into a highly engaging classroom environment for all students (WVDE, 2009).

Common Core State Standards. In June of 2010, West Virginia adopted the Common Core State Standards (CCSS) which will influence a future revision of West Virginia's Algebra I CSOs. Mathematics curriculum and instruction under the CCSS will put a stronger emphasis on student development of conceptual mathematics understanding. The adoption of the CCSS will also influence a restructuring and renaming of the current Algebra I course to Mathematics I. The National Governors Association Center for Best Practices (NGA Center) and the Council of Chief State School Officers (CCSSO) coordinated this state-led initiative to institute a single set of clear educational standards for mathematics that states can voluntarily adopt (Common Core State Standards Initiative, 2011). Teachers, school administrators, parents, and educational experts used the best existing evidence and highest state standards across the U.S. and the globe to create the CCSS. Their intent is to reflect both aspirations for students and the realities of the classroom. These standards hope to ensure that students are prepared for college or to enter the workforce, and teachers, parents, and students have a clear understanding of their expectations. The CCSS intend to improve access to rigorous academic content standards for students with disabilities by supporting instructional accommodations, based on students' IEPs. The CCSS also encourages the use of assistive technology and suggests instructional supports for learning based on the principles of Universal Design for Learning (UDL) (Common Core State Standards Initiative, 2011). In June of 2010, states were asked to review the CCSS, with the hope that they would be adopted. By the end of September in 2011, 44 states adopted the CCSS, including 
West Virginia, and the district of Columbia Washington D.C. (Common Core State Standards Initiative, 2011).

\section{Research-Based Mathematics Instruction}

The use of research-based mathematics instruction in U.S. schools is not only required by NCLB (2001), but also strongly researched and encouraged by government, professional, and state lead organizations (Common Core State Standards Initiative, 2011; NCTM, 2006 \& 2009; National Research Council, 2001). The National Research Council identifies research-based recommendations for mathematics teaching practices that can improve student learning. A summary of the recommendations suggest that instruction should: (a) address the needs of all students, by providing a variety of instructional strategies that encourage discourse; (b) provide meaning making through connections; (c) encompass various types of assessments; (d) link experience to abstraction; and (e) continuously monitor student progress through formative assessment (National Research Council, 2001).

Similarly, Franke, Kazemi, and Battey (2007) identified a need for students to have more opportunities to "develop both concepts and skills, to develop flexibility in their abilities to engage with mathematical ideas, and to engage in what some may call higher order or critical thinking” (p.228). According to the National Research Council (2001), mathematics instruction should focus on making all students proficient in mathematics, while facilitating instruction that is highly engaging and rigorous for all students. Mathematical proficiency means that for any individual to learn mathematics successfully they must master the following five, interwoven and interdependent strands:

(1) conceptual understanding- comprehension of mathematical concepts, operations, and relations, (2) procedural fluency- skill in carrying our procedures flexibly, accurately, efficiently, and appropriately, (3) strategic competence- ability to formulate, represent, 
and solve mathematical problems, (4) adaptive reasoning- capacity for logical thought, reflection, explanation, and justification, (5) productive disposition- habitual inclination to see mathematics as sensible, useful and worthwhile, coupled with a belief in diligence and one's own efficacy (National Research Council, 2001,p.5).

This description of mathematical understanding and proficiency embraces the idea that learning is not just about a teacher dispensing information and a student receiving it; it is instead about a teacher facilitating an engaging environment that encourages sense-making in a meaningful context.

According to studies by Goldman, Hasselbring, and the Cognition and Technology Group at Vanderbilt (1997) and Rittle-Johnson and Alibali (1999), meaningful and balanced instruction should address the main three types of mathematical domains: conceptual knowledge, declarative knowledge, and procedural knowledge. Because problem solving encompasses all of these skills, when these three domains are addressed problem solving skills are also utilized and developed (Goldman et al., 1997; Hudson \& Miller, 2006; Rittle-Johnson \& Alibali, 1999). An intense review of studies focusing on mathematics teaching and classroom practices by Franke, Kazemi, and Battey (2007) identified what they felt were the three central practices to teaching and learning mathematics: “(1) creating mathematical classroom discourse, (2) developing classroom norms that support opportunities for mathematical learning, and (3) building relationships that support mathematical thinking" (p.226). These central practices identified are further supported in How People Learn (National Research Council, 2000). The key findings noted in How People Learn are:

(1) Students come to the classroom with preconceptions about how the world works. If their initial understanding is not engaged, they may fail to grasp the new concepts and information that are taught, or they may learn them for purposes of a test but revert to their preconceptions outside the classroom.

(2) To develop competence in an area of inquiry, students must: (a) have a deep foundation of factual knowledge, (b) understand facts and ideas in the context of a 
conceptual framework, and (c) organize knowledge in ways that facilitate retrieval and application.

(3) A metacognitive approach to instruction can help students learn to take control of their own learning by defining learning goals and monitoring their progress in achieving them.

(National Research Council, 2000, p.14-18)

The findings reported in Adding It Up, How People Learn and similar findings and

recommendations by other researchers stressed the importance of facilitating a learning environment that encourages mathematical proficiency through meaningful student engagement and discourse, while addressing the mathematical domains of conceptual, declarative, procedural, and problem solving knowledge (Franke, Kazemi, \& Battey, 2007; Hudson \& Miller, 2006; National Research Council, 2000, 2001).

\section{Research-Based Algebra Instruction}

The push for all students to complete an Algebra I course before graduation nationwide has sparked research about student learning as related to algebra instruction (Kieran, 2007; National Research Council 2000, 2001). Kieran (2007) identified the following themes found in the research on the learning and the teaching of algebra from 1990 to present day: (a) as the vision of school algebra has widened, the beliefs in how it is learned has widened to include multiple representations, realistic problem solving scenarios, and the use of various types of technology; (b) sources of meaning in algebra are found in the algebraic structure involving the letter-symbolic form and multiple representations, meaning from the problem context, and meaning from the exterior of the problem context such as through linguistic activities, body language, metaphors, and life experience; (c) algebra is an activity that can be conceptualized through generational, global/meta-level, and transformational activities; and (d) many teachers lack the ability to identify their students' actual algebraic thinking ability, which in turn produces 
low expectations from teachers and enables students to develop many misconceptions and difficulties in algebra. The National Research Council (2000, 2001) and the NMAP (2008) gave similar recommendations about the teaching of algebra, addressing many of the themes identified by Kieran (2007). Both groups agree on the following suggestions: (a) teachers must elicit and build on the preexisting understandings students bring with them to the classroom; (b) instruction should be based on main concepts, which are taught indepth by providing examples and practice using muliple representions to provide a foundation of factual knowledge; (c) teaching metacongitive skills should be integrated into the curriculum through questioning and discourse; (d) formative assessments should be used regularily so progress can be monitored by both the teacher and the student; and (e) the study of algebra should not start with a formal algebra course, but begin in early grades (NMAP, 2008; National Research Council 2000, 2001). The "Algebra for All" initiative encouraged research on not only how students best learn algebra, but specifically on the needs of all students in an Algebra I classroom setting. In response to IDEA (2004) and NCLB (2001), mathematics teachers and curriculum developers have been required to utilize research-based practices to develop innovative ways to meet the mathematical needs and promote mathematical proficiency for diverse learners, especially those with MLD (White, 2004).

\section{Teaching and Learning for Students with Mathematical Learning Disabilities}

Based on the recommendations by NCTM (2000) and the National Research Council (2001) teachers should facilitate instructional practices that meet the needs of all students in their classrooms. Mandates in IDEA (2004) changed the classroom demographics across the U.S. to include more students with specific learning disabilities, such as MLD, in general education 
mathematics classes. This change required more general education teachers to become knowledgeable in effective instructional strategies for students with MLD.

\section{Students with MLD}

According to Mazzacco (2007) "MLD is a biologically based, behaviorally defined condition” (p.30). Cognitive deficits when learning and understanding mathematics are characteristics of students with MLD. Although many students struggle with mathematics, students with MLD have a recognized condition that is not primarily caused by environmental factors. It is known that students with MLD share many cognitive and behavioral characteristics, but there is not an identified common set of core deficits (Mazzacco, 2007, p.44). Based on her research Mazzacco (2007) stated:

We also know that basic skills in mathematical cognition, such as the representation of numerosity, underlie some of the challenges experienced by children with MLD, and that other challenges may result from impairments in cognitive substrates that support mathematics' performance. The lack of consensus as to which of these skills is primary or secondary, or the degree to which they are evident in different study samples, is due at least in part to the wide range of criteria used across studies to classify children as having MLD in terms of definitions and the tests used to measure math-related skills (p.44).

IDEA (2004) and NCLD (2008) define a specific learning disability as, "A disorder in one or more of the basic psychological processes involved in understanding or using language, spoken or written, that may manifest itself in the imperfect ability to listen, think, speak, read, write, spell or to do mathematical calculations...”(NCLD, 2008, p.1). A specific learning disability must not be the result of inadequate instruction in reading or mathematics and/or "primarily the result of a visual, hearing, or motor disability; mental retardation; emotional disturbance; cultural factors; environmental or economic disadvantage or limited English proficiency"(NCLD, 2008, p.2). 
In order to improve mathematics instruction on a national level for students with MLD, studies have been conducted to research the cognitive and behavioral characteristics students with MLD share. Steele (2002) identified the following characteristics of students with MLD: memory deficiencies, visual and auditory processing problems, abstract reasoning difficulties, and organizational issues. When students display these characteristics, they may encounter these specific problems: weakness in memorization of facts or sequences; difficulty understanding mathematics content, vocabulary, and oral or written directions; incorrect use and application of number lines, place value, coordinate graphing, or other concepts that require the application of an understanding of spatial relations; and difficulty solving problems that require multiple skills such as reading, writing, mathematical computations, and reasoning (Steele, 2002). Allsopp, Lovin, Green, and Savage-Davis (2003) identified many of the same characteristics as Steele (2002), including attention problems, cognitive-processing problems, memory problems, and metacognitive problems such as weaknesses in having the ability "to apply appropriate learning strategies, to evaluate their effectiveness, and to change strategies when current ones are not successful"' (p.310).

Maccini and Gagnon (2000) identified seven main characteristics of students diagnosed as MLD: (a) difficulty processing information which results in problems learning to read and problem-solve; (b) difficulty with distinguishing the relevant information in story problems; (c) low motivation, self-esteem, or self-efficacy to learn due to repeated academic failure; (d) problems with higher-level mathematics that require reasoning and problem-solving skills; (e) learners' reluctance to try new academic tasks or to sustain attention to task; (f) difficulty with self-monitoring and self-regulation during problem-solving; and (g) difficulty with arithmetic, computational deficits. Since secondary students with MLD exhibit various cognitive and 
behavioral characteristics, mathematics curriculum and instruction must encompass multiple instructional strategies, methods and interventions to meet the needs of students with MLD in their LRE. A learning environment that promotes learning for all addresses the needs of students' with MLD, based on their learning characteristics (Spitzer, White \& Flores, 2009).

\section{Effective Instructional Strategies for Students with MLD}

The challenges most students with MLD experience while trying to learn mathematics content emphasize the importance in identifying the instructional strategies and assessment accommodations that aid these students in their learning process (Maccini \& Gagnon, 2006). As

mandated by IDEA (2004), students with disabilities should have access to the general education curriculum and are entitled to research-based approaches to teaching mathematics skills. A review of studies addressing effective mathematical instructional strategies for students with MLD identified six potentially beneficial recommended instructional strategies for students with MLD: (1) visual and graphic depictions, (2) systematic and explicit instruction, (3) student thinkalouds, (4) peer-assisted learning, (5) formative assessment data provided to teachers, and (6) formative assessment data provided directly to students (Allsopp, Kyger, Lovin, Gerretson, Carson \& Ray, 2008; Allsopp, Lovin, Green \& Savage-Davis, 2003; Brodesky \& Gross, 2009; Foegen, 2008; Gagnon \& Maccini, 2001; Gersten \& Clarke, 2007; Hudson \& Miller, 2006; Hutchinson, 1993; Ives, 2007; Ketterlin-Geller, Chard \& Fien, 2008; Kortering, deBettencourt \& Braziel, 2005; Maccini \& Gagnon, 2000, 2002, 2006; Steele, 2002; Steele \& Steele, 2003; Strickland \& Maccini, 2010; Witzel, Smith \& Brownell, 2001).

Research on the use of visual and graphic depictions with students with MLD focuses on two main instructional tools: graphic organizers and visual aids that provide multiple mathematical representions. A study by Kooy (1992) investigated the effect of graphic 
organizers on the mathematical comprehension of 23 high school special education seniors and found that the use of graphic organizers generated higher quiz scores in mathematics for students with disabilties. Visual representations such as graphic depictions and pictorial illustrations can be used by teachers to clarify and explain problems, so students can develop a better mathamtical understanding of problems. Van Garderen (2007) examined the effectiveness of using diagrams during instruction for students with MLD. This study found that students with MLD improved in the number of diagrams they used, their ability to generate diagrams, and their word problem solving performance increased. Owen and Fuchs (2002) found that visual representations were more effective when combined with explict instruction, because teachers can explicitly teach students to use a specific strategy based on the visual aid. Manalo, Bunnell, and Stillman (2000) found that visual representations are most benifical for students when both the teacher and the student regularly use the visual aid.

The NMAP (2008) reccomended explict instruction for students with MLD, because research has shown that it improves the performance of students with MLD in computation, word problems, and transferring of mastered skills to new situations. Rittle-Johnson and Star (2007) found that students benefit when teachers model several problems with different characteristics through explicit instruction. The Panel cautioned, however, that while explict instruction facilitates better achievement results for students with MLD, no research supports exclusively using this method for teaching students with MLD (NMAP, 2008).

Brodesky and Gross (2009) investigated strategies for making mathematics more accessible to students with MLD and found that promoting understanding through discourse improved learning for students with MLD. Student "think-aloud" is a self-regulating technique that can help address organization and impulsivity problems, which are common in students with 
MLD. Miller, Butler, and Lee (1998) found that self-monitoring and self-questioning strategies can be linked to improved achievement for students with MLD. Another strategy that encourages communication of mathematical ideas is peer-assisted learning. Peer-assisted learning, also refered to as peer-mediated instruction, is defined as "pairs of students working collaboratively on structured, indivdualized activities" (Kunsch, Jitendra \& Sood, 2007, p.1). Baker, Gersten, and Lee (2002) found peer-assisted instruction appeared to help low-achieving students who have mathematical learning difficulties. The use of peer-assisted learning was also investigated by Fuchs and Fuchs (1997) and was found to increase student growth and achievement for students with MLD when compared to a traditional teacher-led instructional model.

Formative assessment can also be helpful because it identifies students' strengths, weaknesses, and helps drive daily instruction. Gersten, Chard, Jayanthi, Baker, Morphy, and Flojo (2009) investigated the impact of formative assessment data and feedback to teachers and to students with MLD. They found that when teachers were provided specific information on each student's individual performance, the student's mathematics achievement increased (Gersten et al., 2009). It was also found that when this information was also given to a special educator, there was an even stronger effect on student achievement. Providing students with formative assessment results appeared to affect their effort, and self-motivation, more than their mathematical achievement (Gersten et al., 2009).

In addition to the strategies discused above, in supporting mathematics learning for students with MLD many studies strongly suggested the use of a concrete, representational, and then abstract (CRA) instructional sequence (Gagnon \& Maccini, 2001; Maccini \& Gagnon, 2006; Steele, 2002; Steele \& Steele, 2003; Strickland \& Maccini, 2010; Witzel, Riccomini \& 
Schneider, 2008; Witzel, Smith \& Brownell, 2001). Gagnon and Maccini (2001, 2006), Steele and Steele (2002), Witzel, Smith and Brownell (2001) and Witzel, Riccomini and Schneider (2008) recommended that this sequence be included in all secondary mathematics courses for students with MLD. The recommendation for CRA addresses MLD students' need to first experience the concrete representation of a concept before being able to understand the concept abstractly. The three stages of CRA are interrelated and should not be utilized as isolated activities; when they are isolated, students are unlikely to grasp the abstract understanding of the desired mathematical concept (Witzel, Riccomini \& Schneider, 2008). According to Witzel, Riccomini and Schneider (2008) "CRA is an instructional sequence that teaches students both the procedures of mathematics and the overarching mathematical concepts that are essential and that will eventually help students become mathematically proficient” (p.271).

Even when students are provided effective instruction through previously discussed strategies it does not necessarily mean they will maintain those skills over time, especially students with MLD. When the introduction of a concept or skill is in a meaningful context, the enhancement of mathematics instruction occurs for all students and the maintanance of skills and knowledge is best faciltated for all students (Maccini \& Gagnon, 2000; Miller \& Hudson, 2006). Presenting mathematical concepts in meaningful contexts, by providing a real world connections, is one instructional strategy reccommended by researchers to meet the needs of students with MLD in an Algebra I setting (National Research Council, 2001; Witzel, Smith \& Brownell, 2001; NMAP, 2008).

Spitzer, White and Flores (2009) support the recommendations above and the belief that all students can learn by suggesting the use of strategies such as learning about your students, fostering a positive learning environment, using multiple representations, and making 
connections. When a teacher believes all students can learn, the identification of how students learn best and the use of alternative instructional approaches, which meet all students' needs, are an integral part of daily instruction.

\section{Implementation of Effective Instructional Strategies}

IDEA (2004) requires that students with disabilities are educated in their LRE. This principle supports the instruction of students with disabilities to take place in a general education setting to the maximum extent possible with the use of supplementary aids and services (Turnbull, Turnbull, \& Wehmeyer, 2007). Two major implementation strategies utilized to provide effective instruction for students with MLD in their LRE are differentiation and, more specifically, the utilization of the response-to-intervention framework (RTI).

Differentiation. Through differentiation, effective instructional strategies for students with MLD can be incorporated into an inclusive mathematics classroom to meet the needs of all students. Differentiation of mathematics instruction is an instructional practice that many school systems aim to implement in order to meet the needs of all students, especially those with SLD, who are served in a general education setting. When investigating the use of differentiation in education across the U.S. it is described in various and often discrepant ways (Ellis, 2009).

Carol Tomlinson (1999), a leading researcher in the field of differentiation, describes it as:

In differentiated classrooms, teachers begin where students are, not the front of a curriculum guide. They accept and build upon the premise that learners differ in important ways. Thus, they also accept and act on the premise that teachers must be ready to engage students in instruction through different learning modalities, by appealing to different interests, and by using varied rates of instruction along with varied degrees of complexity...Although differentiated classrooms embody common sense, they still can be difficult to achieve (pg.2).

Ellis (2009) summarized Tomlinson's description of differentiation as varying one's

actions as a teacher to meet the specific needs of all students. He noted that for true 
differentiated instruction to occur, the focus of instruction must shift away from normative practices that have traditionally characterized mathematics instruction, such as teacher centered lecture and teacher demonstration followed by students' individual work on rote procedures. Ellis further emphasized that differentiation does not mean a change in the curriculum based on students' perceived abilities, but instead a change in how the required content is taught to the students. Tomlinson supported Ellis's beliefs by emphasizing that differentiation does not require a change in content based on ability but just a change in process and product (Tomlinson, 1999). Likewise the CCSS support Ellis's belief by stating that instructional accommodations for students with disabilities should not change the content standards to be learned but change utilized materials and/or procedures for these students (Common Core State Standards Initiative, 2011). Differientated instruction coupled with data driven instruction are the foundation for RTI.

Response-to-Intervention. Response-to-intervention is a data driven implementation strategy that provides intense, tiered, interventions for struggling students, such as those with MLD (Fuchs \& Fuchs, 2005). The intent of RTI is to act as a type of filter to help identify students with MLD and to guide instruction for struggling students. At the seondary level RTI is used mainly as an instructional guide based on students' needs. This is in contrast to its use as an identification tool of students with MLD in early grades (Riccomini, 2010). At the secondary level RTI services are typically offered through a three-tiered approach (Duffy, 2007). Tier 1 occurs in the general education setting where researched-based instruction, progress monitoring, and support is given to all students. Any students who are struggling at the tier 1 level receive specialized remediation in the general education setting. In tier 2, students who have not been sucessful with the interventions at tier 1 receive more intensive and targeted interventions in a general education setting, but typically provided by a special educator. Student progress is more 
closely monitored in tier 2 and, if an intervention is not successful, a different one is implemented. In tier 3, based on parental consent, students either under go a comprehensive evaluation for a SLD or are moved to a special education setting to receive instruction.

Gersten, Beckman, Clarke, Foegen, Marsh, Star, et al. (2009) gave the following evidence-based recommendations of instructional practices to utilize during RTI tier 2 and 3 mathematics instruction: (a) intervention should be explicit and systematic including modeling of the problem solving process, opportunities for discourse, corrective feedback, guided practice, and frequent cumulative review; (b) intervention should include instruction on solving word problems that is based on common underlying structures; (c) intervention materials should provide students with multiple visual representations of mathematical ideas, and teachers should be proficient in the utilization of multiple visual mathematical representations as an instructional tool; (d) each session should include approximately 10 minutes of time towards building fluent retrieval of basic arithmetic facts; and (e) instruction must include motivational strategies to engage all students (pg. 6). Riccomini (2010) cautioned that if instruction for "at-risk" students does not implement effective instructional approaches, RTI implementation efforts would have little positive effect on improving students' learning of mathematics.

\section{Effective Strategies for Teaching Algebra I to Students with MLD}

Algebra has been referred to as the "gatekeeper" course to higher level mathematics. Because it is also frequently a graduation requirement, educators must make algebra content accessible to students with MLD (Witzel et al., 2008). Foegen (2008) believed it is important for students to pass an Algebra I course and that students with MLD should receive instruction which utilizes CRA and many of the subsequently described instructional strategies. The small amount of research surrounding teaching algebra to students with MLD mainly focuses on the 
needs of students in an Algebra I classroom and effective teaching strategies for meeting those needs (Gagnon \& Maccini, 2001; Steele \& Steele, 2003; Strickland \& Maccini, 2010; Witzel, Riccomini \& Schneider, 2008; Witzel, Smith \& Brownell, 2001). The needs of the students are based on the characteristics of students with MLD and strongly address the need for concrete representation before abstract material. Because Algebra I is traditionally taught in an abstract manner, many of the effective teaching strategies suggested by leading researchers in the field address how to make this traditionally abstract content concrete and more accessible to students with MLD (Gagnon \& Maccini, 2001; Ives, 2007; Steele \& Steele, 2003; Strickland \& Maccini, 2010; Witzel, Riccomini \& Schneider, 2008; Witzel, Smith \& Brownell, 2001).

Maccini and Gagnon (2001) suggested the following interventions as key components to effective teaching strategies for serving students with MLD in algebra: "teaching prerequisite skills, definitions, and strategies; providing direct instruction in problem representation and problem solution; providing direct instruction in self-monitoring procedures; using organizers; incorporating manipulatives; teaching conceptual knowledge; and providing effective instruction” (p.9). Steele and Steele (2003) supported these suggestions by identifying similar strategies to implement when teaching algebra to students with MLD. Their suggested strategies are: "teacher directed strategies such as modeling, guided practice, and corrective feedback on responses to practice problems; self-questioning and self-monitoring strategies such as through summary charts/checklists, step-by-step prompts for problem-solving; cognitive strategies that combine multisensory instruction with a cognitive approach called cognitive assault strategy; mnemonics for memorizing rules, steps, and other procedures; and the use of concrete manipulative materials"(p.623). 
Witzel, Smith and Brownell (2001) echo the importance of these same instructional techniques and state that it is imperative for educators to follow these three principles to help students make connections between arithmetic to algebra: "(a) teach students through stories that connect mathematics instruction to students' lives, (b) prepare students for more difficult concepts by making sure students have the necessary prerequisite knowledge for learning a new mathematics strategy, and (c) explicitly instruct students in specific skills using think aloud techniques when modeling”(p.102). Hutchinson (1993) examined cognitive instruction strategy using self questioning techniques. A group of students with MLD were taught how to use a cognitive strategy for problem solving in an Algebra I class. The first phase of the strategy was problem representation and the second focused on problem solution. The use of this strategy improved Algebra I performance on word problems. Further, maintenance and transfer of the strategy was evident for students with MLD (Hutchinson, 1993). The need for student dialogue in algebra instruction for students with MLD is highly reccommended (Witzel, Smith \& Brownell, 2001). The importance of dialogue in the learning, teaching, and assessing of algebraic concepts is noted by many researchers, whether it is cognitive instruction/assault strategy, student interviews, or self-questioning (Burns, 2010; Foegen, 2008; Gagnon \& Maccini, 2001; Hutchinson, 1993; Steele \& Steele, 2003; Witzel et al., 2001).

Witzel (2005) investigated the use of CRA in inclusive Algebra I instruction of solving linear algebraic functions. In this study a pretest and posttest was given to two groups of students: those who were taught using CRA and those who were taught in a traditionally abstract explicit manner. Both groups showed improvement from the pretest to the posttest, but the greatest gains were in the group who were instructed using CRA (Witzel, 2005). The students taught using CRA were higher achieving than the other group as measured through a comparison 
of statewide achievement test results and final grade for the Algebra I course (Witzel, 2005). The results of these studies support the recommendations of using CRA and cognitive strategies in Algebra I instruction for with students with MLD.

Ives (2007) investigated the instruction of students with specific learning disabilities who were heterogeneously grouped. Ives specifically examined the intensive use of graphic organizers and how their use related to the learning of how to solve systems of equations for students with MLD. Students who were taught using graphic organizers outperformed the students who did not receive instruction with graphic organizers on a posttest.

Technology use consists of calculators, videos, and computer systems that aid in student doing and learning of mathematics (NCTM, 2000). Two studies specific to Algebra I instruction for students with MLD addressed two of the three different types of technology in one study. Enhanced Anchored Instruction (EAI) is video or computer-based instruction with hands-on group activities focused on students' algebraic understanding, and is intended to improve the problem solving and overall mathematics performance of students with MLD in self-contained and inclusive classrooms (Bottge, Rueda, LaRoque, Serlin \& Kwon, 2007; Bottge, Rueda, Serlin, Hung, \& Kwon, 2007). Students with MLD instructed using EAI showed improvement in problem solving, as measured by pretest and posttest assemssments, but outcomes on their computational skills were not the same. The performance of students with MLD on the problem solving post assessments matched or exceed the performance of their nondisabled peers. Further, mixed results for students with MLD, some scoring higher and some scoring lower on the posttest, existed when examining improvements in compuational skills (Bottge, Rueda, LaRoque et al., 2007; Bottge, Rueda, Serlin et al., 2007). EAI materials must be purchased by educators to use in their classrooms, and if used by school districts professional development is typically 
offered for educators about the recommended implementation of EAI. The use of calculators is one type of technology that typically is used with no monetary cost to the educators. Limited research exists about calculator use for students with MLD in an Algebra I course. An NSF funded research project in Missippi high schools found that regular calculator use during Algebra I instruction, specifically Texas Instruments (TI) Navigator, changed students' with MLD attitudes toward mathematics and calculator use (Riales, James \& Ivy, 2011). Further, the researchers from this study suggested that the regular use of the TI-Navigator during Algebra I instruction for student with MLD, coupled with intensive teacher interventions and support for students with MLD could be a successful mix of instructional practices for teaching students with MLD.

Two different reviews of algebra interventions and instructional strategies for teaching algebra to secondary students with MLD summarized and organized the previously described research into the following strategies that improve students' performance in algebra: (a) general problem-solving strategies in problem represenation and problem solutions, (b) self-monitoring strategies, (c) the concrete-representation-abstract instructional sequence, (d) teaching prerequisite skills, (e) explict instruction, (f) technology, and (g) graphic organizers (Maccini, McNaughton, \& Ruhl, 1999; Strickland \& Maccini, 2010).

\section{Implementation Issues When Instructing Students with MLD}

Foegen (2008) observed the need for further research surrounding instruction of students with MLD in a heterogeneous setting. The majority of studies on the instruction of students with MLD focus on instruction in a homogeneous setting, which is not what many school districts currently implement due to NCTM recommendations and state requirements set forth by NCLB (2001). In most U.S. classrooms students with MLD are taught in an inclusive setting with 
general educators who may not have knowledge of best practices and accomodations to provide for students with MLD, while the special educator in the same classroom may have a strong knowledge base of accomodations and modifications to utilize for students with MLD but not an in-depth mathematics content knowledge (Maccini \& Gagnon, 2006). The previously described senerio contributes to instructional implementation issues for students with MLD.

\section{Mathematics Instructional Issues for Students with MLD}

The change from instructing students with MLD in a self-contained classroom taught by a special educator, with a small student to teacher ratio, to mathematics instruction in a general education inclusive classroom, with a mathematics teacher and possibly a special educator has raised different issues when trying to meet the needs of students with MLD. According to research, when teaching mathematics to secondary students with MLD the three main implementation issues are: (a) teacher preparation, (b) access to curricula, and (c) the educational placement of the student (Allensworth, Nomi, Montgomery \& Lee, 2009; Brodesky, Gross, McTigue \& Tierney, 2004; DeSimone \& Parmer, 2006; Loveless, 2009; Lusk, Thompson \& Daane, 2008; Maccini \& Gagnon, 2002, 2006; Servilio, 2009; Viadero, 2010).

Teacher preparation. The issue of teacher preparation when teaching mathematics to students with MLD is legally addressed by the "highly qualified" requirements of educators in both NCLB (2001) and IDEA (2004). The mandates by both NCLB (2001) and IDEA (2004) have motivated teacher preparation programs across the United States to change their curricula to fit the needs of public school systems. Given these changes, there are still major shortages in both the fields of secondary special education and mathematics (ED, 2010). Approximately 40,000 teaching positions in secondary special education and mathematics are filled by uncertified teachers due to the lack of certified secondary special education and mathematics 
teachers nationwide (ED, 2001). Studies by DeSimone and Parmar (2006), Maccini and Gagnon (2006), Servilio (2009), and Lusk et al. (2008) emphasized the importance of employing certified teachers in mathematics and special education, and in requiring a specific amount of coursework in both of these fields.

DeSimone and Parmer surveyed 228 middle school mathematics inclusion teachers nationwide with the Survey on Teaching Mathematics to Students with Learning Disabilities in Middle School that included Likert-type scale questions, multiple choice questions and open ended questions. This descriptive study provided participants' (a) demographic data, (b) perceptions of the level of administrative supports, (c) reported access to resources for inclusive teaching, (d) beliefs regarding inclusive mathematics classes, (e) beliefs regarding students with $\mathrm{LD}$, (f) prior professional development for teaching inclusive classes, (g) level of comfort in their abilities to adapt mathematics instruction for students with LD, and (h) level of comfort in their abilities to adapt specific mathematics content for students with LD. Following the survey DeSimone and Parmer conducted 26 phone interviews with purposefully selected participants, based on if they volunteered and if they were from the nine states with the largest percentage of surveys. They found that middle school teachers had a limited understanding of the needs of students with LD and had difficulty knowing how to serve these students in an inclusive classroom. These teachers attributed this difficulty to the lack of preparation and exposure to an inclusive classroom during their teacher education program and required in-service education. Maccini and Gagnon (2006) and Servilio (2009) support the belief that as the prevalence of students with LD increases in higher level mathematics courses such as Algebra, general educators need instruction regarding methods that provide meaningful instruction for these students. Servilio employed a quantitative approach to survey 484 general and special education 
teachers, grades Kindergarten to twelfth, from Maryland. This causal comparative design allowed Servilio to identify a relationship between variables across two or more groups. Teachers' perceived needs, as elicited by Servilio, identified various factors that influenced mathematics teachers' need for further mathematics education professional development. General and special education teachers certified in mathematics were more likely to feel their mathematics content knowledge was strong, as compared to those not certified in mathematics. This supports DeSimone and Parmer's (2006) suggestion of employing teachers who are certified in the content in which they are teaching. Further, mandates in NCLB (2001) require certification of secondary special education teachers in a core content area to meet the criteria for "highly qualified" status.

Maccini and Gagnon (2006) surveyed a random nationwide sample of 179 secondary general education mathematics and special education teachers about their use of specific accommodations and instructional practices used during instruction in secondary mathematics courses. Through descriptive demographic questions and Likert-type scale items, the survey addressed three central topics: (1) teacher background information, (2) teacher perceived knowledge of secondary math topics, and (3) specific instructional practices and accommodations teachers used for students with LD. Based on descriptive statistics and a regression model, key findings of the survey were "special education teachers' familiarity with course topics significantly and uniquely contributed to the prediction of the number of instructional practices they provided to secondary students with LD in a mathematics classroom; the number of mathematics methods courses taken by general education teachers contributed to the prediction of the number of instructional practices they made for students with LD"(p.228-9). 
Servilio (2009) supports Maccini and Gagnon with the following, that the majority of educators, both special and general, felt that the greater number of mathematics content courses taken increased their ability to teach mathematics, and the greater number of mathematics methods courses taken increased their mathematics content. Further, Servilio found that the professional development needs of general and special educators differed based on certifications, past educational experiences, and courses in which the educators were teaching. Research indicates that a variety of different factors influence teachers' (special education and mathematics) knowledge of effective instructional strategies for students with MLD (DeSimone \& Parmer, 2006; Maccini \& Gagnon, 2006; Servilio, 2009). Higher level mathematics curriculum becomes more accessible to students with MLD when educators have a strong knowledge base of effective instructional strategies for students with MLD.

Accessibility to curriculum. According to Brodesky and Gross (2009) instruction that is accessible for students with LD should include various mathematics instructional practices and assessment accommodations. When mathematics curriculum is not entirely accessible to students, especially those with LD, desired learning outcomes will rarely occur. Accessibility issues can occur when student's needs are not being met based on employed instructional strategies, accommodations, and/or modifications. Studies have found that there tends to be a correlation between teachers' educational experiences and the instructional practices and modifications they utilize (Maccini \& Gagnon, 2006; DeSimone \& Parmer, 2006).

A project funded by the National Science Foundation and based at the Education Development Center (EDC), Addressing Accessiblity in Mathematics, examined the relationship between the use of effective instructional strategies and access to mathematics curricula for students' with LD (Brodesky \& Gross, 2009). The project is influenced by many different types 
of studies, such as case studies in specfic schools and study groups composed of teachers throughout many different school districts and states. A major influence was a study group from Massachusetts, composed of 102 teachers from 16 schools in five urban and suburban districts whose student populations ranged anywhere from $13 \%$ to $23 \%$ with LD. The field test lasted two years, and teachers met bi-weekly in grade-level groups with mathematics and special educators with an EDC piloted protocol to analyze student work, and then change instruction based on their analysis of students' work. The results of this project influenced the creation of a three-step framework, for teachers to follow when instructing secondary students with MLD: (1) consider the mathematics and the student, (2) identify barriers, and (3) plan, implement, evaluate and revise as needed accessibility strategies (Brodesky \& Gross, 2009). The numerous accessiblity strategies suggested by Brodesky and Gross (2009) can be grouped into eight distinctive categories: (a) helping students understand tasks, (b) helping students access math in varied ways, (c) building student independence, (d) providing tools and handouts, (e) promoting understanding through discourse, (f) helping students manage tasks and organization, (g) adjusting tasks to student needs, and (h) creating supportive environment.

Students' Individualized Education Programs (IEP) legally document required strategies, interventions, accommodations and modifications for students with LD that educators must employ to give the student access to the general education mathematics curriculum. Maccini and Gagnon (2006) investigated what instructional practices and accomodations general and special educators reported using for students with LD, and found the following were the most commonly utilized: "use of calculators; assignment modifications such as adjusted workloads; and increased time for activities and tests" (p.230). There is not an excess of studies regarding how accurately general and special educators follow students' IEP required services (IDEA, 2004). 
Educational placement. The third main issue regarding implementation of mathematics instruction for students with MLD is their educational placement. The IEPs of students with MLD identify and describe their required educational placement. A student's educational placement directly determines the type of instructional practices utilized to teach mathematical content. For example, the instructional practices utilized in a classroom with RTI tier 1 mathematics instruction greatly differs from instructional practices utilized in a self-contained classroom with RTI tier 3 mathematics instruction. Students with MLD are typically served in either a self-contained classroom or an inclusive classroom. A self-contained classroom, typically a classroom providing RTI tier 3 instructions, is a small class setting where students are intensively taught in a more one-on-one setting as compared to a general education classroom. As compared to 1992, the percentage of students with specific learning disabilities who spend more than $80 \%$ of their instructional time in general education has more than doubled, from $21 \%$ to $53.7 \%$ (NCES, 2010). Some recommend that students with MLD who receive their mathematics instruction through inclusion with general education students are instructed using a differentiated curriculum (Brodesky \& Gross, 2009; Maccini \& Gagnon, 2000; Mazzacco, 2007).

According to IDEA (2004), students with MLD should be in their LRE, based on their needs, and for many students that is in the general education setting with differentiated instruction. Some students need additional support that is not guaranteed in the typical general education setting but can be provided in a classroom following the guidelines of RTI tier 2 classroom instruction and intervention (Fuchs \& Fuchs, 2005). In secondary level mathematics, RTI tier 2 typically is a mathematics support course, such as Algebra Support in West Virginia high schools, where the re-teaching of targeted concepts and additional practice occurs (Gersten et al., 2009; WVDE, May 2009). 
Throughout school districts across the U.S., the implementation of RTI tier 2 interventions and instruction faces many obstacles. Gersten et al. (2009) identified the following as the main implementation issues for RTI tier 2 intervention and instruction: (a) teachers may be unfamiliar with how to provide explicit instruction and may not have a strong understanding of the essential mathematics content, (b) instructional materials may not include enough visual models, opportunities for think-alouds, practice and cumulative review, (c) curricular material may not classify problems into problem types, and (d) instructional materials may provide few visual representations, teachers may not fully understand the mathematical ideas that underlie some representations, and teachers may believe that instruction in concrete manipulatives require too much time.

No matter which delivery structure is utilized to instruct students with MLD one of the main goals of their educational placement, as well as other components on their IEP, is to narrow the general education-special education achievement gap between the student and their general education peers by making the curriculum more accessible. The general education-special education achievement gap in mathematics, specifically in Algebra I, and implementation issues surrounding the instruction of Algebra I to student with MLD is frequently discussed and debated nationwide (Allensworth et. al, 2009; Gagnon \& Maccini, 2001; Loveless, 2009; Steele \& Steele, 2003; Viadero, 2010).

\section{Algebra I Implementation Issues for Instruction of Students with MLD}

The general education-special education achievement gap in regards to Algebra I is a popular topic because the majority of all public school students in America must pass an Algebra course in order to graduate (NCES, 2009). This graduation requirement in many U.S. school districts has stemmed from standards set in NCLB (2001) and learning expectations derived from 
NCTM (2000). Students with MLD are among these students, and they are typically served in inclusive classrooms where they frequently struggle with algebra because the content is increasingly abstract (Steele \& Steele, 2003).

The shift from Algebra I not being a graduation requirement for all students to the current trend, in most states, of requiring the completion of an Algebra I course in an inclusive heterogeneous setting caused many issues nationwide when teaching Algebra I to students with MLD. The implementation concerns surrounding instruction of Algebra I concepts to students with MLD are very similar to the general issues found when teaching any mathematical concept to students with MLD. As identified by the literature, access to curricula, teacher preparation and the educational placement of students with MLD are the three main issues surrounding secondary education instruction to students with MLD, including Algebra I instruction (Allensworth et. al, 2009; Brodesky, Gross, McTigue \& Tierney, 2004; DeSimone \& Parmer, 2006; Loveless, 2009; Lusk et. al, 2008; Maccini \& Gagnon, 2002, 2006).

Similar to the general mathematics instructional issues, accessible curricula for students with MLD is typically caused by (a) the incorrect use or lack of needed accommodations and modifications, (b) instruction that does not meet the learning styles and needs of all students, and/or (c) instruction of algebraic concepts in an only abstract manner (Brodesky, Gross, McTigue \& Tierney, 2004; DeSimone \& Parmer, 2006; Maccini \& Gagnon, 2002, 2006; National Research Council, 2000, 2001). Aligning with the "Algebra for All” initiative most ninth graders with MLD nationwide are enrolled in some type of an Algebra I course, and according to many educators, these students are misplaced because they have not yet mastered the arithmetic skills needed for an Algebra I course (Gagnon \& Maccini, 2001; Loveless, 2009; Steele \& Steele, 2003). Placing students with MLD in a course that they do not have the 
prerequisite skills, is another example of making Algebra I curricula inaccessible to students because the rigor of the algebra content is typically reduced to teach prerequisite skills.

A study by Schiller, Schmidt, Muller and Houang (2010) analyzed information from high school transcripts, textbook adoption lists, and survey data from the National Longitudinal Study of Adolescent Health representing a sample of 20,746 students from 1,300 high schools to provide insight on how courses and curricula shape opportunities in mathematics during high school. This study revealed that one third of students nationwide studying Algebra I, including those with MLD, are using arithmetic books in their classes. This finding warrants the need for research of how students with MLD are performing on national algebraic assessments, reflective of NCTM and CCSS recommend Algebra I course content.

Studies nationwide, and specifically in Chicago, found that public schools' efforts to boost Algebra I course enrollment for "at-risk" students in or previous to eighth grade did not improve test scores, prepare students any better for college, or make students any more likely to attend college after graduation (Allensworth et. al, 2009; Loveless, 2009). Loveless (2009) analyzed data from NAEP results of 160,00 eighth graders nationwide and found that $28.6 \%$ of low achievers, students who score in the bottom ten percent of students, are enrolled in advanced math classes (Algebra I, Geometry, Algebra II) as eighth graders. This is more than double the percent of low achievers enrolled in advanced math classes in 2000. These findings by Loveless support Schiller's et. al (2010) statement that “Efforts to promote academic achievement by increasing access to courses, especially in mathematics, may mask educational disparities if variations in curriculum are not also monitored" (p.414).

As noted previously, the main Algebra I educational placement for students with MLD is in a general education setting with differentiated instruction. In many public school districts, 
students who need additional support must enroll in an algebra support course. There is little research completed about this type of delivery structure. In 2003, Chicago public school teachers were given extensive professional development on what type of instructional practices to incorporate into the high school Algebra I support course. The resulting changes in instructional practice and time appeared to slightly improve students' standardized test scores but not passing rates (Allensworth et. al, 2009). After the addition of the double algebra course, the number of special education students who earned an Algebra I or a higher mathematics credit in ninth grade increased, but this same subgroup of students experienced a decline in their GPAs (by .15) and course failures increase (by 7.7 percentage points in mathematics). Allensworth et. al, attribute students' attendance rates and behavioral issues to the failures and lack of increase in GPAs, because their standardized testing scores did increase.

In Orange County, California, the public school district investigated the implementation of the Johns Hopkins Talent Development mathematics program which incorporated double mathematics classes. It appeared that the double courses increased the passing rate for "at-risk" high school students in Algebra I and other advanced mathematics courses (Viadero, 2010). Most studies of the effectiveness of double algebra courses occur locally rather than on a national level, due to the limited amount of studies about this delivery structure of Algebra I for "at-risk" students, including those with MLD. These studies indicate students must have adequate opportunities to learn algebraic skills through improved instruction, not just a change in required courses, to become more successful academically as measured by standardized assessments, GPAs, and graduation rates (Allensworth et. al, 2009; Loveless, 2009; Schiller et. al, 2010). 
However, to date, there is limited research available on teachers' perceptions and the current state of Algebra I instruction for students specifically with MLD. Lusk et. al (2008) surveyed 63 Algebra I general educators from 27 school districts in Alabama to describe their perceptions of teaching Algebra I to students with LD. The survey included background demographic questions, a 16-item Likert scale regarding teachers' perceptions of teaching students with LD, and an open-ended section where participants could provide comments concerning their teaching experiences with students with LD. The survey revealed that $63 \%$ of the participants had no or only one college course addressing LD, $60 \%$ of the respondents believed adequate resources for students with LD did not exist and approximately $60 \%$ believed Algebra I teachers do not have the knowledge and skills necessary to teach students with LD. More specifically, significant relationships identified using a chi-square test existed between collaboration with special education teacher at least once every two weeks and the responses to the following six survey items: “(a) inclusion improves self-esteem of students with LD, (b) adequate resources exist to meet the needs of students with $\mathrm{LD}$, (c) adequate support exists from the special education teacher, (d) students with LD experience more academic success in general education, (e) special educators are comfortable implementing personalized learning plans for students with LD, and (f) students with LD have a basic right to be in the general education classroom." These findings emphasize the need for Algebra I general educators to have more effective pre-service coursework and collaborative time with a special educator on a regular basis.

\section{Algebra I Implementation Issues for Instruction of Students with MLD in West Virginia}

WVDE (2008) Policy 2510 states a student must earn four units of mathematics with a minimum of one Algebra credit, to graduate with a diploma. The recommended delivery of the 
Algebra I CSOs for the "at-risk" student population in West Virginia is through a heterogeneously mixed Algebra I class and an Algebra Support class. WVDE course recommendations for Algebra Support was created following the RTI tier 2 design, which does align with the NMAP's recommendation for "explicit instruction" for students with MLD and those having mathematical difficulties (WVDE, 2008, 2009). During the 2009-10 school year $25 \%$ of the students enrolled in Algebra I in West Virginia were also enrolled in Algebra Support (WVEIS, 2010). A major implementation issue for Algebra Support in West Virginia is that Policy 2510 does not ensure the proper implementation and scheduling of the Algebra Support course as recommended by WVDE. Although the course recommendations for Algebra Support follow the RTI tier 2 design, as recommended by the NMAP, counties are not required to structure Algebra Support following the WVDE recommendations. This freedom of interpretation has resulted in distinctly different types of course offerings under the same name, Algebra Support, which not only differ from county to county but from high school to high school.

According to the WVDE Mathematics Coordinator, Algebra Support should facilitate authentic mathematics teaching and learning for "at risk" students (Maynus, 2010). A common goal of this course is to make Algebra I content more accessible to "at-risk" students through development of metacognitive and critical problem solving skills (Maynus, 2010). Maynus stressed the twenty-first century student does not always need to know how to do the mathematics, specifically the procedures, but must be able to know how to access it, whether that be through technology or the use of manipulatives (Maynus, 2010). West Virginia public schools has offered Algebra Support since the 2008-09 school year, but the first WVDE professional development session focused on Algebra I Support and specific instructional 
practices to utilize for secondary students with MLD was held in October of 2010. At this session, teachers received materials and resources, now available online at the WVDE Mathematics website, to utilize while teaching Algebra I Support. These materials include sample letters for guardians explaining the purpose of Algebra I Support, diagnostic assessments for identifying students' strengths and weaknesses, as well as instructional materials and manipulatives grounded in CRA, differentiated instruction, and the use of technology (Maynus, 2010). Currently there is no WVDE mandated format for the structure of an Algebra Support class, nor a WVDE created evaluation or assessment to monitor how all counties are implementing Algebra Support.

\section{Summary}

The primary responsibility of teachers is to facilitate instruction which promotes learning for all students, including those with MLD. Teachers must be able to identify each student's learning styles and needs and then teach in a manner which engages all students. An analysis of the literature suggests that students with MLD tend to struggle in Algebra I courses nationwide, which is a cause for concern because Algebra I is a graduation requirement in the majority of school districts across the United States (Steele \& Steele, 2003). Many studies identify the following characteristics of students with MLD: (a) difficulty processing information which results in problems learning to read and problem-solve; (b) difficulty with distinguishing the relevant information in story problems; (c) low motivation, self-esteem, or self-efficacy to learn due to repeated academic failure; (d) problems with higher-level mathematics that require reasoning and problem-solving skills; (e) learners-reluctant to try new academic tasks or to sustain attention to task; (f) difficulty with self-monitoring and self-regulation during problemsolving; and (g) difficulty with arithmetic, computational deficits (Allsopp, Lovin, Green, \& 
Savage-Davis, 2003; Maccini \& Gagnon, 2000; Steele, 2002). To meet the needs of students with MLD in an Algebra I classroom, curriculum and instruction must encompass multiple instruction strategies, practices and interventions specifically designed to address these characteristics.

An analysis of studies addressing effective mathematical instructional strategies for Algebra I instruction of students with MLD identified eight potentially beneficial recommended instructional strategies: (a) general problem-solving strategies in problem represenation and problem solutions, (b) self-monitoring strategies (including the use of student think-alouds), (c) peer-assisted learning, (d) the concrete-representation-abstract instructional sequence, (e) teaching prerequisite skills, (f) explict instruction, (g) technology, and (h) graphic organizers (Allsopp, Kyger, Lovin, Gerretson, Carson \& Ray, 2008; Allsopp, Lovin, Green \& SavageDavis, 2003; Brodesky \& Gross, 2009; Foegen, 2008; Gagnon \& Maccini, 2001; Gersten \& Clarke, 2007; Hudson \& Miller, 2006; Hutchinson, 1993; Ives, 2007 Ketterlin-Geller, Chard \& Fien, 2008; Kortering, deBettencourt \& Braziel, 2005; Maccini \& Gagnon, 2000, 2002 \& 2006; Maccini, McNaughton, \& Ruhl, 1999; Steele, 2002; Steele \& Steele, 2003; Strickland \& Maccini, 2010; Witzel, Smith \& Brownell, 2001). According to both the National Research Council and the NMAP students learn algebraic concepts best when: (a) teachers elicit and build on the preexisting understandings students bring with them to the classroom; (b) instruction is based on main concepts, which are taught indepth by providing examples and practice using multiple representions to provide a foundation of factual knowledge; (c) teaching metacongitive skills is integrated into the curriculum through questioning and discourse; (d) formative assessments are used regularily so progress can be monitored by both the teacher and the student; 
and (e) the study of algebra is not begun with a formal algebra course, but begins in early grades (NMAP, 2008; National Research Council 2000, 2001).

When student needs are identified, a variety of instructional strategies designed to meet student needs are utilized, and the knowledge of how students best learn algebraic concepts are considered, an opportunity for student success occurs. A review of the existing literature implies the requirement for all students in West Virginia to complete an Algebra I credit before graduation necessitates that all Algebra I teachers must learn how to facilitate instruction, as described above, to meet the needs of all students especially students diagnosed with MLD. Research has investigated aspects of the current state of mathematics instruction for secondary students with MLD (DeSimone \& Parmar, 2006; Lusk et. al, 2008; Maccini \& Gagnon, 2006; Servilio, 2009). However, none of these studies specifically addressed the current state of Algebra I instruction for this population regarding (a) educators' opportunities to develop knowledge for teaching students with MLD, (b) educators' perceptions of how beneficial their educational experiences were in helping them teach students with MLD, (c) educators' instructional practices, assessments and accommodations for students with MLD, and (d) educators' perceived issues when teaching Algebra I to students with MLD. Furthermore, the primary research that guided these studies utilized a quantitative approach, which does not allow for elaboration of survey responses. These factors warrant the need for a descriptive mixed methods sequential study investigating the current state of Algebra I instruction for students with MLD. 


\section{CHAPTER 3: METHODOLOGY}

\section{Study Design}

This descriptive study employed a sequential mixed methods design with a survey and follow-up interviews. The research for this study occurred during the spring 2011 semester. To inform the larger study the researcher first conducted a pilot study in January 2011, followed by the larger study in February-April of 2011.

Similar to DeSimone and Parmar (2006), this study used a mixed methods design and elicited teacher perceptions and insights to the current state of Algebra I instruction for students with MLD in West Virginia. The purpose of selecting a mixed methods design for this study was to allow the quantitative data to drive the development of qualitative measures. Further, the mixed methods design facilitated the use of triangulation in design and analysis. The inherent method strengths of both qualitative and quanititive designs strengthen results when the purpose of a mixed-methods design is the development of valid constructs and triangulation (Greene, Caracelli \& Graham, 1989).

The research project addressed the following questions:

1. What opportunities have Algebra I/Algebra Support educators from West Virginia had to develop knowledge for teaching students with MLD?

2. What are West Virginia's Algebra I/Algebra Support educators' perceptions regarding how beneficial their educational experiences and opportunities were in helping them develop knowledge for teaching students with MLD?

3. How do West Virginia's Algebra I/Algebra Support educators' instructional practices for students with MLD align with the recommended best practices to utilize for students with MLD? 
4. What are West Virginia's Algebra I/Algebra Support educators' perceived issues with regard to the instruction of algebra to students with MLD?

\section{Pilot Study Description and Design}

The first part of this project was the completion of a pilot study. The pilot study used a survey to identify the current state of Algebra I instruction for students with MLD from the surveyed county. Prior to the start of the pilot study in early January, professionals in the field (university faculty members, mathematics educators, and special educators) reviewed the survey and provided comments that prompted some changes in wording of survey questions. The researcher surveyed pilot study participants during the first two weeks in January and then conducted the follow up phone interviews during the last week in January. The following is a detailed description of the pilot study that informed the design and implementation of the larger, state-wide research project.

Participants in the pilot study consisted of secondary general and special education teachers of Algebra I and Algebra Support from a mid-sized county located in the eastern panhandle of West Virginia. Fifteen educators from this mid-sized county were either secondary general or special education teachers of Algebra I and/or Algebra Support. Seven (six general educators and one special educator) of the 15 educators who taught Algebra I and/or Algebra Support to students returned the survey, and four (three general educators and one special educator) out of the seven surveyed educators participated in the voluntary follow-up interview. The researcher purposefully selected this county for the pilot study location based on the county demographics and the close proximity to the researcher. The county where the pilot study took place has a population of approximately 27,000 (U.S Census Bureau, 2009). The racial and income characteristics of the population in this county are very similar to the racial and income 
characteristics of West Virginia's total population. The county's median household income in is $\$ 42,308$ and $13.8 \%$ of the population lives below the poverty level (U.S Census Bureau, 2009). The median household income in West Virginia is $\$ 37,528$ and $17.4 \%$ of the population lives below the poverty level (U.S Census Bureau, 2009). A large majority (approximately 95\%) of the population in both the selected county and the state of West Virginia is Caucasian (U.S Census Bureau, 2009). The county's schools serve approximately 4,460 students and $98 \%$ of the teachers in these schools meet the highly qualified standards, as set by NCLB (WVEIS, 2010). West Virginia public schools serve approximately 281,894 students (WVEIS, 2010). The majority, $96.2 \%$, of teachers who teach mathematics in the surveyed county are highly qualified in that core content, as determined by NCLB (WVEIS, 2010). In West Virginia public schools, $89.5 \%$ of the teachers who teach mathematics are highly qualified in that core content, as determined by NCLB (WVEIS, 2010).

The participants in this study were employees at one of the two middle schools or two high schools located in the county. High School A and Middle School A are located on the eastern end of the selected county. High School A has approximately 540 students, with approximately $74(13.7 \%)$ of those students identified as special education students. Middle School A has approximately 555 students, with approximately 87 (15.7\%) of those students identified as special education students (WVEIS, 2010). High School B is located in the southwestern part of the selected county. High School B has approximately 751 students, with approximately 109 (14.5\%) of those students identified as special education students (WVEIS, 2010). Middle School B is housed in the same building as a primary school so the school population reflects middle and elementary school students' characteristics. There are 
approximately 1,155 students at Primary/Middle School B, with 224 (19.4\%) of those students identified as special education students (WVEIS, 2010).

On the 2009-10 WESTEST II, 22.45\% of the subgroup of students with SLD in West Virginia scored proficient in Mathematics (Mastery or above). In the selected county, 20\% of the subgroup of students with SLD scored proficient in Mathematics. Individual school data separated by subgroups and grades is not available to the public from the WVDE.

Upon approval of the study by the dissertation committee and the West Virginia University Institutional Review Board (IRB), an email was sent to the 15 prospective educators in the selected county. This email contained a cover letter, directions on how to complete the pilot survey, and the survey link (See Appendices A, B, \& C). The cover letter explained the purpose of the pilot study and asked the educators to complete the survey within two weeks. The email included an explanation of confidentiality. Specifically, identifiable demographic information (phone number and email) was only connected to survey responses for the purpose of being contacted for the follow-up qualitative interview. An incentive for teachers to complete the survey was a drawing for a $\$ 50$ gift card to an online book store. After data analysis of the pilot survey responses, the interview questions were generated.

The researcher used both quantitative and qualitative instruments in the pilot study. The quantitative instrument utilized in this pilot study was a researcher developed survey inventory. The survey created for this project, titled Survey of Instructional Practices Implemented by Algebra I General and Special Educators When Educating Students with a MLD (SIP), included three parts. Part I included questions about demographic characteristics and contact information. Part II included Likert-type scale descriptor statements regarding teachers' current instructional practices and oppurtunities to develop a knowledge base for teaching students with MLD. 
Qualitative measures used in the pilot study included Part III of the survey and a standardized open-ended interview. The open-ended survey question, from part III of the survey, prompted participants to discuss any perceived issues involved in Algebra I instruction for students with MLD by asking them to "Please describe your perception related to issues involved in Algebra I instruction for students with MLD?” The researcher asked all surveyed educators from the pilot study to voluntarily participate in an interview in order to provide more insight to their survey responses and to give feedback on the survey instrument. All interviewed participants completed a set of seven questions addressing educators' perception of the survey and general experiences teaching Algebra I to students with MLD. The researcher asked additional questions to specific interviewees based on their use of specific strategies recommended in the research literature for instruction of students with MLD. For example, there was a range of responses regarding the use of CRA so the researcher asked additional questions about the use of CRA to three different participants, selected based on their reported use of CRA. Table 1 lists the specific questions asked and variability in the participants' reported usage. All interviews were conducted over the phone, recorded by the researcher, and then transcribed. 


\section{Table 1}

\section{Pilot Study Interview Questions}

\begin{tabular}{|c|c|}
\hline Interview Question & $\begin{array}{l}\text { Interview Participants } \\
\text { Asked the Question(s) }\end{array}$ \\
\hline Was the survey easy to follow or was there anything that was ambiguous? & All \\
\hline Was there any other information that you would have liked to share on the survey? & All \\
\hline How is Algebra I taught to students with MLD in your school? & All \\
\hline $\begin{array}{l}\text { What are your experiences with this delivery system for teaching Algebra I to students with } \\
\text { MLD? }\end{array}$ & All \\
\hline How do you feel about this delivery system for teaching Algebra I to students with MLD? & All \\
\hline $\begin{array}{l}\text { Can you share any suggestions for an improvement of your schools, and/or the state } \\
\text { departments, delivery system of Algebra I for students with MLD? }\end{array}$ & All \\
\hline $\begin{array}{l}\text { What are any issues you can identify surrounding the instruction of Algebra I to students with } \\
\text { MLD? }\end{array}$ & All \\
\hline $\begin{array}{l}\text { CRA Questions: } \\
\text { What are your experiences with using CRA to teach Algebra I concepts to students with MLD? } \\
\text { How would you define CRA and what does it look like when being implemented in a } \\
\text { classroom? } \\
\text { Where or how did you attain this knowledge of CRA? } \\
\text { How do you feel about using CRA for teaching Algebra I concepts to students with MLD? }\end{array}$ & $\begin{array}{l}1 \text { general educator who } \\
\text { reported using it weekly } \\
1 \text { general educator who } \\
\text { reported using it never } \\
1 \text { special educator who } \\
\text { reported using it never }\end{array}$ \\
\hline $\begin{array}{l}\text { Peer-Assisted Learning Questions: } \\
\text { What are your experiences with using peer-assisted learning to teach Algebra I concepts to } \\
\text { students with MLD? } \\
\text { How would you define peer-assisted learning and what does it look like when being } \\
\text { implemented in a classroom? } \\
\text { Where or how did you attain this knowledge of peer-assisted learning? } \\
\text { How do you feel about using peer-assisted learning for teaching Algebra I concepts to students } \\
\text { with MLD? }\end{array}$ & $\begin{array}{l}1 \text { general educator who } \\
\text { reported using it daily } \\
1 \text { general educator who } \\
\text { reported using it monthly }\end{array}$ \\
\hline
\end{tabular}

Note. The whole subset of CRA Questions and Peer-Assisted Learning Questions were asked of the identified educators in each group.

Quantitative analysis of the pilot study data included descriptive statistics such as mean responses across some Likert-type questions and percentages used to describe the frequency distribution across other Likert-type and demographic questions. The researcher used content analysis to analyze the qualitative data, specifically conventional content analysis of the responses to the open-ended survey question and directed content analysis the transcribed interview responses. This directed content analysis used results from prior research on instruction for students with MLD to identify key concepts used for initial coding (Hsieh \& 
Shannon, 2005). Following the analyses of all data, the researcher verified that the instrumentations clearly addressed the research questions by using the results to answer the four research questions.

Pilot study findings that informed the state-wide study. The data from the pilot study provided enough information for the researcher to answer all four research questions. Based on the pilot study results, the wording of one survey question and addition of one interview question were the only changes made to the instrumentation used during the larger study. An interview participant suggested SIP question 19 needed more clarification about collaboration with colleagues. The original format of the question did not directly address the collaboration between general and special educators, which was the intent of the researcher. The question changed from originally asking "Please indicate how often you collaborate with a special education teacher or a general education teacher about mathematics instruction" to "Please indicate how often you collaborate with a special education teacher (if you are a general educator) or a general education teacher (if you are a special educator) about mathematics instruction."

Based on an interview participant's response, the researcher added the question "What opportunities have you had to develop knowledge for teaching students with MLD?" to the set of initial interview questions for the larger study. An interview participant, who reported using research based "best practices" regularly for students with MLD, stated that she implemented the practices weekly even though she did not think they were beneficial for the students. Probing by the researcher elicited this statement:

I feel that this non-traditional way of teaching is ineffective and the communication that occurs is not helpful to the students' learning of concepts. I get a lot of blank stares and feel like the students are crying just teach me in a traditional manner. I just keep doing it 
because I know it is suppose to work for struggling students at least that is what I was told at the Kagan professional development provided by the county.

This response motivated the researcher to give all interview participants the opportunity to address research questions one and two during the initial set of questions for all interview participants. For the larger study, these changes allowed the survey question to be more explicit and the new interview question to give further insight to the participants' development of knowledge for specific instructional practices. In February 2011, the researcher made any necessary changes to the measures based on the pilot study analyses before starting the larger study.

\section{Participants and Setting of Statewide Study}

Following the pilot study, the researcher conducted a larger statewide study with procedures and population similar to that of the pilot study. Participants in this study consisted of general and special education teachers of Algebra I, Algebra Support, or both Algebra I and Algebra Support from the eight Regional Education Service Agencies (RESA) in West Virginia. During the 2010-11 school year, there were 284 educators in West Virginia who met the qualifications to participate in this study (Maynus, 2010). This study aimed to survey 164 educators, approximately $57 \%$ of the targeted teaching population. The researcher derived this sample size with a sample size calculator, using the population of 284 individuals, a confidence interval of five and a $95 \%$ confidence level. Sixty-three mathematics educators returned the survey. Six respondents were removed from the population because they did not teach students with MLD. This resulted in a 20\% $(n=57)$ response rate from the desired population of 284 Algebra I, Algebra Support, or both Algebra I and Algebra Support educators. Specifically, $66.7 \%(n=38)$ of the participants reported being a general educator, $24.6 \%(n=14)$ a special 
educator, and $8.8 \%(n=5)$ did not specify their teaching role. Further, 59.6\% $(n=34)$ reported teaching only Algebra I, 5.3\% $(n=3)$ reported teaching only Algebra Support, $22.8 \%(n=13)$ reported teaching both Algebra I and Algebra Support, and 12.3\% (n=7) did not identify which type of algebra course they taught.

A response rate of $30 \%$ to $50 \%$ in educational research is a reasonable expectation (Gay, Mills \& Airasian, 2009). The response rate of $20 \%$ for this study is a minimum return rate, because it is unknown what percentage of the 284 Algebra I and Algebra Support teachers who did not respond to the survey were included on the email contact list. In October 2010, the researcher obtained 72 Algebra I and Algebra Support teachers' email addresses at the West Virginia Department of Education (WVDE) Algebra Support professional development session. The email contact list included these 72 addresses of Algebra I and Algebra Support educators and all addresses from the WVDE mathematics listserv. It is unknown how many Algebra I and Algebra Support teachers are members of the mathematics listserv because membership to the listserv is optional for mathematics teachers in West Virginia. As a member of the WVDE special education listserv, the researcher also requested permission to use it to contact Algebra I and Algebra Support special educators, but the WVDE special education listserv webmaster denied permission for use. The researcher created email list was the only known resource available with contact information for Algebra I and Algebra Support teachers; thus it was difficult to determine how many Algebra I and Algebra Support teachers received information regarding this study. At the start of the project the researcher believed she had access to all the names and email addresses of the 284 Algebra I and Algebra Support teachers through the WVDE; after the completion of the pilot study, she received notification that she did not have this access. Rather than having access to the names of all Algebra I and Algebra Support 
teachers in West Virginia, the researcher was only provided access to the total number of Algebra I and Algebra Support educators in West Virginia. Given this situation, it is likely the return rate for Algebra I and Algebra Support teachers who teach students with MLD would be higher under different survey distribution conditions.

The researcher intended to interview approximately 16 educators, two from each RESA, who first participated in the survey component of this study. Interviewees were purposefully selected based on the RESA of employment, type of educator (general or special education), and survey responses. From the 27 survey respondents who volunteered for follow-up interviews, the researcher selected a purposeful sample of 16 educators: one general and one special educator from five of the eight RESA's (II, IV, V, VI and VII) and two general educators from the remaining RESA's (I,III, and VIII) because no special educators from RESA I, III, or VIII participated in the survey and volunteered for the interview. In the sample of 16, the researcher purposefully selected individuals whose survey responses followed the trends and themes developed from the survey, as well as participants whose survey responses differed from the survey trends and themes. For example, a finding from the survey indicated that less than half of the participants reported using CRA at least once on a weekly basis, and CRA is one of the recommended "best practices" to use when teaching algebraic concepts to students with MLD. Thus, the researcher selected an interview participant who reported daily use of CRA and one that reported never using CRA. Five of the 16 interview participants contacted consented and completed the interview. While the interview sample was smaller than originally desired, it was representative of the original survey respondents. The sample included five interviewees, who represented five of the eight RESAs, both general and special educators, and educators with different types of certification. 


\section{Procedures}

In late February 2011, the researcher contacted participants via professional email addresses collected by the researcher at the WVDE Algebra Support professional development session in October 2010 and from the WVDE mathematics education listserv. The invitation email contained a cover letter, directions on how to complete the survey, and the survey link (See Appendices A, B, and C). The cover letter explained the purpose of the study, and asked the educators to complete the survey within three weeks. It informed participants that identifiable demographic information (phone number and email) would be confidential and used only to connect participants to their survey responses for the purpose of being contacted for the followup interview and/or if they win a gift card. As in the pilot study, an incentive for teachers to complete the survey was a drawing for a $\$ 50$ gift card to an online book store. A week prior to the survey submission deadline, an email was sent to the email list reminding teachers who qualified that they only had one week remaining to complete the survey.

After analysis of the survey data, the researcher generated interview questions (Appendix E) and then contacted 16 educators to participate in the interview. As described previously, participants were purposefully selected based on the RESA of employment, type of educator, and their survey responses. In April 2011, these interviews took place over the phone and were audio taped for later transcription.

\section{Instrumentation}

The researcher utilized two types of instruments to collect data during this study: a survey and follow-up interviews. The quantitative instrument was a survey; qualitative instruments included the open ended survey question and follow-up interviews. In this study, the development of the qualitative follow-up interview was influenced by the quantitative survey 
data and results, strengthening the results of this study. Triangulation in design was utilized in the development of the survey questions, interview questions, and the selection of interview participants. This allowed both the qualitative and quantitative data to be used together to answer specific research questions.

\section{Quantitative Instrument}

The quantitative instrument utilized in this study was a survey inventory, developed by the researcher, to identify the current state of Algebra I instruction for students with MLD in West Virginia and educators' opportunities to develop a knowledge base for working with students with MLD. This instrument was adapted from the West Virginia Mathematics Program Improvement Review, the Regular Education Initiative Teacher Survey (REITS), and the Mathematics Professional Development Inventory (MPDI) (Lusk, Thompson \& Daane, 2008; Servilio, 2009; WVDE, 2007). These surveys were selected because they have been used to evaluate teacher perceptions and instructional practices reguarding the mathematics instruction of students with MLD.

The survey created for this study, titled Survey of Instructional Practices Implemented by Algebra I General and Special Educators When Educating Students with a MLD (SIP), included three parts. Part I provided questions about demographic characteristics and contact information. Part II included Likert-type scale descriptor statements regarding teachers' current instructional practices and oppurtunities to develop a knowledge base for teaching students with MLD. Part III consisted of an open ended question that provided partipants additonal space for comments concerning the current state of Algebra I instruction to students with MLD in their classroom.

The assessment's content validity and reliablity was established by: (a) review of the existing literature on mathematics instruction for students with MLD, (b) review of West 
Virginia Content Standards and Objectives, (c) independent analysis of the

SIP items by two mathematics educators and two special educators, (d) independent analysis of the SIP items by three university faculty members with expertise in mathematics and learning disabilities, (e) Cronbach's Alpha to determine the inter-item consistency across all Likert-type scale SIP questions (23-24 and 26), and (f) revisions based on the results of the pilot study. The themes and connections between the existing literature and West Virginia's Content Standards and Objectives are outlined in chapter two. The analysis of the SIP by educators and faculty members, coupled with the pilot study findings resulted in some changes in wording on the survey, described previously.

\section{Qualitative Instruments}

This study utilized two qualitative measures, an open-ended survey question and standardized open-ended interviews. An open-ended question at the end of the survey helped supplement the information obtained from the survey and influenced the creation of interview questions. After survey collection and analysis, participant selection for the follow-up interviews occurred via email. Upon participant consent, the interviews were audio recorded then transcribed. The intent of these standardized open-ended interviews was to provide insight to the trends and occurrences identified through the survey.

Survey question. The last question on the survey, question 27, utilized an open-ended response format to the following prompt, "Please describe your perception related to issues involved in Algebra I instruction for students with MLD." This prompt was included in the survey to give further insight to the quantitative data obtained by the survey, and to provide direction for the development of interview questions. 
Interview. The interview instrument used was a standardized open-ended interview using the exact wording and sequence of questions, as well as questions worded in a completely open-ended format (Patton, 2002). This method of interview instrumentation was selected based on its strengths of increasing comparability of responses and facilitating organization and analysis of data (Patton, 2002). Some of the interview questions were analysis driven, because the researcher based the questions on the quantitative analysis of the survey and analysis of the existing literature regarding teaching Algebra I to students with MLD. Specifically, three of the six initial questions (Question 1, 2, and 6) asked to each interview participant addressed the themes of educational placement of students, access to curriculum, and teacher preparation. Maccini and Gagnon $(2002,2006)$ identified these themes as common issues when teaching secondary mathematics to students with MLD. All interviews included the following six initial questions:

1. How is Algebra I taught to students with MLD in your school?

2. What are your experiences with this delivery system for teaching Algebra I to students with MLD?

3. How do you feel about this delivery system for teaching Algebra I to students with MLD?

4. Can you share any suggestions for an improvement of your school's, and/or the state department's, delivery system of Algebra I for students with MLD?

5. What are any issues you can identify surrounding the instruction of algebra to students with MLD?

6. What opportunities have you had to develop knowledge for teaching students with MLD? 
Following the initial six questions, the researcher assigned interviewees specific questions based on their survey responses. Through the additional questions, the researcher addressed participants' use and knowledge of CRA and peer-assisted learning. For example, the survey data revealed that $43.5 \%$ of the surveyed participants used CRA, a highly recommended strategy as identified by literature, weekly as an instructional strategy to meet the needs of students with MLD. However, $71.5 \%$ of surveyed participants reported that they felt prepared to provide opportunities for students to use manipulatives to verify mathematical reasoning. This data displayed a discrepancy between the knowledge of instructional practices educators reported and their use of that practice. As a result, the researcher formed additional questions for specific interviewees about their use and knowledge of CRA. Interviews took place with participants who reported rarely using CRA, as well as participants who reported using it weekly. Table 2 identifies each type of additional question presented to the participants, the questions asked, and which participants the researcher assigned to those questions. 
Table 2

Description of Additional Interview Questions

Topic of Interview Questions
Additional

Questions

Interview

Participants

Asked the

Questions
Use and What are your experiences with using CRA to teach Algebra I concepts to students with knowledge of MLD?

CRA

How would you define CRA and what does it look like when being implemented in a classroom?

Where or how did you attain this knowledge of CRA?

How do you feel about using CRA for teaching Algebra I concepts to students with MLD?

Can you please describe any other perceptions regarding the use of CRA during instruction of Algebra I to students with MLD?
Teacher Ageneral educator who reported using it rarely

Teacher Bgeneral educator who reported using it weekly

Teacher C-special educator who reported using it rarely

Teacher D-special educator who reported using it weekly

Teacher E-special educator who reported using it weekly

Use and knowledge of Peer-Assisted Learning
What are your experiences with using peer-assisted learning to teach Algebra I concepts to students with MLD?

How would you define peer-assisted learning and what does it look like when being implemented in a classroom?

Where or how did you attain this knowledge of peer-assisted learning?

How do you feel about using peer-assisted learning for teaching Algebra I concepts to students with MLD?

Can you please describe any other perceptions regarding the use of peer-assisted learning during instruction of Algebra I to students with MLD?
Teacher Ageneral educator who reported using it daily

Teacher Bgeneral educator who reported using it monthly

Teacher E-special educator who reported using it weekly 


\section{Data Analysis}

To answer the research questions and examine the current state of Algebra I instruction for students with MLD in West Virginia the researcher used both quantitative and qualitative analyses. All statistical data were entered into and derived through Statistical Package for Social Science (SPSS). The quantitative analyses informed the qualitative analysis because findings from the quantitative analyses influenced the use of specific codes during the directed content analysis of the interview transcripts. Triangulation was then used to examine similarities in the three previously described analyses.

\section{Quantitative Analysis}

To describe the current state of Algebra I instruction for students with MLD in West Virginia, descriptive statistics, correlations, and chi-square tests were used to analyze the data in order to determine a relationship between educators' opportunities to expand their knowledge/practice of teaching students with MLD and their backgrounds. First, descriptive statistics were calculated based on the participants' responses to questions 1, 2, and 4-22 (See Appendix B). This analysis identified the specific demographic characteristics of the surveyed population. To answer specific research questions, the researcher analyzed relationships between specific demographic characteristics and currently implemented instructional practices. After descriptive statistics were calculated, the researcher investigated a relationship between the participants' demographic characteristics and responses to these questions using a chi-square test.

The researcher used a chi-square when frequencies for participants' responses classified into categories were the best manner to analyze the data (Gravetter \& Wallnau, 2009). Further, a chi-square analysis was used when the relationship between two variables was examined 
(Gravetter \& Wallnau, 2009). The researcher also used two different types of correlations: a Spearman correlation when comparing two ordinal values, and a Pearson correlation when comparing two dichotomous values. Statistical analysis was set at $p$ values for all alpha less than .05 .

Question 1. To determine what opportunities Algebra I and Algebra Support educators had to develop knowledge for teaching students with MLD, first descriptive statistics of frequency and percentages were generated based on participant responses to questions number 20-22. These statistics described how many hours of professional development participants reported attending and the format of these sessions. Next, a chi-square analysis or Spearman's rho was used to determine if there were a relationship between a participant's educational and professional development opportunities for developing knowledge for teaching students with MLD and demographic characteristics, including years of teaching experience, size of county, role in education, certification, and highly qualified status.

Question 2. To determine Algebra I and Algebra Support educators' perceptions regarding how beneficial their educational experiences and opportunities were in helping them develop knowledge for teaching students with MLD the researcher analyzed participant responses to question number 23. This question was made up of 16 sub-questions that directly asked participants to reflect on how their professional development experiences prepared them to teach students with MLD. After calculating descriptive statistics of frequency and percentages, the researcher investigated a relationship between the participants' demographic characteristics and responses to this question. Using chi-square analysis, Spearman rho correlation, or Pearson correlation at each item level the researcher investigated the relationship between teachers' perception and demographic characteristics: years of teaching experience, role in education, 
degree, number of courses taken that address the characteristics of students with MLD, and certification.

Question 3. To determine how Algebra I and Algebra Support educators' instructional practices for students with MLD aligned with the recommended best practices to utilize for students with MLD the researcher first identified the types of instructional practices, assessments, and accommodations educators utilized for students with MLD through descriptive statistics based on the survey responses to question number 24. After calculating descriptive statistics of frequency and percentages, the researcher investigated a relationship between the participants' demographic characteristics and responses to this question with chi-square analysis, Spearman rho correlation, or Pearson correlation at each item level. The researcher analyzed the relationship between participant's instructional practices and the following demographic characteristics: gender, years of teaching experience, specific grade level, number of courses taken that address the characteristics of students with MLD, size of county, role in education, number of hours of mathematics methods courses taken, certification, highly qualified status, number of students with MLD in class, and how often the teacher collaborated with a special or general educator.

Question 4. To determine Algebra I and Algebra Support educators' perceived issues with regard to the instruction of algebra to students with MLD the researcher calculated the mean of participants' responses to number 25 and 26, and then the descriptive statistics of frequency and percentages. A relationship between participants' perceived issues and the following demographic characteristics were analyzed: years of teaching experience, number of mathematics classes that they taught, size of county, role in education, RESA, how often the teacher collaborated with a special or general educator and highly qualified status in 
mathematics. Dependent on what variables were being compared the researcher performed a chi-square analysis, Spearman correlation, or Pearson correlation at each item level. Table 3 includes descriptions of the quantitative and qualitative methods used to address each research question, and what specific data sources were analyzed together with demographic variables. 
Table 3

Data Analysis Overview

\begin{tabular}{|c|c|c|}
\hline Research Questions & Data Sources & Data Analysis \\
\hline $\begin{array}{l}\text { What opportunities have Algebra I/Algebra Support educators } \\
\text { from West Virginia had to develop knowledge for teaching } \\
\text { students with MLD? }\end{array}$ & $\begin{array}{c}\text { SIP } 27 \\
\text { Interviews }\end{array}$ & $\begin{array}{c}\text { Descriptive statistics: } \\
\text { Frequency \& } \\
\text { Percentages } \\
\text { Chi-square } \\
\text { Spearman's rho } \\
\text { Conventional Content } \\
\text { Analysis } \\
\text { Directed Content } \\
\text { Analysis }\end{array}$ \\
\hline $\begin{array}{l}\text { What are West Virginia's Algebra I/Algebra Support educators' } \\
\text { perceptions regarding how beneficial their educational } \\
\text { experiences and opportunities were in helping them develop a } \\
\text { knowledge for teaching students with MLD? }\end{array}$ & SIP 23 & $\begin{array}{l}\text { Descriptive statistics: } \\
\text { Frequency \& } \\
\text { Percentages } \\
\text { Spearman's rho }\end{array}$ \\
\hline & $\begin{array}{l}\text { SIP } 27 \\
\text { Interviews }\end{array}$ & $\begin{array}{l}\text { Conventional Content } \\
\text { Analysis } \\
\text { Directed Content } \\
\text { Analysis }\end{array}$ \\
\hline $\begin{array}{l}\text { How do West Virginia's Algebra I/Algebra Support educators' } \\
\text { instructional practices for students with MLD align with the } \\
\text { recommended best practices to utilize for students with MLD? }\end{array}$ & $\begin{array}{l}\text { SIP } 27 \\
\text { Interviews }\end{array}$ & $\begin{array}{c}\text { Descriptive statistics: } \\
\text { Frequency \& } \\
\text { Percentages } \\
\text { Chi-square } \\
\text { Spearman's rho } \\
\text { Pearson } \\
\text { Conventional Content } \\
\text { Analysis } \\
\text { Directed Content } \\
\text { Analysis }\end{array}$ \\
\hline $\begin{array}{l}\text { What are West Virginia's Algebra I/Algebra Support educators' } \\
\text { perceived issues with regard to the instruction of algebra to } \\
\text { students with MLD? }\end{array}$ & $\begin{array}{l}\text { SIP } 27 \\
\text { Interviews }\end{array}$ & $\begin{array}{c}\text { Descriptive statistics: } \\
\text { Frequency, } \\
\text { Percentages \& Mean } \\
\text { Chi-square } \\
\text { Spearman's rho } \\
\text { Pearson } \\
\text { Conventional Content } \\
\text { Analysis } \\
\text { Directed Content } \\
\text { Analysis }\end{array}$ \\
\hline
\end{tabular}




\section{Qualitative Analysis}

Data collected through the review of existing research literature, the open-ended survey question responses, and the interview responses was analyzed by using qualitative methods. The first qualitative analysis procedure used in this study was the conventional content analysis of research articles about recommended best practices to utilize for students with MLD in secondary mathematics and educators' perceived instructional issues when teaching Algebra I to this population. Conventional content analysis allows the categories and names for categories to flow from the data, without influence of preconceived beliefs, and is typically used when research literature on a phenomenon is limited (Hsieh \& Shannon, 2005). The categories found in this analysis informed interview questions and became the framework for all directed content analysis coding later in the study. As noted by Patton (2002) using the same categories when coding data allows patterns and clear regularities of data to emerge, resulting in the identification of meaningful findings.

The researcher read each article collected in the survey of existing literature, highlighted key words used as codes, and compared the frequency of these codes across the documents to identify emergent themes. The researcher identified themes about the recommend best practices and perceived issues through open coding of articles about these types of practices. The recommended "best practices" for teaching secondary mathematics to students with MLD include: (a) explicit instruction, (b) classwide peer tutoring, (c) technology use, (d) graphic organizers, (e) graduated instructional sequence/CRA, and (f) cognitive strategy instruction. The survey of literature also identified the following as educators' perceived issues surrounding Algebra I instruction for students with MLD: (a) teacher preparation, (b) access to curriculum, and (c) educational placement. See Table 4 for a list of key words used in coding of literature, 
number of articles coded and identified themes regarding best practices and perceived issues when teaching students with MLD.

Table 4

Themes of Best Practices and Perceived Issues When Teaching Students With MLD

\begin{tabular}{|c|c|c|}
\hline Theme & $\begin{array}{l}\text { Number of } \\
\text { Articles Coded }\end{array}$ & $\begin{array}{l}\text { Examples of Key Words } \\
\text { Used in Coding }\end{array}$ \\
\hline \multicolumn{3}{|l|}{ Best Practices } \\
\hline Explicit Instruction & 5 & $\begin{array}{l}\text { Explicit Instruction, Direct } \\
\text { Instruction, Explicitly Instruct }\end{array}$ \\
\hline Classwide Peer Tutoring & 7 & $\begin{array}{l}\text { Peer-assisted, Peer-mediated, } \\
\text { Collaborative Groups, Pairs of } \\
\text { Students, Classwide Peer } \\
\text { Tutoring }\end{array}$ \\
\hline Technology & 6 & $\begin{array}{l}\text { Technology, Computers, } \\
\text { Graphing Calculator, Applets, } \\
\text { Video }\end{array}$ \\
\hline Graphic Organizers & 6 & $\begin{array}{l}\text { Graphic Organizer, Visual } \\
\text { Graphic Depiction, Diagram, } \\
\text { Graphic or Visual Aid }\end{array}$ \\
\hline Graduated Instructional Sequence/CRA & 10 & $\begin{array}{l}\text { CRA, Graduated Instructional } \\
\text { Sequence, Concrete } \\
\text { Representational Abstract, } \\
\text { Manipulatives }\end{array}$ \\
\hline Cognitive Strategy Instruction & 8 & $\begin{array}{l}\text { Think-Alouds, Multisensory } \\
\text { Instruction, Cognitive Assault } \\
\text { Strategies, Cognitive } \\
\text { Approach, Dialogue }\end{array}$ \\
\hline \multicolumn{3}{|l|}{ Perceived Issues } \\
\hline Teacher Preparation & 4 & $\begin{array}{l}\text { Teacher Preparation, } \\
\text { Certification, Education } \\
\text { Program, In-service }\end{array}$ \\
\hline Access to Curriculum & 8 & $\begin{array}{l}\text { Access to Curriculum, } \\
\text { Understanding Tasks, } \\
\text { Prerequisite skills, Lack of } \\
\text { Accommodations and/or } \\
\text { Modifications, Speed of } \\
\text { Instruction }\end{array}$ \\
\hline Educational Placement & 7 & $\begin{array}{l}\text { RTI, Self-Contained } \\
\text { Classroom, Inclusion, } \\
\text { Inclusive Classroom, Inclusive } \\
\text { Setting }\end{array}$ \\
\hline
\end{tabular}

To use the codes found in this analysis during directed content analysis coding later in the study, the researcher had to define each code so the presence of that code could be identified. The following are operational definitions of the six codes that the researcher used when 
analyzing data regarding best practices for teaching algebra concepts to students with MLD. Explicit instruction is instruction that involves a teacher demonstrating step-by-step specific strategies for solving various problem types and students using this plan to think their way through a problem. Classwide peer tutoring is an instructional method based on group reinforcement that actively engages all students in the process of learning and applying mathematical skills in a systematic way. Technology use during instruction includes the use of any kind of technology by the student or teacher to meet an instructional goal. Graphic organizers are visual representations of concepts, ideas, or individuals' knowledge.

CRA/Graduated Instructional Sequence is instruction sequence that teaches both procedural and conceptual knowledge and provides concrete, representational, and then abstract opportunities for students to reason through and make connections between mathematical concepts. Cognitive strategy instruction combines multisensory instruction with a cognitive approach. Specifically, the key steps in this strategy include guidance with prompts as needed, rehearsing steps or procedures in writing or orally, helping students stay actively involved in instruction while being focused, and providing models.

The following are operational definitions of the three codes that the researcher used when analyzing data regarding perceived issues when teaching algebra concepts to students with MLD. Teacher preparation refers to any perceptions regarding types of educational experience, preservice or in-service, intended to prepare educators with the skills necessary to be a teacher. Access to curriculum refers to any issue that impedes students' opportunities and ability to access the WVDE outlined curriculum. Examples of access to curriculum issues are (a) student characteristics such as attention span, motivation, concept retention, (b) speed of instruction based on curriculum mapping, (c) the lack of instruction, as identified by literature, which meets 
the needs of students with MLD, and (d) availability of manipulatives. Issues with educational placement focus on the type of educational placement where instruction takes place for students with MLD. Examples of issues regarding educational placement are (a) class size, as measured by the number of students, (b) time length of class, and (c) support of special education teacher for students and general educators.

Next, the researcher used conventional content analysis with open coding to first analyze the open-ended survey responses from SIP question 27 and identify themes. During the first step of coding, the researcher identified key words that described each statement and then created category codes from those key words. Some categories had only one response coded under it, while others had as many as five responses coded under it. The open-ended responses were coded with 13 different thematic category codes to identify teachers' perceived issues regarding Algebra I instruction to students with MLD. The researcher then used similarity between responses coded under different thematic category codes to identify three broad themes, and compared those themes to the themes present in the literature analysis.

Upon the completion of this comparison, the researcher conducted, transcribed, and then analyzed the interviews using directed content analysis. According to Hsieh and Shannon (2005), "directed content analysis is guided by a more structured process than in a conventional approach" and it can be used to further describe existing research about a phenomenon (pg. 1281). The researcher used the deductive coding approach of directed content analysis for the interviews to further describe existing research identified by the literature. This approach specifically addressed each research question, by taking into account prior research that influenced the creation of this study. The three steps used when analyzing interview responses using directed content analysis included: (1) highlight the text that describes what is being 
researched(in this case teachers' perceptions), (2) categorize all highlighted text with the predetermined codes, and (3) give a new code to any highlighted text that could not be categorized in the predetermined codes (Hsieh \& Shannon, 2005).

The researcher first used directed content analysis coding with the themes from the analysis of literature to examine the content of each interview separately. The following are the codes used during the directed content analysis of the interviews for perceived issues (a) teacher preparation, (b) access to curriculum, (c) educational placement, or (d) other perceived issues not identified by literature. Further, the researcher used the following codes during the directed content analysis of the interviews for best practices (a) explicit instruction, (b) classwide peer tutoring, (c) technology, (d) graphic organizer, (e) CRA/ Graduated Instructional Sequence, (f) Cognitive Strategy Instruction, and (g) other utilized practices.

The researcher searched the text of each interview transcript for recurring words or themes in order to identify a pattern in teachers' perceptions regarding Algebra I instruction of students with MLD (Patton, 2002). Following the directed content analysis of each individual interview transcript, the researcher completed a cross-interview directed content analysis comparison between all interview transcripts. The researcher took notes during this crossinterview analysis and recorded data in a chart for organizational purposes (See Appendix G). The cross-interview analysis used the same coding as the individual interview analysis.

The researcher utilized a constant comparative method throughout the literature analysis, qualitative data collection, and analysis. This is the act of continually comparing newly gathered data with previously collected data to inform the development of theoretical categories (Patton, 2002). The purpose of the constant comparative method in this study was to identify if a 
relationship existed within the participants' qualitative data, and between the qualitative data and the trends found in the quantitative analysis of the survey.

\section{Triangulation}

The researcher used two types of triangulation in this study: data and methodological. Data triangulation uses a variety of data sources in a study to answer a specific question (Patton, 2002). The data triangulation first occurred when the literature review themes were compared to the open coding categories of the responses to SIP question 27, then again when the literature review themes were used in the coding of the interviews. The other occurrence of data triangulation in this study is when the researcher used data from each data source to address each research question. The use of multiple methods, such as quantitative and qualitative, to study a single issue is an example of methodological triangulation (Patton, 2002). The use of these types of triangulation strengthens results by combining and comparing data from multiple sources, analyzed with multiple methods (Patton, 2002). Further, triangulation facilitated the identification of convergent or divergent data in this study. The identification of data convergence or divergence in a study facilitates a greater opportunity for insight and explanation of study results (Clark \& Creswell, 2007). The researcher used data and methodological triangulation to increase the credibility and quality of the findings, as compared to only obtaining data from one method and source.

\section{Limitations and Threats to Validity}

This study had threats to validity in three areas: identification of Algebra I and Algebra Support teachers statewide, survey response rate, and clarity of the instrumentation. The email list, provided through West Virginia Department of Education resources, used to contact participants included 504 addresses of K-12 mathematics, special or general educators, and 
administrators from across West Virginia. Some of these individuals qualified as participants for this study being Algebra I/Algebra Support teachers for students with MLD; others did not. All teachers on the list were sent an email explaining the study. If the educators taught Algebra I, collaborated in Algebra I, or taught Algebra Support to students with MLD then they were asked to complete the online survey. The West Virginia Department of Education only provided the number of teachers that taught Algebra I and Algebra Support, not a list containing all the names of teachers who taught Algebra I, collaborated in Algebra I, or taught Algebra Support statewide. Therefore, the previously described email contact list was the only way for the desired population to be contacted, and there was no guarantee that all Algebra I and Algebra Support educators statewide were included on the email list.

Not knowing the names, or at least the email addresses, of all the Algebra I and Algebra Support educators affected the sample size for this study. If the researcher had access to a list of all 284 Algebra I /Algebra Support educators' names their email addresses could have been retrieved using the West Virginia Department of Education email directory. It is unknown how many of the 284 Algebra I and Algebra Support teachers statewide were included on the contact list. Further, the number of special educators who participated in this study was much fewer than the number of general educators. This influences the findings of the study because it is difficult to compare both groups that have such a large variance in size.

Response rate was a threat for validity because if, for example, the targeted educators were uninterested in the study, did not receive the survey, or did not have time then they may not have completed the survey. Threats to validity concerning response rate were minimized by including an explanation letter of what the study was investigating and how the study results benefited the educator. Further, to encourage participation, a follow-up email reminding 
educators of the survey deadline and thanking those who already completed the survey was sent a week before the survey deadline date.

Another threat to validity is the instrumentation. Specifically, the survey had to be very clear and all questionable terms defined. Analysis of the pilot study survey results and interview responses guided the development of a survey and interview questions that yielded valid and reliable results. For example, during the pilot study survey many teachers reported using peer assisted learning, but through the interviews many participants revealed that they did not feel this practice was successful nor did they know how to implement it in their classroom. This finding resulted in the addition of further questions about educators' knowledge of practices and comfort level of implementation in the survey and interviews for the larger study. The mixed-method design of development provides validity of constructs and results because the strengths of both qualitative and quantitative designs are employed. The influence of the quantitative survey data and results on the development of the qualitative follow-up interview is an example of how this design strengthened the study results and provided validity.

\section{Summary}

The mixed methods study was designed to describe educators' perceptions regarding Algebra I instruction for students with MLD in West Virginia and how they developed a knowledge base for this practice. The theoretical perspectives of positivism and constructivism influenced the design of this study. The researcher used surveys and interviews for data collection instruments. Quantitative methods of survey data analyses included descriptive and inferential statistics, specifically, correlations, and chi-square tests in order to determine a relationship between educators' opportunities to expand their knowledge/practice of teaching students with MLD and their backgrounds. Qualitative methods of analyses of existing 
literature, the open ended survey responses, and interviews included conventional and directed content analysis. The next chapter discusses the results of these analyses. 


\section{CHAPTER 4: RESULTS}

This study used a mixed methods design to describe educators' perceptions regarding Algebra I instruction for students with MLD in West Virginia and educators' preparation for this practice. The researcher identified educators' educational and professional development experiences and their perceptions regarding these experiences. Both quantitative and qualitative methods were used to collect and analyze the data. An alpha level of .05 was used for all statistical tests. To address the four research questions, the researcher combined data sources of 57 surveys and five follow-up interviews. Throughout this chapter, when survey participants' responses to the open-ended SIP question 27 are quoted the participant is referred to by their survey number. Further, the interview participants are referred to as "Teacher" with their assigned letter A-E. Six sections in this chapter present the results of the data analyses. The first section summarizes the demographic variables for survey and interview participants. Sections two through four address each research question individually with both quantitative and qualitative results and the convergence and divergence of these results. The final section is a summary of the findings by research question.

\section{Demographic Information}

\section{Survey Participants}

A total of 57 educators participated in this study. The demographic information collected through the survey primarily focused on participant's certifications, their years of experience teaching, characteristics of their school's and district's instructional environments, and their professional development experiences. Table 5 presents demographic variables for surveyed participants. 
Table 5

Demographic Variables for Survey Participants

\begin{tabular}{|c|c|}
\hline Variable & $\begin{array}{l}\text { Number of } \\
\text { Participants } \\
(\%)^{*}\end{array}$ \\
\hline \multicolumn{2}{|l|}{ Current teaching position } \\
\hline Special education teacher & $14(24.6)$ \\
\hline General education teacher & $38(66.7)$ \\
\hline \multicolumn{2}{|l|}{ Gender } \\
\hline Male & $17(29.9)$ \\
\hline Female & $38(66.7)$ \\
\hline \multicolumn{2}{|l|}{ Educational level } \\
\hline Bachelor degree & $19(33.3)$ \\
\hline Master's degree & $30(52.6)$ \\
\hline Doctoral degree (completed or pursing) & $2(3.5)$ \\
\hline \multicolumn{2}{|l|}{ Certification } \\
\hline Mathematics 5- Algebra & $7(12.3)$ \\
\hline Mathematics $7-12$ or 5 -Adult & $33(57.9)$ \\
\hline Special education Multi-categorical 5-Adult & $11(19.3)$ \\
\hline Mathematics 5-9 and Multi-categorical 5-Adult & $2(3.5)$ \\
\hline Mathematics 5-9 and NBCT & $1(1.8)$ \\
\hline \multicolumn{2}{|l|}{ "Highly qualified" in mathematics as defined by NCLB } \\
\hline Yes & $37(97.4) * *$ \\
\hline No & $1(2.63)^{* *}$ \\
\hline \multicolumn{2}{|c|}{ "Highly qualified" in special education as defined by NCLB } \\
\hline Yes & $12(85.7)^{* *}$ \\
\hline No & $2(14.3)^{* *}$ \\
\hline \multicolumn{2}{|l|}{ Years of experience teaching } \\
\hline $1-3$ & $10(17.5)$ \\
\hline $4-6$ & $9(15.8)$ \\
\hline $7-10$ & $3(5.3)$ \\
\hline 10 or $>$ & $31(54.4)$ \\
\hline \multicolumn{2}{|l|}{ Years of experience teaching Algebra I } \\
\hline $1-3$ & $16(28.1)$ \\
\hline $4-6$ & $10(17.5)$ \\
\hline $7-10$ & $7(12.3)$ \\
\hline 10 or $>$ & $22(38.6)$ \\
\hline \multicolumn{2}{|l|}{ RESA location } \\
\hline I & $3(5.3)$ \\
\hline II & $5(8.8)$ \\
\hline III & $4(7)$ \\
\hline IV & $4(7)$ \\
\hline $\mathrm{V}$ & $7(12.3)$ \\
\hline VI & $4(7)$ \\
\hline VII & $14(24.6)$ \\
\hline VIII & $10(17.5)$ \\
\hline \multicolumn{2}{|c|}{ County size (measured by number of students who graduate annually) } \\
\hline$<200$ & $14(24.6)$ \\
\hline $200-400$ & $12(21.1)$ \\
\hline $401-600$ & $10(17.5)$ \\
\hline $601-800$ & $4(7)$ \\
\hline 800 or $>$ & $15(26.3)$ \\
\hline \multicolumn{2}{|l|}{ No. of classes taught daily } \\
\hline 1 & $0(0)$ \\
\hline 2 & $4(7)$ \\
\hline 3 & $19(33.3)$ \\
\hline 4 & $4(7)$ \\
\hline 5 & $8(14)$ \\
\hline
\end{tabular}




\begin{tabular}{|c|c|}
\hline 6 & $7(12.3)$ \\
\hline 7 or $>$ & $12(21.1)$ \\
\hline \multicolumn{2}{|l|}{ Algebra course currently teaching } \\
\hline Algebra I & $34(59.6)$ \\
\hline Algebra Support & $3(5.3)$ \\
\hline Algebra I and Algebra Support & $13(22.8)$ \\
\hline \multicolumn{2}{|c|}{ Algebra I delivery model used for the majority of students with MLD } \\
\hline Inclusion & $46(80.7)$ \\
\hline Resource classroom taught by a special educator & $7(12.3)$ \\
\hline \multicolumn{2}{|l|}{ No. of students with MLD in Algebra class } \\
\hline $0-5$ & $35(61.4)$ \\
\hline $6-10$ & $12(21.1)$ \\
\hline 11 or $>$ & $6(10.5)$ \\
\hline \multicolumn{2}{|l|}{ Amount of collaborative time with co-teacher } \\
\hline Daily & $30(52.6)$ \\
\hline 2-3 times a week & $10(17.5)$ \\
\hline Once a week & $4(7)$ \\
\hline Once every two weeks & $3(5.3)$ \\
\hline Less than twice a month & $7(12.3)$ \\
\hline \multicolumn{2}{|c|}{ No. of undergraduate and graduate courses taken that addressed students with MLD } \\
\hline None & $16(28.1)$ \\
\hline One & $7(12.3)$ \\
\hline Two & $8(14.0)$ \\
\hline Three & $8(14.0)$ \\
\hline Four or more & $14(24.6)$ \\
\hline \multicolumn{2}{|c|}{ No. of professional development hours, in the past 3 years, regarding students with MLD } \\
\hline 6 hours or less & $40(70.2)$ \\
\hline $7-15$ hours & $4(7)$ \\
\hline 16-35 hours & $2(3.5)$ \\
\hline More than 35 hours & $7(12.3)$ \\
\hline
\end{tabular}

The survey participants represented all eight Regional Education Service Agencies

(RESA) in West Virginia, with the majority of participants reported being from RESA 7

(24.6\%), RESA 8 (17.5\%), and RESA 5 (12.3\%). The participants represented all county sizes

present in West Virginia, as measured by the annual number of graduating seniors. The county size breakdown was as follows: less than 200 students (24.6\%), 200-400 students (21.1\%), 401600 students (17.5\%), 601-800 students (7\%) and 800 or more students (26.5\%).

The number of reported female participants $(66.7 \%)$ outnumbered the male participants (29.9\%) almost two to one. Two participants did not did not classify their gender, but their omission does not affect the approximate two to one ratio distribution. Fifty-two participants identified their current teaching position with an approximate three to one ratio of general 
mathematics educators $(66.7 \%)$ to special educators $(24.6 \%)$. Certification status reported by the participants supports the difference in the number of general educators as compared to special educators.

At least $70 \%$ of participants had only one type of secondary mathematics certification, either fifth grade through Algebra I, seventh through twelfth grade, or fifth grade through adult. About $19 \%$ of the participants reported having certification in only multi-categorical special education fifth grade through adult. Even though all surveyed participants taught mathematics to a population of students with MLD, only two participants had a mathematics certificate $\left(5^{\text {th }}-9^{\text {th }}\right.$ grade) and multi-categorical special education certificate ( $5^{\text {th }}$-Adult). About $97 \%$ of the general educators were "highly qualified" to teach mathematics, as defined by NCLB, and approximately $85 \%$ of the special educators were "highly qualified" to teach special education. Further, 52.6\% of the participants earned a masters degree and $3.5 \%$ of the participants were working towards a doctoral degree in education. On average, each participant took approximately two courses that addressed students with MLD during their graduate and undergraduate programs. During the previous three years prior to the survey completion, $70.2 \%$ of participants reported completing six or less hours of professional development regarding students with MLD.

All participants taught Algebra I content to students with MLD either via an Algebra I course (59.6\%), Algebra Support course (5.3\%), or both $(22.8 \%)$ to students with MLD. Most $(80.7 \%)$ of the participants reported that the majority of students with MLD at their school take these courses through the full inclusion model. The majority of participants $(61.4 \%)$ had no more than five students with MLD in their Algebra I class. While 52.6\% of participants reported daily collaborative planning time with their co-teacher, the other participants' responses ranged from $17.5 \%$ who had collaborative time two to three days a week to $12.3 \%$ of participants who 
had collaborative time less than twice a month. All of these demographic variables influence the instructional environments of students with MLD and describe the current state of Algebra I instruction for students with MLD in West Virginia.

\section{Interview participants}

Of the 57 participants surveyed, five volunteered for and participated in the follow-up interviews. Table 6 summarizes the interviewee's demographic information.

Table 6

Demographic Variables of the Follow-Up Interview Participants

\begin{tabular}{|c|c|}
\hline Variable & $\begin{array}{l}\text { Number(\% } \\
\text { of total } \\
\text { interviewees) }\end{array}$ \\
\hline \multicolumn{2}{|l|}{ Current teaching position } \\
\hline Special education teacher & $3(60)$ \\
\hline General education teacher & $2(40)$ \\
\hline \multicolumn{2}{|l|}{ Gender } \\
\hline Male & $2(40)$ \\
\hline Female & $3(60)$ \\
\hline \multicolumn{2}{|l|}{ Educational level } \\
\hline Bachelor degree & $3(60)$ \\
\hline Master's degree & $2(40)$ \\
\hline Doctoral degree (completed or pursing) & 0 \\
\hline \multicolumn{2}{|l|}{ Certification } \\
\hline Mathematics 5- Algebra & $1(20)$ \\
\hline Mathematics $7-12$ or 5 -Adult & $1(20)$ \\
\hline Special education Multi-categorical 5-Adult & $2(40)$ \\
\hline Mathematics 5-9 and Multi-categorical 5-Adult & $1(20)$ \\
\hline Mathematics 5-9 and NBCT & $0(0)$ \\
\hline \multicolumn{2}{|l|}{ "Highly qualified" in mathematics as defined by NCLB } \\
\hline Yes & $1(50)^{*}$ \\
\hline No & $1(50)^{*}$ \\
\hline \multicolumn{2}{|c|}{ "Highly qualified" in special education as defined by NCLB } \\
\hline Yes & $2(66.7)^{*}$ \\
\hline No & $1(33.3)^{*}$ \\
\hline \multicolumn{2}{|l|}{ Years of experience teaching } \\
\hline $1-3$ & $3(80)$ \\
\hline $4-6$ & $2(20)$ \\
\hline $7-10$ & $0(0)$ \\
\hline 10 or $>$ & $0(0)$ \\
\hline \multicolumn{2}{|l|}{ Years of experience teaching Algebra I } \\
\hline $1-3$ & $4(80)$ \\
\hline $4-6$ & $1(20)$ \\
\hline $7-10$ & $0(0)$ \\
\hline 10 or $>$ & $0(0)$ \\
\hline \multicolumn{2}{|l|}{ RESA location } \\
\hline I & $0(0)$ \\
\hline II & $0(0)$ \\
\hline III & $1(20)$ \\
\hline IV & $1(20)$ \\
\hline
\end{tabular}




\begin{tabular}{|c|c|}
\hline $\mathrm{V}$ & $1(20)$ \\
\hline VI & $0(0)$ \\
\hline VII & $1(20)$ \\
\hline VIII & $1(20)$ \\
\hline \multicolumn{2}{|c|}{ County size (measured by number of students who graduate annually) } \\
\hline$<200$ & $1(20)$ \\
\hline $200-400$ & $1(20)$ \\
\hline $401-600$ & $1(20)$ \\
\hline $601-800$ & $0(0)$ \\
\hline 800 or $>$ & $2(40)$ \\
\hline \multicolumn{2}{|l|}{ No. of classes taught daily } \\
\hline 1 & $0(0)$ \\
\hline 2 & $1(20)$ \\
\hline 3 & $3(60)$ \\
\hline 4 & $0(0)$ \\
\hline 5 & $1(20)$ \\
\hline 6 & $0(0)$ \\
\hline 7 or $>$ & $0(0)$ \\
\hline \multicolumn{2}{|l|}{ Algebra course currently teaching } \\
\hline Algebra I & $4(80)$ \\
\hline Algebra Support & $3(60)$ \\
\hline \multicolumn{2}{|c|}{ Algebra I delivery model used for the majority of students with MLD } \\
\hline Inclusion & $5(100)$ \\
\hline Resource classroom taught by a special educator & $0(0)$ \\
\hline \multicolumn{2}{|l|}{ No. of students with MLD in Algebra class } \\
\hline $0-5$ & $2(40)$ \\
\hline $6-10$ & $2(40)$ \\
\hline 11 or $>$ & $1(20)$ \\
\hline \multicolumn{2}{|l|}{ Amount of collaborative time with co-teacher } \\
\hline Daily & $3(60)$ \\
\hline 2-3 times a week & $0(0)$ \\
\hline Once a week & $2(40)$ \\
\hline Once every two weeks & $0(0)$ \\
\hline Less than twice a month & $0(0)$ \\
\hline \multicolumn{2}{|c|}{ No. of undergraduate and graduate courses taken that addressed students with MLD } \\
\hline None & $1(20)$ \\
\hline One & $0(0)$ \\
\hline Two & $1(20)$ \\
\hline Three & $1(20)$ \\
\hline Four or more & $2(40)$ \\
\hline \multicolumn{2}{|c|}{ No. of professional development hours, in the past 3 years, regarding students with MLD } \\
\hline 6 hours or less & $2(40)$ \\
\hline $7-15$ hours & $1(20)$ \\
\hline 16-35 hours & $1(20)$ \\
\hline More than 35 hours & $1(20)$ \\
\hline
\end{tabular}

For the most part, the interview sample was representative of the 57 survey participants particularly when looking at educators' description of their schools' and districts' instructional environments and their professional development and educational experiences. Specifically, similarities existed between the reported collaborative time with a co-teacher ( $52.6 \%$ of the 
survey population vs. $60 \%$ of the interview participants reported daily collaboration), size of county (see Tables 5 and 6 for comparison), Algebra I delivery model for students with MLD ( $80.7 \%$ of the survey population vs. $100 \%$ of the interview participants used inclusion), and the format of attended professional development sessions ( $79.1 \%$ of the survey participants vs. $80 \%$ of the interview participants attended professional development workshop on mathematics teaching that addressed students with MLD).

As compared to the surveyed participants, the interview sample had a larger percent of special educators represented (60\% of the interview participants vs. $24.6 \%$ of the survey participants), a smaller percent of "highly qualified" educators ( $20 \%$ of the interview participants highly qualified in mathematics and $40 \%$ highly qualified in special education vs. $64.9 \%$ of the survey participants highly qualified in mathematics and $21.1 \%$ highly qualified in special education), and more teachers with less teaching experience ( $80 \%$ of the interview participants had one to three years teaching experience vs. $17.5 \%$ of the survey participants who had one to three years teaching experience and $54.4 \%$ who had 10 or more years teaching experience).

\section{Quantitative Results}

The researcher obtained the quantitative results through the following types of analyses of the survey data: (a) descriptive statistics, (b) correlations, and (c) chi-square test for independence. The researcher used the results of these analyses to answer the four research questions.

\section{Educational and Professional Development Opportunities}

The first research question was: What opportunities have Algebra I/Algebra Support educators from West Virginia had to develop knowledge for teaching students with MLD? To 
answer this question with quantitative results the researcher analyzed the survey data.

Participants reported developing knowledge for teaching students with MLD through college courses and professional development sessions.

Number of college courses. As displayed in Table 5, the greatest percentages of participants took either none $(28.1 \%)$ or four or more courses $(24.6 \%)$ that addressed students with MLD as part of their college coursework. Further, the researcher compared the number of reported college courses that addressed students with MLD taken by participants who reported being a special educator to the number of courses taken by participants who reported being a general educator. Figure 1 displays this comparison.

Figure 1

Number of College Courses That Addressed Students with MLD-Special Educators vs. General Educators

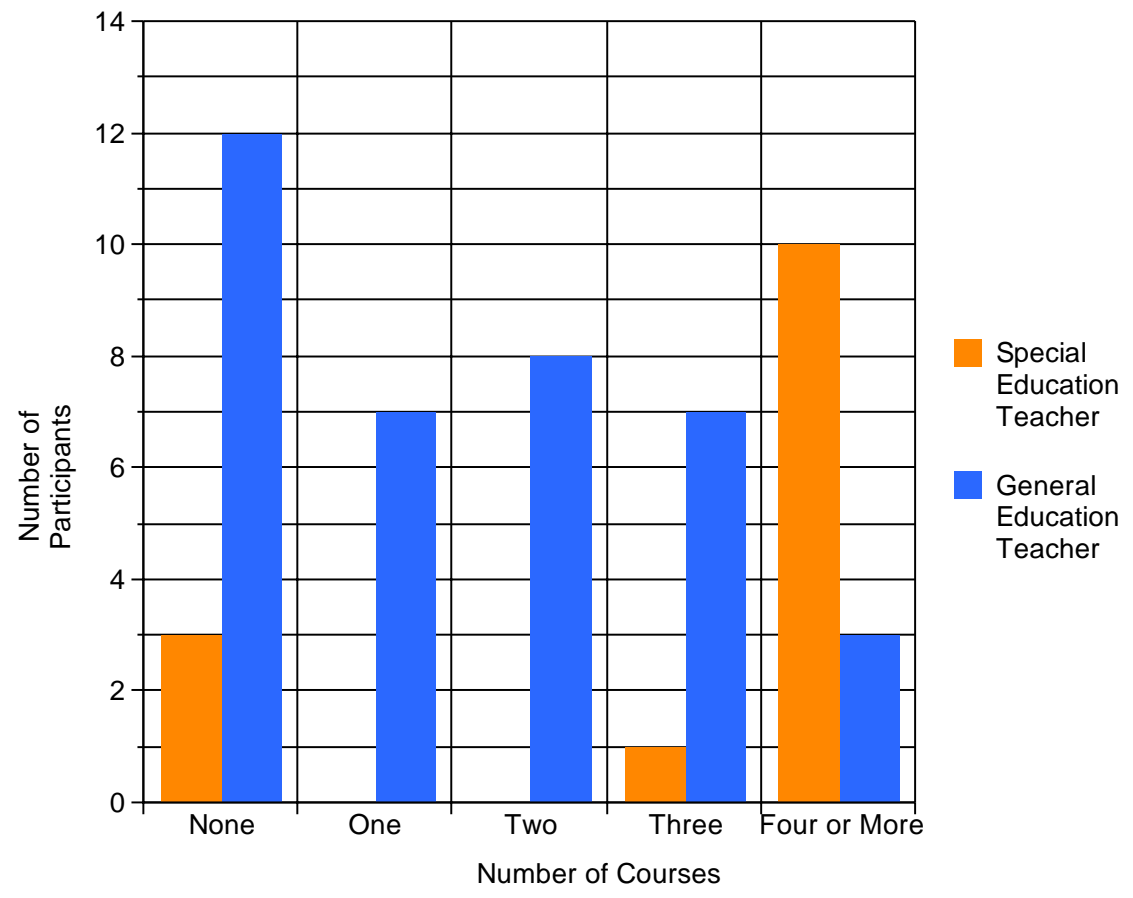


This comparison allowed for clarification on the number of courses taken by special educators as compared to general educators. As observed in Figure 1, the majority of special educators $(N=10)$ completed four or more classes that addressed students with MLD. The number of general education participants who completed classes that addressed students with MLD has less variety than the number of special educators' course completions. The largest group of general educators $(N=12)$ completed no classes, while the smallest group $(N=3)$ completed four or more classes. The researcher performed a chi-square test of independence to examine the relation between a teacher's role as a special or general educator and the number of college courses taken that addressed students with MLD. A significant relationship between these variables existed, $X^{2}(8, N=53)=24.265, p=0.002$. Thus, these variables are not independent and special educators were more likely to have taken a greater number of classes addressing students with MLD than general educators.

A chi-square test of independence used to examine the relationship between certification and the number of courses, again, supported the difference between the relationship of courses taken by general and special educators. This differed from the previous comparison because some of the participants who reported being a special or general educator did not have certification in the field in which they were teaching. The relationship between certification and the number of courses taken that addressed students with MLD was significant, $X^{2}(16, N=52)$ $=37.339, p=0.002$. Educators certified in special education multi-categorical fifth grade through adult accounted for $64.3 \%$ of all teachers who took four or more courses that addressed the characteristics of students with MLD. Those dually certified in mathematics fifth through ninth grade and multi-categorical special education accounted for $14.3 \%$ in the same category. Educators certified in only mathematics accounted for only $21.4 \%$ of the teachers who took four 
or more college courses that addressed students with MLD. Educators from this same (only certified in mathematics) accounted for $93 \%$ of all teachers who took no courses that specifically addressed students with MLD. Educators with special education certification were more likely to have taken more classes addressing students with MLD than secondary mathematics certified teachers with fifth grade-Algebra certification, seventh grade-twelfth grade certification, or fifth grade through adult certification. Table 7 contains the data regarding these results. 
Table 7

\begin{tabular}{|c|c|c|c|c|c|c|c|c|}
\hline \multirow{3}{*}{\multicolumn{3}{|c|}{ rtification and Numb }} & of $\mathrm{Co}$ & ge Co & es $A d d$ & $\operatorname{sing} \Lambda$ & & \multirow{3}{*}{ Total } \\
\hline & & & \multicolumn{5}{|c|}{$\begin{array}{l}\text { How many college courses (undergraduate and graduate) have } \\
\text { you taken that address the characteristics and needs of students } \\
\text { with MLD? }\end{array}$} & \\
\hline & & & None & One & Two & Three & $\begin{array}{l}\text { Four or } \\
\text { more }\end{array}$ & \\
\hline \multirow{20}{*}{ Certification } & \multirow{4}{*}{ 5-Algebra } & Count & 1 & 0 & 2 & 1 & 2 & 6 \\
\hline & & $\begin{array}{l}\% \text { within What is your } \\
\text { certification? }\end{array}$ & $16.7 \%$ & $.0 \%$ & $33.3 \%$ & $16.7 \%$ & $33.3 \%$ & $100.0 \%$ \\
\hline & & $\begin{array}{l}\% \text { within How many college } \\
\text { courses (undergraduate and } \\
\text { graduate) have you taken that } \\
\text { address the characteristics and } \\
\text { needs of students with MLD? }\end{array}$ & $6.7 \%$ & $.0 \%$ & $25.0 \%$ & $12.5 \%$ & $14.3 \%$ & $11.5 \%$ \\
\hline & & $\%$ of Total & $1.9 \%$ & $.0 \%$ & $3.8 \%$ & $1.9 \%$ & $3.8 \%$ & $11.5 \%$ \\
\hline & \multirow{4}{*}{$\begin{array}{l}\text { Mathematics } \\
7-12 \text { or 5- } \\
\text { Adult }\end{array}$} & Count & 12 & 7 & 6 & 6 & 1 & 32 \\
\hline & & $\begin{array}{l}\% \text { within What is your } \\
\text { certification? }\end{array}$ & $37.5 \%$ & $21.9 \%$ & $18.8 \%$ & $18.8 \%$ & $3.1 \%$ & $100.0 \%$ \\
\hline & & $\begin{array}{l}\% \text { within How many college } \\
\text { courses (undergraduate and } \\
\text { graduate) have you taken that } \\
\text { address the characteristics and } \\
\text { needs of students with MLD? }\end{array}$ & $80.0 \%$ & $100.0 \%$ & $75.0 \%$ & $75.0 \%$ & $7.1 \%$ & $61.5 \%$ \\
\hline & & $\%$ of Total & $23.1 \%$ & $13.5 \%$ & $11.5 \%$ & $11.5 \%$ & $1.9 \%$ & $61.5 \%$ \\
\hline & \multirow{4}{*}{$\begin{array}{l}\text { Special } \\
\text { education } \\
\text { Multi- } \\
\text { categorical } \\
\text { 5-Adult }\end{array}$} & Count & 1 & 0 & 0 & 1 & 9 & 11 \\
\hline & & $\begin{array}{l}\% \text { within What is your } \\
\text { certification? }\end{array}$ & $9.1 \%$ & $.0 \%$ & $.0 \%$ & $9.1 \%$ & $81.8 \%$ & $100.0 \%$ \\
\hline & & $\begin{array}{l}\% \text { within How many college } \\
\text { courses (undergraduate and } \\
\text { graduate) have you taken that } \\
\text { address the characteristics and } \\
\text { needs of students with MLD? }\end{array}$ & $6.7 \%$ & $.0 \%$ & $.0 \%$ & $12.5 \%$ & $64.3 \%$ & $21.2 \%$ \\
\hline & & $\%$ of Total & $1.9 \%$ & $.0 \%$ & $.0 \%$ & $1.9 \%$ & $17.3 \%$ & $21.2 \%$ \\
\hline & \multirow{4}{*}{$\begin{array}{l}\text { Mathematics } \\
5-9 \text { and } \\
\text { Multi- } \\
\text { categorical } \\
\text { 5-AD }\end{array}$} & Count & 0 & 0 & 0 & 0 & 2 & 2 \\
\hline & & $\begin{array}{l}\% \text { within What is your } \\
\text { certification? }\end{array}$ & $.0 \%$ & $.0 \%$ & $.0 \%$ & $.0 \%$ & $100.0 \%$ & $100.0 \%$ \\
\hline & & $\begin{array}{l}\% \text { within How many college } \\
\text { courses (undergraduate and } \\
\text { graduate) have you taken that } \\
\text { address the characteristics and } \\
\text { needs of students with MLD? }\end{array}$ & $.0 \%$ & $.0 \%$ & $.0 \%$ & $.0 \%$ & $14.3 \%$ & $3.8 \%$ \\
\hline & & $\%$ of Total & $.0 \%$ & $.0 \%$ & $.0 \%$ & $.0 \%$ & $3.8 \%$ & $3.8 \%$ \\
\hline & \multirow{4}{*}{$\begin{array}{l}\text { Mathematics } \\
5-9 \text { and } \\
\text { NBCT }\end{array}$} & Count & 1 & 0 & 0 & 0 & 0 & 1 \\
\hline & & $\begin{array}{l}\% \text { within What is your } \\
\text { certification? }\end{array}$ & $100.0 \%$ & $.0 \%$ & $.0 \%$ & $.0 \%$ & $.0 \%$ & $100.0 \%$ \\
\hline & & $\begin{array}{l}\% \text { within How many college } \\
\text { courses (undergraduate and } \\
\text { graduate) have you taken that } \\
\text { address the characteristics and } \\
\text { needs of students with MLD? }\end{array}$ & $6.7 \%$ & $.0 \%$ & $.0 \%$ & $.0 \%$ & $.0 \%$ & $1.9 \%$ \\
\hline & & $\%$ of Total & $1.9 \%$ & $.0 \%$ & $.0 \%$ & $.0 \%$ & $.0 \%$ & $1.9 \%$ \\
\hline \multirow[t]{4}{*}{ Total } & & Count & 15 & 7 & 8 & 8 & 14 & 52 \\
\hline & & $\begin{array}{l}\% \text { within What is your } \\
\text { certification? }\end{array}$ & $28.8 \%$ & $13.5 \%$ & $15.4 \%$ & $15.4 \%$ & $26.9 \%$ & $100.0 \%$ \\
\hline & & $\begin{array}{l}\% \text { within How many college } \\
\text { courses (undergraduate and } \\
\text { graduate) have you taken that } \\
\text { address the characteristics and } \\
\text { needs of students with MLD? }\end{array}$ & $100.0 \%$ & $100.0 \%$ & $100.0 \%$ & $100.0 \%$ & $100.0 \%$ & $100.0 \%$ \\
\hline & & $\%$ of Total & $28.8 \%$ & $13.5 \%$ & $15.4 \%$ & $15.4 \%$ & $26.9 \%$ & $100.0 \%$ \\
\hline
\end{tabular}


The next chi-square test of independence was used to examine a relationship between "highly qualified" mathematics status and the number of courses taken that addressed students with MLD. This relationship was significant, $X^{2}(4, N=52)=14.941, p=0.005$. Appendix $\mathrm{G}$ contains the data regarding these results. This data indicated that a larger percentage of teachers who were "highly qualified" in mathematics took fewer courses that addressed students with MLD as compared to those who were not "highly qualified" in mathematics. These findings lead the researcher to examine the relation between "highly qualified" in special education and the number of college courses. The relation between "highly qualified" special education status and the number of courses taken that addressed students with MLD was also significant, $X^{2}(4, N=51)=25.170, p=0.000$. Appendix $\mathrm{H}$ contains the data regarding these results. This data indicated that a larger percentage of teachers who were "highly qualified" in special education took more courses that addressed students with MLD as compared to those who were not "highly qualified" in special education.

The researcher next conducted a Spearman's rho correlation to determine if a correlation existed between a teacher's years of teaching experience and the amount of college courses taken that addressed students with MLD. There was a negative correlation between these two variables, which was statistically significant $\left(r_{s}(51)=-0.374, p=.007\right)$. Thus, as the years teaching experience increased the number of college courses taken addressing students with MLD decreased. More specifically, a Spearman's rho correlation was used to determine if a correlation existed between the years experience teaching Algebra I and the amount of college courses taken that addressed students with MLD. There was a negative correlation between these two variables, which was statistically significant $\left(r_{s}(53)=-0.357, p=.009\right)$. 
Using chi-square or Spearman rho, the researcher found no significant relationships between the numbers of college courses taken that addressed students with MLD and gender $\left(X^{2}\right.$ $(4, N=53)=6.059, p=0.195)$, level of higher education $\left(r_{s}(47)=0.21, p=.889\right)$, RESA of employment $\left(X^{2}(28, N=51)=39.308, p=0.076\right)$, size of county $\left(X^{2}(16, N=53)=7.555\right.$, $p=0.961)$, and the algebra course the teacher taught $\left(X^{2}(8, N=48)=10.536, p=0.229\right)$. It is worth noting that while the relationship was not significant relative to the standard alpha level of .05 the $\mathrm{p}$ value was less than .10 when examining the relationship between the number of college courses taken that addressed students with MLD and the RESA of employment.

Amount of professional development offerings. The next data analyzed was the responses regarding professional development offerings. As recorded in Table 5, the majority of participants $(70.2 \%)$ completed six hours or less of professional development regarding students with MLD over the three previous years prior to survey completion. Appendix I compares the valid responses of participants, classified by RESA of employment, to SIP question 21 that addressed the number of professional development hours. Chi-square and correlation analyses gave further insight to the survey responses surrounding the amount of professional development hours. A chi-square test of independence examined the relation between RESA of employment and the hours of professional development sessions completed that addressed students with MLD. This was significant, $X^{2}(21, N=51)=35.714, p=0.024$, indicating that these two variables are dependent. Thus, RESA IV (50\% completed six or less hours and 50\% completed 16-35 hours) and RESA VII (64.3\% completed six or less hours, 7.1\% completed 7-15 hours, 28.6\% completed more than 35) had participants with various amounts of professional development hours that addressed students with MLD, while $75 \%$ or more of the participants from RESAs I, 
II, III, V, VI and VIII reported taking six hours or less of professional development addressing students with MLD, over the past three years.

A Spearman's rho correlation was run to determine if a correlation existed between the number of college courses completed that addressed students with MLD and the amount of professional development sessions attended that addressed students with MLD. There was a positive correlation between these two variables, which was statistically significant $\left(r_{s}(53)=0.508, p=.000\right)$. This finding indicated that as the number of college courses increased, the number of professional development course completed also increased, but this does not indicate a causal relationship.

No significant correlations were found between the number of professional development sessions completed that addressed students with MLD and years teaching experience $\left(r_{s}(51)=-\right.$ $0.215, p=.130)$, teaching position $\left(X^{2}(6, N=53)=7.313, p=0.293\right)$, gender $\left(X^{2}(3, N=53)\right.$ $=6.144, p=0.105)$, level of higher education $\left(r_{s}(47)=-0.070, p=.641\right.$.), "highly qualified" status in special education $\left(X^{2}(3, N=51)=5.185, p=0.159\right)$, "highly qualified status in mathematics $\left(X^{2}\right.$ $(3, N=52)=1.261, p=0.738)$, size of county $\left(X^{2}(12, N=53)=20.916, p=0.052\right)$, and the algebra course the teacher taught $\left(X^{2}(6, N=48)=5.254, p=0.512\right)$. It is worth noting that while the relationship was not significant relative to the standard alpha level of .05 the p value was less than .10 when examining the relationship between the number of professional development sessions completed and the size of the county.

Format of professional development offerings. To further investigate the professional development sessions for teachers of students with MLD, SIP question 22 asked participants to identify the format of any professional development related to mathematics teaching for students with MLD that they attended. Participants had nine options to select from, with the last option 
being other and a description text box available for further details. Responses regarding the format of attended professional development sessions that addressed students with MLD are summarized in Table 8.

Table 8

Format of Attended Professional Development Sessions That Addressed Students with MLD

\begin{tabular}{|c|c|c|c|}
\hline Professional Development Format & $\begin{array}{l}\text { Total Number of } \\
\text { Special Educators } \\
\text { Who Attended } \\
\text { Session Type } \\
\text { Totals }(\%)^{*}\end{array}$ & $\begin{array}{l}\text { Total Number of } \\
\text { General } \\
\text { Educators Who } \\
\text { Attended Session } \\
\text { Type } \\
\text { Totals }(\%) * \\
\end{array}$ & $\begin{array}{l}\text { Total Number of } \\
\text { Educators Who } \\
\text { Attended Session } \\
\text { Type } \\
\text { Totals }(\%)^{*}\end{array}$ \\
\hline $\begin{array}{l}\text { Attendance at a workshop on } \\
\text { mathematics teaching }\end{array}$ & $8(66.7)$ & $26(83.9)$ & $34(79.1)$ \\
\hline $\begin{array}{l}\text { Observation of other teachers teaching } \\
\text { mathematics as part of your own } \\
\text { professional development }\end{array}$ & $7(58.3)$ & $7(22.6)$ & $14(32.6)$ \\
\hline $\begin{array}{l}\text { Study group of teachers (Professional } \\
\text { Learning Community) on mathematics } \\
\text { teaching issues }\end{array}$ & $3(25)$ & $10(32.3)$ & $13(30.2)$ \\
\hline $\begin{array}{l}\text { A formal college/university course in } \\
\text { the teaching of mathematics }\end{array}$ & $4(33.3)$ & $4(12.9)$ & $8(18.6)$ \\
\hline $\begin{array}{l}\text { A formal college/university } \\
\text { mathematics course }\end{array}$ & $1(8.3)$ & $3(9.7)$ & $4(9.3)$ \\
\hline $\begin{array}{l}\text { Service as a mentor and/or peer coach } \\
\text { in mathematics teaching as part of a } \\
\text { formal arrangement that is recognized } \\
\text { or supported by the school or district }\end{array}$ & $3(25)$ & $2(6.5)$ & $5(11.6)$ \\
\hline $\begin{array}{l}\text { Attendance at a national or state } \\
\text { mathematics teacher association } \\
\text { meeting }\end{array}$ & $2(16.7)$ & $8(25.8)$ & $10(23.3)$ \\
\hline $\begin{array}{l}\text { Collaboration on mathematics teaching } \\
\text { issues with a group of teachers at a } \\
\text { distance using telecommunications } \\
\text { (distance learning) }\end{array}$ & $2(16.7)$ & $4(12.9)$ & $6(14)$ \\
\hline $\begin{array}{l}\text { Other: Co-teaching workshops offered } \\
\text { through the county }\end{array}$ & $0(0)$ & $1(3.2)$ & $1(2.3)$ \\
\hline $\begin{array}{l}\text { Other: County-wide math cadre focused } \\
\text { on Algebra Readiness }\end{array}$ & $1(8.3)$ & $0(0)$ & $1(2.3)$ \\
\hline
\end{tabular}

*These percents were determined with the total population that responded to SIP question 22 . 
The majority of participants $(79.1 \%)$ who responded to SIP question 22 attended a workshop on mathematics teaching that addressed students with MLD. The next three highest responses regarding professional development session formats were observation of other teachers teaching mathematics (32.6\%), study group of teachers (Professional Learning Community) on mathematics teaching issues $(30.2 \%)$, and national or state mathematics teacher association meetings (23.3\%). As observed in Table 8, there were differences between the attendance percentages for each of the top four formats when analyzed by teaching role (special educator or general educator). To further examine relationships between different demographic variables and educators' professional development attendance the data was analyzed with the chi-square test of independence.

The results of this analysis found statistically significant relationships between seven different sets of demographic variables as related to types of professional development completed regarding mathematics instruction for student with MLD. Chi-squared values and pvalues of these seven relationships are reported in Table 9. The significant findings between (a) a formal college/university course in the teaching of mathematics and years of experience teaching and (b) a formal college/university mathematics course and years of experience teaching, indicating that no teachers that reported teaching for 10 or more years took a formal mathematics course or formal course in the teaching of mathematics that addressed students with MLD. The significant relationships between (a) the completion of a formal college/university course in the teaching of mathematics and level of higher education, and (b) formal college/university mathematics course and level of higher education indicated that if the participant reported earning a master's degree they were more likely than those with bachelor 
degrees to have completed a formal course in the teaching of mathematics that addressed students with MLD or a formal mathematics course.

Significance (as recorded in Table 9) between reported observation of other teachers as professional development and certification specify that, the majority of respondents $(53.3 \%)$ who reported professional development in the format of observations were certified special education teachers. Likewise, $46.7 \%$ of these participants who reported professional development in the format of observations were certified in mathematics seventh grade through adult or fifth grade through adult. The significant relationship between reported observation of other teachers and "highly qualified" in special education status specify that of those special educators who reported being "highly qualified" in special education $63.6 \%$ completed professional development in the form of observations of other teachers. Whereas, $79.4 \%$ of the teachers that reported not being "highly qualified" in special education did not complete professional development in the form of observation of other teachers.

The relationship between attendance at a workshop on mathematics teaching and years of experience teaching Algebra I emphasize that the majority of all teachers in the subgroups of years experience teaching Algebra I, with the exception of those in one to three years, reported attendance at a workshop on mathematics teaching. Further, $50 \%$ of teachers with one to three years experience teaching Algebra I attended a workshop on mathematics teaching that addressed students with MLD, while the other $50 \%$ of that population did not attend any workshops that addressed students with MLD. 
Table 9

Significant Chi-square Results between Types of Professional Development Sessions and Demographic Characteristics

\begin{tabular}{|c|c|c|c|c|c|}
\hline $\begin{array}{c}\text { Type of Professional } \\
\text { Development }\end{array}$ & $\begin{array}{l}\text { Demographic } \\
\text { Characteristic }\end{array}$ & $\overline{D f}$ & $N$ & $X^{2}$ & $P$ \\
\hline $\begin{array}{l}\text { A formal college/university course } \\
\text { in the teaching of mathematics }\end{array}$ & $\begin{array}{l}\text { Years of experience } \\
\text { teaching }\end{array}$ & 3 & 44 & 11.096 & .011 \\
\hline $\begin{array}{l}\text { A formal college/university } \\
\text { mathematics course }\end{array}$ & $\begin{array}{l}\text { Years of experience } \\
\text { teaching }\end{array}$ & 3 & 44 & 12.310 & .006 \\
\hline $\begin{array}{l}\text { A formal college/university course } \\
\text { in the teaching of mathematics }\end{array}$ & $\begin{array}{l}\text { Level of higher } \\
\text { education }\end{array}$ & 4 & 41 & 10.2383 & .036 \\
\hline $\begin{array}{l}\text { A formal college/university } \\
\text { mathematics course }\end{array}$ & $\begin{array}{l}\text { Level of higher } \\
\text { education }\end{array}$ & 4 & 41 & 11.448 & .022 \\
\hline $\begin{array}{l}\text { Observation of other teachers } \\
\text { teaching mathematics as part of } \\
\text { your own professional } \\
\text { development (formal or informal) }\end{array}$ & Certification & 4 & 45 & 11.520 & .021 \\
\hline $\begin{array}{l}\text { Attendance at a workshop on } \\
\text { mathematics teaching }\end{array}$ & $\begin{array}{l}\text { Years of experience } \\
\text { teaching Algebra I }\end{array}$ & 3 & 47 & 8.820 & .032 \\
\hline $\begin{array}{l}\text { Observation of other teachers } \\
\text { teaching mathematics as part of } \\
\text { your own professional } \\
\text { development (formal or informal) }\end{array}$ & $\begin{array}{l}\text { "Highly qualified" in } \\
\text { special education as } \\
\text { defined by NCLB }\end{array}$ & 1 & 45 & 7.186 & .007 \\
\hline
\end{tabular}

\section{Perceptions Regarding Educational and Professional Development Opportunities}

The second research question was: What are West Virginia's Algebra I/Algebra Support educators' perceptions regarding how beneficial their educational experiences and opportunities were in helping them develop a knowledge base for teaching students with MLD? This question gave insight to the results of research question one, based on the responses to SIP question 23.

Description of perceptions based on preparedness. Survey participants described their preparedness to use different research recommended instructional strategies when teaching students with MLD based on their educational and professional development experiences (see Table 10). The research recommend practices identified in this question include those from the 
review of literature on best practices for teaching mathematics to students with MLD and the practices identified on the West Virginia Mathematics Program Improvement Review Survey.

Table 10

Level of Preparedness to Use Specific Practices When Teaching Students with MLD

\begin{tabular}{|c|c|c|c|c|c|}
\hline Instructional Practices & $\begin{array}{l}\text { Not Well } \\
\text { Prepared } \\
\text { Totals }(\%) *\end{array}$ & $\begin{array}{l}\text { Somewhat } \\
\text { Prepared } \\
\text { Totals }(\%)^{*}\end{array}$ & $\begin{array}{l}\text { Prepared } \\
\text { Totals }(\%) *\end{array}$ & $\begin{array}{l}\text { Well } \\
\text { Prepared } \\
\text { Totals }(\%) *\end{array}$ & $\begin{array}{l}\text { Very Well } \\
\text { Prepared } \\
\text { Totals }(\%)^{*}\end{array}$ \\
\hline $\begin{array}{l}\text { Develop lessons that provide opportunities for } \\
\text { students to actively construct their own } \\
\text { mathematical knowledge }\end{array}$ & $2(4.1)$ & $11(22.4)$ & $21(42.9)$ & $13(26.5)$ & $2(4.1)$ \\
\hline $\begin{array}{l}\text { Provide opportunities for students to use } \\
\text { manipulatives to verify mathematical reasoning }\end{array}$ & $1(2)$ & $13(26.5)$ & $13(26.5)$ & $17(34.7)$ & $5(10.2)$ \\
\hline Use cooperative learning groups & $2(4.1)$ & $9(18.4)$ & $12(24.5)$ & $15(30.6)$ & $11(22.4)$ \\
\hline $\begin{array}{l}\text { Listen/ask questions as students work in order to } \\
\text { gauge their understanding }\end{array}$ & $0(0)$ & $8(16.3)$ & $8(16.3)$ & $21(42.9)$ & $12(24.5)$ \\
\hline $\begin{array}{l}\text { Develop students' conceptual understanding of } \\
\text { mathematics }\end{array}$ & $0(0)$ & $6(12.2)$ & $21(42.9)$ & $17(34.7)$ & $5(10.2)$ \\
\hline $\begin{array}{l}\text { Manage a class of students engaged in hands-on } \\
\text { project- based work }\end{array}$ & $3(6.1)$ & $6(12.2)$ & $18(36.7)$ & $16(32.7)$ & $6(12.2)$ \\
\hline $\begin{array}{l}\text { Lead a class of students using investigative } \\
\text { strategies }\end{array}$ & $2(4.1)$ & $12(24.5)$ & $12(24.5)$ & $21(42.9)$ & $2(4.1)$ \\
\hline $\begin{array}{l}\text { Model multiple problem-solving strategies and have } \\
\text { students apply what they have learned }\end{array}$ & $1(2)$ & $7(14.3)$ & $16(32.7)$ & $19(38.8)$ & $6(12.2)$ \\
\hline Connect math to real-life contexts and careers & $1(2)$ & $6(12.2)$ & $19(38.8)$ & $16(32.7)$ & $7(14.3)$ \\
\hline $\begin{array}{l}\text { Take students' prior understanding into account } \\
\text { when planning curriculum and instruction }\end{array}$ & $0(0)$ & $1(2)$ & $20(40.8)$ & $20(40.8)$ & $8(16.3)$ \\
\hline $\begin{array}{l}\text { Use a variety of assessment strategies to measure } \\
\text { students' success }\end{array}$ & $0(0)$ & $7(14.3)$ & $13(26.5)$ & $23(46.9)$ & $6(12.2)$ \\
\hline $\begin{array}{l}\text { Teach classes containing students of heterogeneous } \\
\text { abilities }\end{array}$ & $1(2)$ & $4(8.2)$ & $19(38.8)$ & $16(32.7)$ & $9(18.4)$ \\
\hline $\begin{array}{l}\text { Teach classes containing students with different } \\
\text { learning styles }\end{array}$ & $0(0)$ & $9(18.4)$ & $15(30.6)$ & $15(30.6)$ & $10(20.4)$ \\
\hline $\begin{array}{l}\text { Use appropriate techniques for students with } \\
\text { Mathematical Learning Disabilities }\end{array}$ & $2(4.1)$ & $12(24.5)$ & $17(34.7)$ & $16(32.7)$ & $2(4.1)$ \\
\hline $\begin{array}{l}\text { Recognize and respond to the needs of students with } \\
\text { Mathematical Learning Disabilities }\end{array}$ & $2(4.2)$ & $9(18.8)$ & $16(33.3)$ & 19 (39.6) & $2(4.2)$ \\
\hline $\begin{array}{l}\text { Encourage classroom participation of students with } \\
\text { Mathematical Learning Disabilities }\end{array}$ & $4(8.3)$ & $3(6.3)$ & $14(29.2)$ & $20(41.7)$ & 7 (14.6) \\
\hline
\end{tabular}

*The number of respondents varied because of missing cases and these percents were determined with the total population that responded to SIP question 23. 
According to the survey responses of well prepared and very well prepared, the majority of educators felt most prepared to use eight of the 16 surveyed instructional practices: listen and ask questions as students work in order to gauge their understanding during instruction (67.4\%); use cooperative learning groups (53.0\%); model multiple problem-solving strategies and have students apply what they have learned (51.0\%); consider students' prior understanding when planning curriculum and instruction (57.1\%); use a variety of assessment strategies to measure students' success $(59.1 \%)$; teach heterogeneously grouped classes $(51.1 \%)$; teach classes containing students with different learning styles (51.0\%); encourage classroom participation of students with MLD (56.3\%).

Responses to four of the 16 sub-questions from SIP question 23 indicated that more than $25 \%$ of participants were not fully prepared to implement specific surveyed instructional practices, as determined by combined responses of not well prepared and somewhat prepared: develop lessons that provide opportunities for students to actively construct their own mathematical knowledge (26.5\%); provide opportunities for students to use manipulatives to verify mathematical reasoning $(28.5 \%)$; lead a class of students using investigative strategies (29.6\%); and use appropriate techniques for teaching students with MLD (29.6\%). Three of the four instructional practices participants felt not fully prepared to implement practices that specifically address a "hands on" or active approach to learning mathematics.

The researcher examined if any relationships existed between the number of college courses taken that addressed the characteristics and needs of students with MLD and educators' perceptions of their professional development experiences with a Spearman's rho correlation. There was a significant positive correlation between the number of college courses taken that 
addressed the characteristics and needs of students with MLD and teachers' perceived preparedness to facilitate six specific practices when teaching students with MLD. These positive correlations indicate that as the number of classes participants completed increased, their perceived preparedness for specific practices increased. The six instructional practices were: (a) use cooperative learning groups $\left(r_{s}(48)=0.327, p=.023\right)$, (b) model multiple problem-solving strategies and have students apply what they have learned $\left(r_{s}(48)=0.319, p=.027\right),(\mathrm{c})$ use a variety of assessment strategies to measure students' success $\left(r_{s}(48)=0.302, p=.037\right)$, (d) use appropriate techniques for students with $\operatorname{MLD}\left(r_{s}(48)=0.460, p=.001\right)$, (e) recognize and respond to the needs of students with MLD $\left(r_{s}(47)=-0.425, p=.003\right)$, and (f) encourage classroom participation of students with $\operatorname{MLD}\left(r_{s}(47)=0.336, p=.021\right)$.

\section{Implemented Practices and Alignment to Literature Recommended Practices}

The third research question was: How do West Virginia's Algebra I educators' instructional practices for students with MLD align with the recommended best practices to utilize for students with MLD? The first part of answering this research question required identification of the types of instructional practices utilized and frequency of use by participants (Table 11). The researcher then compared these descriptive statistics to the identified practices, assessments, and accommodations described in Chapter 2.

Reported use of literature recommended instructional practices. Table 11 displays the analysis of data from SIP question 24. 
Table 11

Frequency of Utilized Literature Recommended Instructional Practices by Participants When Teaching Students with MLD

\begin{tabular}{|c|c|c|c|c|c|}
\hline & $\begin{array}{l}\text { Daily } \\
\text { Totals } \\
(\%)^{*}\end{array}$ & $\begin{array}{l}\text { Weekly } \\
\text { Totals } \\
(\%)^{*} \\
\end{array}$ & $\begin{array}{c}\begin{array}{c}\text { Monthly } \\
\text { Totals } \\
(\%)^{*}\end{array} \\
\end{array}$ & $\begin{array}{l}\text { Rarely } \\
\text { Totals } \\
(\%)^{*} \\
\end{array}$ & $\begin{array}{l}\text { Never } \\
\text { Totals } \\
(\%)^{*}\end{array}$ \\
\hline $\begin{array}{l}\text { Students solving real-life } \\
\text { problems }\end{array}$ & $16(33.3)$ & $25(52.1)$ & $7(14.6)$ & $0(0)$ & $0(0)$ \\
\hline Mathematical writing (reflections) & $6(12.5)$ & $12(25.0)$ & $14(29.2)$ & $14(29.2)$ & $2(4.2)$ \\
\hline Demonstrating/modeling & $29(60.4)$ & $15(31.3)$ & $4(8.3)$ & $0(0)$ & $0(0)$ \\
\hline Students using manipulatives & $1(1.8)$ & $21(43.8)$ & $14(29.2)$ & $12(25.0)$ & $0(0)$ \\
\hline Visual and graphic depictions & $27(56.3)$ & $18(37.5)$ & $2(4.2)$ & $1(2.1)$ & $0(0)$ \\
\hline Student think-alouds & $21(43.8)$ & $18(37.5)$ & $6(12.5)$ & $2(4.2)$ & $1(2.1)$ \\
\hline Peer-assisted learning & $28(58.3)$ & $18(37.5)$ & $2(4.2)$ & $0(0)$ & $0(0)$ \\
\hline $\begin{array}{l}\text { Formative Assessment Data } \\
\text { provided to teachers and students }\end{array}$ & $6(12.8)$ & $21(44.7)$ & $14(29.8)$ & $6(12.8)$ & $0(0)$ \\
\hline $\begin{array}{l}\text { CRA(Concrete-Representational- } \\
\text { Abstract) }\end{array}$ & $3(6.5)$ & $17(37.0)$ & $12(26.1)$ & $6(13.0)$ & $8(17.4)$ \\
\hline Students in groups or teams & $16(33.3)$ & $22(45.8)$ & $9(18.8)$ & $0(0)$ & $1(2.1)$ \\
\hline Calculator problem solving & $40(83.3)$ & $7(14.6)$ & $1(2.1)$ & $0(0)$ & $0(0)$ \\
\hline $\begin{array}{l}\text { Review of Skills and procedures } \\
\text { with step by step prompts }\end{array}$ & $35(72.9)$ & $11(22.9)$ & $2(4.2)$ & $0(0)$ & $0(0)$ \\
\hline Whole-class discussion & $39(81.3)$ & $7(14.6)$ & $1(2.1)$ & $1(2.1)$ & $0(0)$ \\
\hline Lecture with student note taking & $23(47.9)$ & $22(45.8)$ & $0(0)$ & $2(4.2)$ & $1(2.1)$ \\
\hline Student-led discussion & $12(25.0)$ & $21(43.8)$ & $7(14.6)$ & $8(16.7)$ & $0(0)$ \\
\hline Individualized assignments & $17(36.2)$ & $13(27.7)$ & $6(12.8)$ & $8(17.0)$ & $3(6.4)$ \\
\hline $\begin{array}{l}\text { Extended time on tests and } \\
\text { assignments }\end{array}$ & $22(46.8)$ & $19(40.4)$ & $6(12.8)$ & $0(0)$ & $0(0)$ \\
\hline Assessment modifications & $17(35.4)$ & $20(41.7)$ & $8(16.7)$ & $3(6.3)$ & $0(0)$ \\
\hline
\end{tabular}


According to the survey results, the majority of participants who responded to SIP question 24 used the following practices and accommodations daily: (a)demonstrating/modeling (60.4\%), (b) visual and graphic depictions (56.3\%), (c) peer-assisted learning (58.3\%), (d) calculator problem solving $(83.3 \%)$, (e) review of skills and procedures with step by step prompts (72.9\%), and (f) whole class discussion (81.3\%). These are all recommended practices to use when teaching mathematics to students with MLD. The following are recommended practices and accommodations for students with MLD that the majority of participants who responded to SIP question 24 used at least weekly: (a) student think-alouds (43.8\% daily and $37.5 \%$ weekly), (b) formative assessment data provided to teachers and students $(12.8 \%$ daily and $44.7 \%$ weekly), (c) students in teams or groups (33.3\% daily and $45.8 \%$ weekly), (d) student-led discussions (25\% daily and $43.8 \%$ weekly), (e) individualized assignments (36.2\% daily and $27.7 \%$ weekly), (f) extended time on tests and assignments (46.8\% daily and $40.4 \%$ weekly), and (g) assessment modifications (35.4\% daily and $41.7 \%$ weekly). It is worth noting that $47.9 \%$ of participants reported daily use of lecture with student note-taking, an element of explicit instruction, and $45.8 \%$ reported using it weekly. The majority of participants who responded to SIP question 24 reported using CRA on a monthly basis or less $(26.1 \%$ monthly, $13 \%$ rarely, and $17.4 \%$ never). Similarly, the majority of participants who responded to SIP question 24 reported using manipulatives on a monthly basis or less $(29.2 \%$ monthly and $25 \%$ never).

Next, the researcher examined relationships between different demographic variables and educators' reported use of recommend instructional practices with a chi-square test of independence. The researcher found statistically significant relationships between six different sets of variables as related to reported instructional practices. Table 12 reports the Chi-squared 
values and p-values of these six relationships. It is important to note the degrees of freedom for the data reflect the collapsing of data sets if no data existed within that data set. For example, when examining the relationship between gender and assessment modifications no participant reported never using assessment modifications, so that data set was collapsed and the degrees of freedom calculation was based on two gender options and four frequencies of use (daily, weekly, monthly, rarely). Significance was found between instructional practices and the demographic characteristics of teaching position, certification, gender, "highly qualified" status in mathematics, and "highly qualified" status in special education.

Table 12

Significant Chi-square Results between Types of Utilized Instructional Practices and Demographic Characteristics

\begin{tabular}{llllll}
\hline \multicolumn{1}{c}{ Instructional Practice } & $\begin{array}{l}\text { Demographic } \\
\text { Characteristic }\end{array}$ & Df & N & $X^{2}$ & $\boldsymbol{P}$ \\
\hline $\begin{array}{l}\text { Review of Skills and procedures } \\
\text { with step by step prompts }\end{array}$ & $\begin{array}{l}\text { Current Teaching } \\
\text { Position }\end{array}$ & 4 & 48 & 11.345 & 0.023 \\
Assessment modifications & Gender & 3 & 48 & 11.626 & 0.009 \\
Visual and graphic depictions & Certification & 12 & 47 & 23.939 & 0.021 \\
$\begin{array}{l}\text { Calculator problem solving } \\
\text { Lecture with student note taking }\end{array}$ & $\begin{array}{l}\text { Highly Qualified in } \\
\text { Mathematics }\end{array}$ & 3 & 47 & 11.695 & 0.009 \\
$\begin{array}{l}\text { Formative Assessment Data } \\
\text { provided to teachers and students }\end{array}$ & $\begin{array}{l}\text { Highly Qualified in } \\
\text { Special Education }\end{array}$ & 3 & 45 & 9.231 & 0.026 \\
\hline
\end{tabular}

The significant findings from Table 12 emphasized the following descriptive statistics in regard to teaching position and gender: (a) the majority of both general (73.5\%) and special (75.0\%) educators reported daily review of skills and procedures with step by step prompts, and

(b) females reported providing assessment modifications more frequently (45.5\% daily and $39.3 \%$ weekly) as compared to males (46.7\% weekly and $40 \%$ monthly). Further when 
analyzing reported practices as related to certification, (a) participants certified in mathematics 712 or 5-adult (58.6\% daily) and multi-categorical special education(70\% daily) reported the most frequent use of visual and graphic depictions, while $25 \%$ of those certified in mathematics 5-9 reported daily visual and graphic depictions use and 62.5\% reported weekly use; and (b) almost all participants certified in mathematics $7-12$ or 5-adult (93.1\%) and $100 \%$ of the participants dually certified in mathematics 5-9 and multi-categorical special education reported daily use of calculator problem solving, while only $62.5 \%$ of the multi-categorical special education certified teachers and $71.4 \%$ of the 5-Algebra certified teachers reported daily use of calculator problem solving. Teachers "highly qualified" in mathematics reported more frequent use of lecture with student note taking ( $61.8 \%$ daily and $32.4 \%$ weekly) as compared to those who are not "highly qualified" in mathematics (15.4\% daily and $77.0 \%$ weekly). Furthermore, $88.9 \%$ of participants "highly qualified" in special education reported providing formative assessment to teachers and students weekly, as compared to those who are not "highly qualified" in special education that reported daily (16.7\%), weekly (33.3\%), monthly (33.3\%) and rarely (16.7\%).

Based on Spearman's rho, there was a significant correlation between years experience teaching and the use of three instructional practices. The possible range on SIP question 24 was one to five, where one indicated daily, two indicated weekly, three indicated monthly, four indicated rarely, and five indicated never. The possible range on the years experience was one to four, where one indicated one to three years, two indicated four to six years, three indicated seven to ten years, and four indicated more than ten years.

There was a significant positive correlation between years experience and the use of real life problems during instruction, $\left.r_{s}(53)=0.356, p=.015\right)$. Based on the SIP rating scales this indicates that as the participants' years experience increased, their reported use of real life 
problems decreased. Another significant positive correlation was between years of experience and the review of skills and procedures with step by step prompts during instruction $\left(r_{s}(46)\right.$ $=0.394, p=.007)$. This indicates that as the participants' years experience increased, their reported use of review of skills and procedures with step by step prompts during instruction decreased. There was a significant negative correlation between years experience and the facilitation of students in groups or teams during instruction $\left(r_{s}(46)=-0.305, p=.040\right)$. Thus, as the participants' years experience increased, so did their use of groups or teams.

Spearman's rho revealed that a significant negative correlation existed between the number of students with MLD in the participants' Algebra class and the use of four instructional practices. The possible range on SIP question 24 was one to five, where one indicted daily, two indicated weekly, three indicated monthly, four indicated rarely, and five indicated never. The possible range on the number of students with MLD as their primary disability (SIP question 18) was one to three, where one indicated one to five students, two indicated six to ten students, and three indicated eleven or more students. These negative correlations indicate as the number of students with MLD increased, the amount of use of the specific practices also increased. There was a significant negative correlation between the number of students with MLD in the participants' Algebra class and the use of: (a) real life problems during instruction $\left(r_{s}(47)=-\right.$ 0.357, $p=.014)$, (b) demonstrating/modeling during instruction $\left(r_{s}(47)=-0.394, p=.006\right),(\mathrm{c})$ calculator problem solving during instruction $\left(r_{S}(47)=-0.290, p=.048\right)$, and $(d)$ extended time on tests and assignments, $\left(r_{S}(46)=-0.322, p=.029\right)$.

The final correlation found with Spearman's rho was a positive correlation between the amount of collaborative time with a special education teacher (if the participant was a general educator) or general education teacher (if the participant was a special educator) and the use of 
two instructional practices. The possible range on SIP question 24 was one to five, where one indicated daily, two indicated weekly, three indicated monthly, four indicated rarely, and five indicated never. The possible range on the amount of collaborative time (SIP question 19) was one to five, where one indicated daily, two indicated two to three times a week, three indicated once a week, four indicated once every two weeks, and five indicated less than twice a month. These positive correlations indicate as the amount of collaborative time decreased, the amount of use of the specific practices also decreased, and as the amount of collaborative time increased the use of the specific practices also increased. The two significant correlations with the amount of collaborative time were between students using manipulatives $\left(r_{s}(46)=-0.322, p=.029\right)$ and whole class-discussions $\left(r_{s}(48)=0.314, p=.030\right)$. Specifically with the use of manipulatives, $56 \%$ of participants who reported collaborating daily with a general or special educator use manipulatives weekly, and $57.1 \%$ of participants who reported collaborating with a general or special less than twice month rarely use manipulatives.

\section{Perceived Issues Surrounding the Algebra I Instruction of Students with MLD}

The fourth research question was: What are West Virginia's Algebra I/Algebra Support educators' perceived issues surrounding the instruction of algebra to students with MLD? The primary data analyzed quantitatively to answer this question came from SIP questions 25 and 26. Through these data sources, participants identified their perception of how effectively students with MLD were taught mathematics at their school and rated perceived issues surrounding Algebra I instruction of students with MLD.

Perceptions of how effectively students with MLD were taught Algebra I. Of the 50 participants who responded to SIP question $25,14 \%(N=7)$ strongly agreed and $42 \%(N=21)$ agreed that students with MLD were effectively taught mathematics at their school. Twenty-four 
percent $(N=12)$ disagreed and 2\% $(N=1)$ strongly disagreed that students with MLD were effectively taught mathematics at their school. Eighteen percent $(N=9)$ of the participants did not agree nor disagree that students with MLD were effectively taught mathematics at their school. Given these percents and the ratings of one representing strongly agree and five representing strongly disagree, the mean agreement level of participants to the statement, "students with MLD are effectively taught mathematics at my school" was $2.58(\mathrm{SD}=1.07)$. This mean indicated a more favorable than not perception of the mathematics instruction for students with MLD in the participants' specific schools.

Perceptions of issues when teaching Algebra I to students with MLD. A summary of SIP question 26 responses $(N=48)$ addressing perceived issues when teaching Algebra I to students with MLD are in Table 13. The Cronbach's Alpha for the reliability of the statements for SIP question 26 was reliable at 0.769 . Provided in Table 13 is a summary of participant's agreement or disagreement that the statement is a problem and a ranking of the survey statements from low to high by the mean and standard deviation.

Table 13

Teachers' Perceptions of Issues When Teaching Algebra I to Students with MLD (1= Not a Problem, 2=Slight Problem, 3=Moderate Problem, 4= Significant Problem, 5= Severe Problem)

\begin{tabular}{lll}
\hline \multicolumn{1}{c}{ Statement } & Mean & SD \\
\hline Availability of appropriate curriculum materials (texts, calculators, software, etc.) & 2.02 & 1.07 \\
Availability of and access to computers and other technology & 2.30 & 1.37 \\
Availability of funds for mathematics materials and supplies & 2.50 & 1.03 \\
Availability of in-service opportunities for math teachers & 2.73 & 1.23 \\
Pressure to prepare students for state assessment & 3.08 & 1.41 \\
\hline
\end{tabular}

A majority of the participants had favorable perceptions, as measured by an agreement level mean of less than three. Availability of appropriate curriculum materials (text, calculators, software, etc.) was not a problem for $40.4 \%$ of the SIP question 26 respondents and $29.8 \%$ reported that it was a slight problem. Almost $40 \%(39.6 \%)$ of respondents reported the 
availability of and access to computers and other technology was not a problem, and $22.9 \%$ reported it as a slight problem. Availability of funds was a moderate problem for $33.3 \%$ of respondents, but only a slight problem for $31.3 \%$ and not a problem for $18.8 \%$. In the "other" response to SIP question 26 Survey Participant 3 wrote, "There is a lack of funding to provide training to special education co-teachers that are not comfortable in the math classroom".

Based on the frequency distribution, the majority of respondents did not have favorable perceptions of the availability of in-service opportunities for math teachers. It was a moderate problem for $25 \%$, significant problem for $25 \%$, and a severe problem for $6.3 \%$. Further, the majority of respondents did not have favorable perceptions of the pressures to prepare students for assessments. It was not a problem for $16.7 \%$ of respondents and $22.9 \%$ found it to be a slight problem. This pressure was a moderate problem for $16.7 \%$, significant problem for $22.9 \%$ and a severe problem for $20.8 \%$.

Based on Spearman's rho, a negative correlation existed between the availability of inservice opportunities for math teachers and the amount of collaborative time with either a special educator (if the participant was a general educator) or general educator (if the participant was a special educator), which was statistically significant $\left(r_{s}(47)=-0.352, p=.015\right)$. Further, Spearman's rho revealed a correlation between participants"' perceptions of their schools effectiveness of teaching mathematics to students with MLD and two perceived issues when teaching Algebra I to students with MLD: (a) their perceived issues in regard to availability of in-service opportunities for math teachers $\left(r_{s}(48)=0.474, p=.001\right)$, and (b) perceived issues in reguards to the pressure to prepare students for state assessments $\left(r_{s}(48)=0.448, p=.001\right)$.

In the "other" response to SIP question 26 Survey Participant 25 addressed this issue: 
There is too much to do in a classroom with too many kids, with not enough one on one time for students who need help with too much pressure for tests and not enough focus on needed material for next level of math.

This statement not only addressed the issue of assessment pressures on teachers and students, but also other issues that emerged through the qualitative analyses of data.

\section{Qualitative Results}

Qualitative analyses included: (a) conventional content analysis of existing literature, (b) conventional content analysis of the open ended survey responses from SIP question 27, (c) directed content analysis of each interview, followed by (d) cross interview analysis. The researcher used the results of these four analyses to answer the research questions.

The conventional content analysis of the literature framed the directed content analysis of the interview transcripts because the thematic category codes identified through open coding of the literature guided the directed content analysis of the interview transcripts (See Table 14).

\section{Table 14}

\section{Thematic Category Codes Used for Directed Content Analysis of Interview Transcripts}

Perceived Issues

Teacher Preparation

Educational Placement

Access to Curriculum

\section{Emergent Code}

Instruction That Includes Everyday Life Experiences

\section{Best Practices}

Explicit Instruction

Classwide Peer Tutoring

Technology

Graphic Organizers

Graduated Instructional Sequence/CRA

Cognitive Strategy Instruction 
Themes similar to those that emerged from the literature review were identified in the interview data regarding issues and instructional practices utilized when teaching Algebra I to students with MLD. The researcher expected parallel findings because the transcripts were analyzed deductively using directed content analysis. The following are the six emergent themes from the interviews: (a) varied teacher preparation experiences through higher education, (b) varied teacher preparation experiences through professional development sessions, (c) varied classroom instructional environments, (d) inclusive classroom instruction issues, (e) limited use of CRA and manipulatives, and (f) challenging student characteristics. These themes are identified as emergent because they are more specific than the ones identified through the literature analysis. The researcher identified these themes by first coding the data using the codes listed Table 14 . Instruction that included everyday life experiences was the only emergent code identified. The researcher then analyzed the interview responses categorized under each individual code. For example, all interview responses coded under teacher preparation were analyzed for similarities and differences. Through analyzing the responses categorized under each of the three perceived issues codes, individually, and comparing the types of reported instructional practices by each interviewee, six themes emerged. The emergence of these themes is discussed in detail according to each specific research question they address.

The conventional content analysis of the open ended survey responses from SIP question 27 identified participants' perceived issues about teaching students with MLD. Table 15 lists the three emergent themes from SIP question 27 responses, thirteen codes used during conventional content analysis of the responses to SIP question 27, number of responses coded for each code, and examples of the key words used during coding. 
Table 15

Codes Used To Analyze Participants' Perceived Issues When Teaching Students With MLD

\begin{tabular}{|c|c|c|c|}
\hline Theme & Thematic Category Code & $\begin{array}{l}\text { Number of } \\
\text { Responses Coded }\end{array}$ & $\begin{array}{l}\text { Examples of } \\
\text { Key Words } \\
\text { Used in Coding }\end{array}$ \\
\hline \multirow[t]{7}{*}{$\begin{array}{l}\text { Inclusive } \\
\text { Classroom } \\
\text { Instruction }\end{array}$} & $\begin{array}{l}\text { Curriculum Mapping/Speed of Introducing New } \\
\text { Concepts }\end{array}$ & 4 & $\begin{array}{l}\text { Slow down, too } \\
\text { fast, slower } \\
\text { pace }\end{array}$ \\
\hline & $\begin{array}{l}\text { Special Education Teachers Role in the General } \\
\text { Education Classroom }\end{array}$ & 2 & $\begin{array}{l}\text { Special } \\
\text { education } \\
\text { teacher }\end{array}$ \\
\hline & Teacher Preparation & 4 & $\begin{array}{l}\text { Little to no in- } \\
\text { service, not as } \\
\text { prepared, } \\
\text { qualified } \\
\text { teacher }\end{array}$ \\
\hline & Algebra CSO's & 3 & $\begin{array}{l}\text { Algebra CSO's, } \\
\text { Watered down } \\
\text { curriculum }\end{array}$ \\
\hline & Lack of Planning Time with Co-Teacher & 1 & Time to plan \\
\hline & $\begin{array}{l}\text { Instruction That Does Not Address a Variety of } \\
\text { Learning Styles }\end{array}$ & 1 & $\begin{array}{l}\text { One size fits all } \\
\text { instruction }\end{array}$ \\
\hline & Assessment Pressure & 1 & Assessment \\
\hline \multirow{3}{*}{$\begin{array}{l}\text { Classroom } \\
\text { Instructional } \\
\text { Environment }\end{array}$} & Class Time & 4 & $\begin{array}{l}\text { Time, } 90 \text { minute } \\
\text { blocks }\end{array}$ \\
\hline & Class Size & 3 & Class size \\
\hline & Availability of Manipulatives & 2 & Manipulatives \\
\hline \multirow[t]{3}{*}{$\begin{array}{l}\text { Student } \\
\text { Characteristics }\end{array}$} & Student Motivation & 2 & $\begin{array}{l}\text { If willing, give } \\
\text { up }\end{array}$ \\
\hline & Students Lack of Concept Retention and Application & 5 & $\begin{array}{l}\text { Concepts, not } \\
\text { getting good } \\
\text { foundation in } \\
\text { elementary } \\
\text { school, not } \\
\text { ready to grasp } \\
\text { algebra }\end{array}$ \\
\hline & Student's Attention Span & 1 & $\begin{array}{l}\text { Have short } \\
\text { attention spans }\end{array}$ \\
\hline
\end{tabular}

Source: Participant Responses SIP Question 27 
Thirteen issues, the thematic category codes, emerged through coding and categorization of open-ended survey responses (see Table 15) and the researcher separated them into three themes: (a) student characteristics, (b) classroom instructional environment, and (c) inclusive classroom instruction. Furthermore, the inductive themes from the analysis of the survey responses were similar to the emergent themes from the interviews. The survey theme of student characteristics paralleled the interview theme of challenging student characteristics; classroom instructional environment supported the interview theme of varied classroom instructional environments; and inclusive classroom instruction provided further examples of the interview theme of inclusive classroom instruction issues. Thus, the researcher used triangulation of the qualitative analyses results to compare data from different data sources, analyzed differently, to identify the six emergent qualitative themes of (a) varied teacher preparation experiences through higher education, (b) varied teacher preparation experiences through professional development sessions, (c) varied classroom instructional environments, (d) inclusive classroom instruction issues, (e) limited use of CRA and manipulatives, and (f) challenging student characteristics. These are the same themes that were identified through the survey analysis.

\section{Educational and Professional Development Opportunities}

The first research question was: What opportunities have Algebra I educators had to develop knowledge for teaching students with MLD? To address this question with qualitative results the researcher analyzed the open-ended SIP question 27 data and interview data. Two specific teacher preparation themes emerged through these analyses, (a) variation of teacher preparation through higher education, and (b) variation of teacher preparation through professional development. 
Educational opportunities. The researcher coded four survey responses as teacher preparation and none specifically addressed what types of educational opportunities participants had to develop knowledge for teaching Algebra I to students with MLD. The interview data analysis revealed a variation of teacher preparation, specifically through higher education. Table 16 compares the interview responses regarding participants' higher education experiences that addressed Algebra I instruction for students with MLD.

Table 16

Interview Responses Regarding Educational Opportunities for Teaching Algebra I to Students with $M L D$

\begin{tabular}{ll}
\hline Theme & Interview Responses \\
\hline
\end{tabular}

Varied teacher preparation experiences through higher education
"I did my teacher's certification through an alternate masters program, so I had several classes focused on special education diagnosis and the law associated with special education." Teacher B

\footnotetext{
"They showed us teddy bear counters and those rods for fractions and place value and all that, I guess they were trying to say "you need to know what these kids are doing in elementary before they get to you" but what do I do with the manipulatives now? That is what I need to know. I did have one class that was supposed to be for secondary education majors, the teacher was not that great, but she did the best she could. Her focus was mainly on technology and how to get them on websites and stuff." Teacher A

"I went to a teachers college in Florida for Elementary Education, after being an administrative assistant to an elementary school principal for 18 years. I had special education classes on laws and characteristics, but most of what I learned was through observations during my teacher education program and my previous work experience, as well as through mathematics co-teaching in-service by my county. I learned a lot about instructional methods to use for students with MLD or that struggle learning mathematics, but none specific to Algebra I. I mean I learn the subject area from the regular education teacher weekly." Teacher D
}

The majority $(n=4)$ of interview participants reported taking two or more college courses

that addressed the needs and characteristics of students with MLD. Three interviewees shared experiences from their college courses that addressed students with MLD (see Table 16).

Teacher A and Teacher B, both certified in secondary mathematics, shared different types of 
content covered in their higher education classes that addressed students with MLD. These experiences support the theme of variation in teacher preparation to teach Algebra I to students with MLD, because no consistency existed in the content of these higher education courses.

Further, the content required for Teacher D's teacher preparation program differed from the other interviewees because she majored in Elementary Education, with a special education emphasis and had no courses focused on Algebra I content. Through her teacher preparation courses, she learned about instructional practices to use when teaching mathematics to students with MLD, but no practices specific to Algebra I. This is another example of the variety of higher education teacher preparation experiences of Algebra I and Algebra Support educators in West Virginia.

Professional development opportunities. One of the four survey responses coded under teacher preparation specifically addressed professional development opportunities participants had to develop knowledge for teaching Algebra I to students with MLD. Participant 52 stated, "There is little to no in-service for inclusion and regular education teachers who work together to learn new teaching methods." All interviewees participated in some type of professional development regarding the needs and characteristics of students with MLD. Table 17 compares the responses from the interview that addressed professional development opportunities regarding Algebra I instruction for students with MLD. 
Table 17

Interview Responses Regarding Professional Development Opportunities for Teaching Algebra I to Students with MLD

\begin{tabular}{l}
\hline Theme \\
\hline Varied teacher \\
preparation experiences \\
through professional \\
development \\
opportunities
\end{tabular}

Interview Responses

"I have been to few conferences. I went to the Algebra Support Conference."

Teacher A

"I have attended two workshops on math teaching, the Algebra Support training and classroom management training." Teacher B

"I think my dual certification [Special Education and Mathematics] helps me teach math and have more professional development opportunities. I have attended state math meetings, national NCTM meetings, worked with others as a mentor teacher, and was part of a county wide math cadre focused on algebra readiness... More mathematical co-teaching professional development sessions are needed."

Teacher C

"I have had a lot of professional development this year, some on co-teaching. We were fortunate to have some county in-service last year and this year on co-teaching. I am attending as many different PDS [professional development sessions] as I can because I do not know which ones I might need at any given moment... the most recent mathematics co-teaching in-service by my county was voluntary and we attended every few weeks, and received manipulatives to use in a co-teaching Algebra setting." Teacher D

"I went to the Algebra Support Conference in the fall and observed another special education math teacher during my few weeks of school as part of an mentoring program...We got people that have come from the state, auditors for SPED department, and they thought this was the best example of co-teaching they have ever seen, between my Algebra I co-teacher and I. Now, they are sending others to observe how we do things." Teacher E

The majority of interviewees $(n=4)$ attended the WVDE Algebra Support Conference,

but this is the only similarity between all of their attended professional development sessions.

All interviewees taught the same content to students with MLD through either Algebra I,

Algebra Support, or both courses and had similar years experience teaching but had different

professional development experiences. Further, the reported professional development

experiences varied in format and content. For example, Teacher D attended professional

development on mathematics co-teaching, while Teacher $\mathrm{C}$ shared a need for professional 
development on mathematical co-teaching. Further, Teacher $\mathrm{C}$ was a member of a mathematics cadre while the majority of the others reported attendance at a conference on Algebra I instruction. These experiences support the theme of variation in teacher preparation to teach Algebra I to students with MLD because no consistency existed in the content of these sessions and the types of sessions attended by interviewees.

\section{Perceptions Regarding Educational and Professional Development Opportunities}

The second research question was: What are Algebra I educators' perceptions regarding how beneficial their educational experiences and opportunities were in helping them develop a knowledge for teaching students with MLD? This question gave insight to the results of research question one, through responses from SIP question 27 and the interviews. The two themes that addressed this research question are the same themes that addressed question one, (a) variation of teacher preparation through higher education, and (b) variation of teacher preparation through professional development. Table 18 compares the survey and interview responses that supported the emergence of these two themes. 
Table 18

Survey and Interview Responses Regarding Perceptions of Educational and Professional Development Experiences That Addressed Teaching Algebra I to Students with MLD

\begin{tabular}{|c|c|c|}
\hline Theme & Survey Responses & Interview Responses \\
\hline $\begin{array}{l}\text { Varied } \\
\text { teacher } \\
\text { preparation } \\
\text { experiences } \\
\text { through } \\
\text { higher } \\
\text { education }\end{array}$ & $\begin{array}{l}\text { "Teachers are not as } \\
\text { prepared as we need to be } \\
\text { to teach students with } \\
\text { MLD." Participant } 13 \\
\text { "General education } \\
\text { teachers are not as } \\
\text { prepared to address these } \\
\text { issues, and there is not } \\
\text { enough time to plan with } \\
\text { your co-teacher to address } \\
\text { these issues." Participant } 5 \\
\text { "Finding qualified teachers } \\
\text { to co-teach is very } \\
\text { difficult. When the special } \\
\text { education co-teacher does } \\
\text { not understand the } \\
\text { concepts being taught in } \\
\text { class it makes it very } \\
\text { difficult for him/her to } \\
\text { truly assist students." } \\
\text { Participant } 3\end{array}$ & $\begin{array}{l}\text { "I wish that there were more manipulatives used in college classes. } \\
\text { You know if I would have been more familiar with them, and used } \\
\text { them from day one in my classroom... I just really think that if they } \\
\text { would have showed us more manipulatives it would have been a } \\
\text { better use of our time." Teacher A } \\
\text { "As far as training to deal with MLD students, I had not so much } \\
\text { during my teacher certification program. As far as exposure to an } \\
\text { environment like this where I have all these students who make me } \\
\text { scratch my head because I have never seen a collective group of } \\
\text { people who are so you know so inept as far as just social...like how to } \\
\text { interact with other people and how to behave in society and what } \\
\text { society expects from you. It is like, that is the toughest thing for me, I } \\
\text { have never been immersed in a culture like this. I was always around } \\
\text { my fellow honors students in high school, or my family and friends } \\
\text { who have a certain way of approaching life and thinking about life, } \\
\text { and it is just kinda of eye opening to be in this kinda culture where } \\
\text { there is this lack of social awareness I guess." Teacher B }\end{array}$ \\
\hline $\begin{array}{l}\text { Varied } \\
\text { teacher } \\
\text { preparation } \\
\text { experiences } \\
\text { through } \\
\text { professional } \\
\text { development } \\
\text { opportunities }\end{array}$ & $\begin{array}{l}\text { "There is little to no in- } \\
\text { service for inclusion and } \\
\text { regular education teachers } \\
\text { who work together to learn } \\
\text { new teaching methods." } \\
\text { Participant } 52\end{array}$ & $\begin{array}{l}\text { "... They [presenters at the Algebra I Support Conference] showed us } \\
\text { all these manipulatives and all these things that in this utopian society } \\
\text { everyone should be able to use in their classroom. I am just sitting } \\
\text { there scratching my head, like laughing to myself hysterically thinking } \\
\text { there is no way that would work because my kids cannot handle it." } \\
\text { Teacher B } \\
\text { "More mathematical co-teaching professional development sessions } \\
\text { are needed." Teacher C } \\
\text { "I left it [mathematics professional development session] thinking whoa I } \\
\text { have so much to learn about my students, before I can become } \\
\text { comfortable enough to use CRA and manipulatives with my kids. Now I } \\
\text { am over half way into the year, I am hoping next year will be a little } \\
\text { better. I think the biggest thing I learned is that the kids don't think the } \\
\text { way I do. The things I think are just easy and I just get it, it is not the way } \\
\text { they are wired. They need that concrete, they need to be playing with it, } \\
\text { feel it and understand what this means to be able to actually use it. Now } \\
\text { let's put it in picture form, then number form. I did not realize that we } \\
\text { needed to go through all these steps, but well if that is the way they learn } \\
\text { then that is the way I need to do it. It is just different, to me they are just } \\
\text { numbers and I did not get why the kids did not just understand. But, I am } \\
\text { learning not to just assume so much...that was the best training I have }\end{array}$ \\
\hline
\end{tabular}


ever been too, all year. It was better than any of the beginning teacher things mandated by the state. That was the best training in math."

Teacher A

"I think they[professional development sessions] are very necessary because education is constantly changing, just like the curriculum itself.."

Teacher D

"I had never been exposed to a lot of these things. That [professional development session] was a chance for me to be exposed to all the technologies (high and low tech) that can be used in math with MLD students." Teacher E

Perceptions of higher education teacher preparation. Three responses to SIP question 27 addressed educators' perceived preparedness to teach students with MLD based on their higher education teacher preparation program. Participant 13, a highly qualified in mathematics general education teacher with more than ten years teaching experience, and Participant 5, a special education teacher highly qualified in both mathematics and special education, and Participant 3 , a highly qualified in mathematics general education teacher, provided similar responses. In these statements, participants noted a different type of teacher, special or general education, that was not prepared based on their educational experiences.

Two interviewees shared their own perceived preparedness to teach students with MLD based on their educational experiences. Teacher A felt that she had exposure to the use of manipulatives specifically for students with MLD at the elementary level, but not the secondary level where she is currently teaching and certified. She wished that more manipulatives were used in her secondary education college classes, because if she had been more familiar with how to use them then she would have used them from day one of teaching her Algebra I/Algebra Support class. Teacher B shared that he was familiar with special education policies and diagnosis, but he felt that he had not exposure to this type of classroom environment. 
Perceptions of professional development teacher preparation. One response to SIP question 27 addressed educators' perceived preparedness to teach students with MLD based on their professional development experiences. All interviewees participated in some type of professional development that addressed students with MLD and shared their perceptions of these professional development experiences (See Table 18). Teacher B did not feel that the methods and manipulatives presented to him would be feasible to use in his classroom, because, in his opinion, they only would work in a "utopian society". Teacher C specifically identified a need for more mathematical co-teaching professional development sessions for secondary educators. Teachers $\mathrm{A}$ and $\mathrm{E}$ were pleased with their professional development experiences and the types of manipulatives and resources introduced during their sessions. Further Teacher A, shared that she learned about her students' thinking and how it will change her future classroom instruction. The responses regarding educators' perceptions of their professional development experiences identified a perceived need for (a) more mathematical co-teaching professional development sessions and (b) sessions that can be directly applied to educators' classroom practices. Further, these responses also identified that educators having positive perceptions of their professional development experiences were exposed to multiple classroom resources and practices that they felt could be implemented in their classroom.

\section{Implemented Practices and Alignment to Literature Recommended Practices}

The third research question was: How do West Virginia’s Algebra I educators' instructional practices for students with MLD align with the recommended best practices to utilize for students with MLD? A review of literature identified the following as best practices to use when teaching Algebra to students with MLD (a) explicit instruction, (b) classwide peer tutoring, (c) technology, (d) graphic organizers, (e) CRA/Graduated Instructional Sequence, and 
(f) cognitive strategy instruction. Responses addressing alignment of educators' practices to the literature recommended practices influenced the identification of the following two emergent themes from interview and survey responses (a) varied classroom instructional environments, and (b) limited use of CRA and manipulatives. Table 19 provides examples of interview responses that addressed the alignment of interviewees' reported practices to the literature recommended practices for teaching Algebra I to students with MLD. 
Table 19

\section{Best Practices for Teaching Algebra I to Students with MLD Alignment with Literature} Recommendations

\section{Practice \\ Explicit Instruction \\ Classwide \\ Peer \\ Tutoring}

Technology

aphic

Organizers

Cognitive

Strategy

Instruction

\section{Interview Responses}

"We take our time to make sure everyone gets it, and work intensively one-on-one with the MLD students...They get a chance for a little extra practice and firmer understanding of concepts."

Teacher E

"Even though I try weekly, there are very few opportunities I have for the students to work in collaborative groups, because it tends to disintegrate into a social event." Teacher B

"A lot of time, in the past, we have used mixed ability groups. Sometimes it works sometimes it does not. It all depends on the students I have that year." Teacher C

"Cooperative learning, that is just my approach to teaching. My father was a teacher and coach and that was his response to anything you asked him, he would ask you another question and tell you to discuss it with others. He kind of lead you to find out the solution yourself, you know what I am saying. He would ask you only a question in which would take you to the next question... that is the way I operate in my classroom." Teacher E

"My students work in groups of 4." Teacher A

"With CL [Carnegie Learning], as far as the software goes it gives them a lot of higher level questions that I would probably not ask. I would probably dumb things down a bit, you know what I am saying? When the software forces me to use those higher level questions that I should be using, when sometimes they are hard for me to come up with or I might think the kids can't get it. When really they can, so it makes sure everyone is on an even playing field and I am not giving easier questions to some kids." Teacher A

"My SMART Board has worked fairly well, at least in the initial stages of having it in my room. The new technology the kids are excited to come to the front of the room and help out." Teacher B

"We use our SMART boards, and as much technology as possible. I am a firm believer of using as many different sensory activities as possible for comprehension and memorization." Teacher D

"We have 4-5 computers set up in our classroom for students to use individually or in pairs. We use our overhead computer projector for lessons from the internet, and I go on and show videos."

Teacher E

"We use graphic organizers weekly." Teacher D

"We use graphic organizers to help students be able to draw pictures, diagrams, and tables to model situations using multiple methods." Teacher E

"Teaching them strategies to problem solve is very very important. For example, what I try to do is take the possible answers before them during a technology based Westest review, and chunk the information through Odyssey [computer-based mathematics program]. We teach them decoding methods, such as do they need to look for and how to find it. So they do not get to overwhelmed with large chunks of information." Teacher D

"I start them with the idea of how do you learn how to solve problems and then I teach them different ways they can approach problems." Teacher E 
According to the interviewees' responses, technology use was the most frequently reported literature recommended strategies used when teaching Algebra I to students with MLD. As noted in Table 19, the teachers' reported technology use varied from SMART boards, internet videos projected through an LCD projector, in-class computers, to mathematics software. Each interviewee expressed favorable perceptions towards the use of technology for students with MLD. Teacher A, who had students with MLD in her classroom, but no direct support from a special educator during class time, shared how she utilized technology via the Carnegie Learning Algebra Curriculum. She noted the enhancement of student motivation and the ease in providing rigorous activities for students with MLD because of the availability of technology. Specifically, Teacher A emphasized that the software program guaranteed that all students, including those with MLD, were assigned higher level thinking assignments which she would have "dumb things down" for the students with MLD prior to using this specific technology-based curriculum in her classroom.

The use of peer assisted learning was discussed in all five interviews, even though the researcher only directly asked questions about peer assisted learning to three interviewees. All interviewees reported using it at least once a week. In describing the facilitation of this practice all participants used the words, "students in groups" or "students in pairs" to describe what it looked like in their classrooms. No interviewee shared what specific types of peer assisted learning they utilized, for what purpose, nor how or if the activities completed during this type of instruction were assessed.

Two interviewees reported using graphic organizers during typical instruction. Further, two teachers noted using cognitive strategy instruction via Odyssey (a computer program that 
offers tutorials and practice and enables differentiated instruction) and explicit instruction. One teacher alluded to how he and his co-teacher provide extra practice and one-on-one assistance to students with MLD through explicit instruction. Additional to the literature recommended practices, two teachers also noted that they tried to make everyday life connections to all concepts covered in their classes. Specifically Teacher E stated, "We are just trying to meet their needs and present the math in a way that they can apply it to their lives".

Even though the interviewees reported the use of some or all of the recommended practices for teaching Algebra I to students with MLD, there was no evidence that all practices were being implemented similarly in every classroom. Further, while some reported practices appeared to align with literature recommendations, such as Teacher E's use of graphic organizers, others did not appear to align, such as Teacher B's use of peer assisted learning that was not clearly structured and "tends to disintegrate into a social event". The classroom instructional practices described by the interviewees, including the use of explicit instruction, classwide peer tutoring, technology, graphic organizers and cognitive strategy instruction, indicates that statewide a varied Algebra I instructional environment existed for students with MLD.

Survey and interview results on CRA and manipulative use. Graduated Instructional Sequence/CRA is the only literature recommended instructional practice that did not vary in reported use by participants. Many studies strongly suggested the use of a concrete, representational, and then abstract (CRA) instructional sequence be included in all secondary mathematics courses for students with MLD (Gagnon \& Maccini, 2001; Maccini \& Gagnon, 2006; Steele, 2002; Steele \& Steele, 2003; Witzel, Riccomini \& Schneider, 2008; Witzel, Smith \& Brownell, 2001). The recommendation for CRA addresses the need of students with MLD to 
first experience the concrete representation of a concept before being able to understand the concept abstractly. Table 20 provides examples of survey and interview responses regarding the use of CRA/Graduated Instructional Sequence.

Table 20

Responses Regarding the use of CRA/Graduated Instructional Sequence When Teaching Algebra I to Students with MLD

Survey Responses Interview

Responses

"Manipulatives other than technology need to be made more available in pre-set bundles so that a array of concepts are being taught."

Participant 52

"I wish more money was available to purchase hands-on manipulatives." Participant 10
"I went to the Algebra Support Training in October, and they gave me a set of algebra tiles for one or two groups. I went back and was not too comfortable with these but went around my school asking if anyone had them in our math department. One teacher had them up on her shelf, covered with dust, so I got them, the algebra tiles, and by the time I got to them it was so far into the year I am hoping to use them next year. But this year I did not really get to use them at all." Teacher A

"Well usually it starts out pretty well with the few manipulative that I have used. It is kind of like a joke with my colleagues that I feel like I teach kindergarten instead of $8^{\text {th }}$ grade, because everything will start out great for like the first 5-10 minutes. Then after 10 minutes, whether the kids are working in groups or if they are using manipulatives it just disintegrates into this sort of mini chaos that is brought on by this overwhelming lack of maturity from the majority of the class." Teacher B

"We don't use the algebra blocks and things like that." Teacher C

"We use some manipulatives. I think they need more hands on and kinesthetic. Most kids with MLD are concrete, they need to see it, feel it, touch it, taste it-that kind of thing. So the more sensory they can use the better they can visualize the problem without becoming frustrated." Teacher D

"I have scrounged up about 4 sets of algebra blocks that I use." Teacher E

The majority of the interviewees did not report the use of manipulatives and CRA as regularly utilized instructional practices, even though the literature highly recommends both to be used regularly for students with MLD. Two survey responses to SIP question 27 and all interviewees addressed the use of manipulatives. The lack of availability and use of manipulatives, and a related lack of CRA instruction, was an emergent theme in the interviews. 
Lack of available manipulatives, lack of knowledge by the educator on how to use them to teach algebraic concepts, and students' behavior during the use of manipulatives were all noted as reasons why the interviewees did not use manipulatives during instruction on a regular basis. Three interviewees, when asked about manipulatives, directly mentioned "algebra tiles" or "algebra blocks" during their response. These are one type of research-recommended manipulative to use during Algebra I instruction for students with MLD, but there are also other types of manipulatives that can be used by teachers and students. Subsequently, when asked about their use of CRA, most interviewees starting talking about manipulatives, not implementation of all three steps to CRA. Teacher A is the only interviewee that directly addressed these three steps by stating:

They need that concrete, they need to be playing with it, feel it and understand what this means to be able to actually use it. Now let's put it in picture form, then number form. I did not realize that we needed to go through all these steps, but well if that is the way they learn then that is the way I need to do it.

\section{Perceived Issues Surrounding Algebra I Instruction of Students with MLD}

The fourth research question was: What are Algebra I educators' perceived issues surrounding the instruction of algebra to students with MLD? The primary data analyzed to identify the perceived issues surrounding Algebra I instruction of students with MLD came from SIP question 27 and the interview responses. Participants shared their perceptions related to issues involved in Algebra I instruction for students with MLD through the open-ended SIP question 27 that directly asked participants to identify their perceived issues. The following three themes emerged from interview and survey responses regarding perceived issues surrounding Algebra I instruction of students with MLD: (a) varied classroom instructional 
environments, (b) inclusive classroom instructional issues and (c) challenging student characteristics.

Varied classroom instructional environments. Three thematic coding categories from the survey addressed issues with the classroom instructional environment when teaching Algebra I to students with MLD: (a) class time, (b) class size, and (c) availability of manipulatives. Four reoccurring topics were discussed by interviewees in the responses coded under the thematic category of issues with educational placement: (a) class time, (b) class size, (c) Algebra Support framework, and (d) educational placement. These interview and survey responses directly influenced the emergence of the theme of varied Algebra I instructional environment for students with MLD. Table 21 provides examples of survey and interview responses regarding issues with the varied Algebra I classroom instructional environment for students with MLD. 
Table 21

Responses Regarding the Theme of Issues With the Varied Algebra I Classroom Instructional Environment for Students with MLD

Survey Responses

(Thematic Code(s) used to code the response)

"The two biggest challenges faced in the classroom I feel are time and monetary problems. I wish more time could be devoted to teaching students with MLD with fewer interruptions in the schedule. Also, I wish more money was available to purchase hands-on manipulative and more money to create smaller class sizes. With additional funding, more learning could take place."

Participant 10 (class time, availability of manipulatives)

"Math needs to be taught in 90 minute blocks"

Participant 58 (class time)

"Not enough time to work closely enough with the students. Not enough time for students to learn new techniques. Not enough time to put the techniques to use in the classroom." Participant 19 (class time)

"I think to effectively teach students with MLD-we need to have smaller class sizes for more one on one attention." Participant 25 (class size)
Interview Responses

(Thematic Code(s) used to code the response)
"If they [students with MLD] are not in a special education resource math class, I teach them [Algebra I/Algebra Support students, including those with MLD] double periods without a special educator in the room, where the rest of the math classes in my school are just one period. I think that more time is needed with them, two periods is a little long. I think just over an hour would be great." Teacher A (Educational Placement, Algebra Support Framework, and class time)

"In Algebra Support there is no [special education] co-teacher, but they[students with MLD] have a co-teacher in their actual Algebra I course. Some students with MLD have only Algebra I with a co-teacher and some have Algebra I with a co-teacher and Algebra Support. Last year I had it [Algebra I] back to back with Algebra Support and that set up was not very successful because I had 11 boys, 9 of which with behavior problems who were in my room for 100 minutes. It was a little too much, this year we broke it up so we have two separate groups in two separate Algebra classes. They [students with MLD] are together for Algebra Support, but it is later in the day. That [back to back classes] was too much for them. I know we have a lot of students in collaborative setting, but after working with them they need to be in a special education math class instead of collab like their $8^{\text {th }}$ grade case manager suggested." Teacher C (Algebra Support Framework, Educational Placement)

"I want smaller class sizes. Trying to manage 18 kids that have the attention span of a chipmunk is pretty much impossible. Second of all, I would like to have personally shorter class periods. I know my MLD students might think being stuck in my classroom for 90 minutes is awful. If I could, in a perfect world, I would like to break my class period up into two different sections. So I would only have them twice for only 35-40 minutes at a time." Teacher B (Class size, Class time, Algebra Support Framework)

"The first year they[students with MLD] have Algebra Support and Algebra for the whole year, instead of a semester math course like all other freshman. They earn a credit in support and a credit in Algebra. It is just really an algebra course spread out over the year." Teacher E (Algebra Support Framework)

The survey and interview responses both emphasized the issues of class size and class

length. Interviewees stressed the need for students with MLD to have 90 minutes of Algebra 
instruction. However, two interviewees expressed that back to back scheduling of students in Algebra I followed by Algebra Support for 90 minutes straight was too much for students to take at once. Teacher $\mathrm{C}$ shared how her school changed from back to back Algebra I and Algebra Support classes to two separate 45 minute courses taken at different times throughout the day. She reported that student success in these two courses improved after this change.

Participants' responses provide examples of how the Algebra Support framework differs from county to county and school to school across the state of West Virginia. Each interviewee shared different experiences in how their schools implement the Algebra Support framework and the teacher's role and expectations within that framework. Many factors such as the number of students with MLD and those in need of Algebra Support, staffing, and the county's adopted curriculum all appeared to influence the Algebra Support frameworks. Teacher C also noted frustration with the educational placement of ninth-grade students with MLD as required by their IEP's. For example, students with MLD were placed in an inclusive classroom without support instead of a co-taught or self-contained Algebra I class. She felt that many students were misplaced in Algebra I without Algebra Support or a special education co-teacher because there was a lack of communication between the middle school special education case manager and the classroom expectations of ninth-grade students in Algebra I.

Inclusive classroom instructional issues. The following seven thematic coding categories were used to conventionally content code the survey responses that identified the theme of inclusive classroom instructional issues: (a) planning time with co-teacher, (b) preparation of teachers, (c) special educator's role in the general education classroom, (d) Algebra CSOs, (e) curriculum mapping/speed of introducing new concepts, (f) instruction that does not address a variety of learning styles, and (g) assessment pressure. Similarly, three 
reoccurring topics were discussed by interviewees that were later categorized under the thematic coding categories of inclusive classroom instructional issues: (a) teacher preparation, (b) access to curriculum, and (c) educational placement. Specifically, the content of this coded dialogue addressed: (a) teacher preparation, (b) implementation of effective strategies to meet the learning needs of students with MLD, (c) assessment pressure, and (d) collaborative support from a special educator. Following a cross interview analysis of the interview responses exclusively coded under any of the three issues thematic category codes, the researcher determined that there existed issues from each thematic category code specific to the inclusive classroom. Further, topics identified through the survey responses were also able to be categorized under codes specific to the inclusive classroom. Table 22 provides examples of survey and interview responses regarding concerns with the inclusive Algebra I classroom for students with MLD. 
Table 22

Responses Regarding the Theme of Issues With the Inclusive Algebra I Classroom for Students with $M L D$

Survey Responses

(Thematic Code(s) used to code the response)

"Students need accountability on state assessments, or they give up and won't even try if it's hard. They get use to failing assessments; there are no consequences, so they don't care." Participant 25 (Assessment Pressure)

"The Algebra I instruction for students with MLD is not meeting the needs of the students. Finding qualified teachers to co-teach is very difficult. When the special education coteacher does not understand the concepts being taught in class it makes it very difficult for her/him to truly assist students with MLD. The students are receiving a watered down curriculum and then are struggling to pass additional math classes required by the state. In addition, regular ed students that happen to be placed in a co-taught class are not being taught at the high level required by WVDE to then be successful in non co-taught classes. In my county, the Algebra/Algebra Support model is not working for student with MLD and for students without. It is leading to very frustrated students, teachers, and parents." Participant 3 (Teacher Preparation, Special Education Teachers Role in the General Education Classroom, Algebra CSOs)

"General education teachers are not as prepared in how to address these issues and there is not enough time to plan with your co-teacher". Participant 5 (Lack of Planning Time with Co-Teacher, Teacher Preparation)

"The biggest problem at my school is that the special education teachers do the work for them[students with MLD]. I believe they do this because it is easier than helping them." Participant 31 (Special Education Teachers Role in the General Education Classroom)

"These students need a slower pace. It is hard when you are rushed to get everything taught that is needed. A two year class would benefit these students." Participant 36 (Curriculum Mapping/Speed of Introducing New Concepts)

"Too many kids and not enough time to focus on MLD. The rest of the class is held back and impatient when my instruction drags on to get MLD students up to speed." Participant 26 (Curriculum Mapping/Speed of Introducing New Concepts)

"When students are in the General Education classroom with
Interview Responses

(Thematic Code(s) used to code the response)

"And you know we base our approach on a lot of assessments that admittedly and quite frankly the kids do not take seriously, and as teachers we know the kids do not take them seriously. I asked my students over and over again, and you know I am in the classroom watching them give the assessments and they do not take it seriously, so we have to base our approach on this sort of worthless assessment. It does not tell the true story. I just feel that a lot gets lost in, is not seen, when strictly numbers are analyzed. You know when there is a test score at whenever level we kind of lose the story of what is going on behind that test score."

Teacher B (Educational Placement)

"I really liked it better when it was split apart into two years, as Applied math I and Applied math II[Course sequence prior to Algebra I/Algebra Support]. Because whether the students are in a special education class or a collaborative class this pace is very difficult for many of our students with MLD, even with having Algebra I and Algebra Support. It is so hard to keep up with the curriculum mapping. My students were so much more successful whenever it was split up into two years." Teacher C (Access to Curriculum, Educational Placement)

"You have to have, in learning for my certification, taking the courses, and learning about all the multiple intelligences-which make so much sense, you have to be able to present the material in as many different ways as you can because it allows you to treat each learner as an individual. Some teachers do not do this and it is a problem." Teacher E (Teacher Preparation)

"The only time I have to plan with my general education co-teacher is during lunch.” Teacher D (Educational Placement)

"But, classroom management in my inclusion classes is probably one of the biggest barriers, I have such big classes. A lot of these kids needs that one on one time, and I feel like I am running myself ragged trying to get around to help all of them. 
a co-teacher, there is limited opportunity to slow down for re-teaching principles due to pressure to cover all CSO's. Also with differing levels of proficiency, most students in General Education classroom are ready to move on." Participant 38 (Algebra CSOs, Curriculum Mapping/Speed of Introducing New Concepts)

"Some math teachers use on-size-fits-all instruction". Participant 32 (Instruction that does not Address a Variety of Learning Styles)
Cause, you know I can't just stand up there on my stage and teach and expect them to get it, I have to go around and help them." Teacher A (Educational Placement)

Many of the same coded topics, such as (a) teacher preparation, (b) assessment pressures, (c) the need for instruction that meets all learners needs, (d) speed of instruction, and (e) support of a special educator, are present in both the survey and interview responses regarding issues for students with MLD in the Algebra I classroom.

Furthermore, the collaborative model utilized statewide for Algebra I and Algebra Support (as described in Tables 21 and 22 by Participants 3, 5, 31, and 38, and Teachers A,B,C, D and E) varies from school to school and appears to cause many different issues for students with MLD and their teachers in an inclusive Algebra I classroom. The WVDE expects the Algebra I and Algebra Support framework to instruct students with MLD and others who struggle through two separate mathematics classes, Algebra I that is heterogeneously grouped and an Algebra Support class that provides further explicit instruction, time for classwide peer tutoring, and the use of CRA (Maynus, 2010).

Challenging student characteristics. The following are the thematic coding categories from the survey used to identify the theme of challenging student characteristics: (a) student motivation, (b) students' lack of ability to retain concepts and to apply concepts, and (c) student attention spans. Three reoccurring topics coded under access to curriculum from the interviews addressed student characteristics': (a) student motivation, (b) students' lack of pre-algebra skills, 
and (c) students' lack of literacy skills. Table 23 provides examples of survey and interview

responses regarding issues with challenging student characteristics, when teaching Algebra I to

students with MLD.

Table 23

Responses Regarding the Theme of Issues of Challenging Student Characteristics When Teaching Algebra I to Students with MLD

Survey Responses $\quad$ Interview Responses

(Thematic Code(s) used to code the response)

(Thematic Code(s) used to code the

response)

"My perception of issues related in Algebra I instruction with students with MLD is that most students can be taught if willing and open to work involved. That is the key-student motivation." Participant 8 (Student Motivation)

"Some students have the inability to understand the concepts of math...Many struggle and give up on school because they can't get one thing and that is math." Participant 51(Student Motivation, Student Lack of Concept Retention and Application)

"Students are not getting a good foundation in the elementary school to prepare them for this level." Participant 46 (Student Lack of Concept Retention and Application)

"So many students have slipped through the cracks. I have some students that cannot add, subtract, multiply, or divide."

Participant 39 (Student Lack of Concept Retention and Application)

"retention of concepts and ability to apply to "different" problems." Participant 40 (Student Lack of Concept Retention and Application)

"Students with disabilities have short attention spans and at my school they have back to back classes. This is a problem for MLD students to stay on task without becoming a behavior problem." Participant 47 (Attention Spans)
"We were taught, we are supposed to manufacture some short of caring attitude out of kids that don't care about anything in any part of their life let alone math or algebra. You know it is like we are trying to work miracles and make kids who don't care about anything in their life care about math, which typically they have done horribly on in their whole lives, so it is you know an uphill battle. A lot of them are right on the edge of not caring about anything..." Teacher B (Access to Curriculum)

"They are really not prepared on their prealgebra skills. We have to use a calculator and multiplication charts all the time. Their basic skills, whatever the event, beginning of the year in Algebra they can't work with integers. You know... basic basic." Teacher C (Access to Curriculum)

"Reading issues, because a lot of our kids read on a $3-4^{\text {th }}$ grade reading level so that hurts their comprehension of what the problem is asking them to do and the information that is provided. Any type of written information caused problems." Teacher D (Access to Curriculum)

Interviewees and survey participants identified student motivation as a factor that impacted students' work and class participation. Further, interview and survey responses indicated issues with students' with MLD lack of mathematical skills, literacy ability, and past failures. 


\section{Emergent Themes}

As previously described by the research question each theme addressed, the following are the six emergent themes regarding the current state of Algebra I instruction for students with MLD from West Virginia: (a) varied teacher preparation experiences through higher education, (b) varied teacher preparation experiences through professional development sessions, (c) varied classroom instructional environments, (d) inclusive classroom instruction issues, (e) limited use of CRA and manipulatives, and (f) challenging student characteristics. These themes are supported by open-ended survey responses to SIP question 27, interview responses, and a review of existing literature regarding Algebra I instruction for students with MLD.

\section{Triangulation of Data}

The researcher used both data and methodological triangulation during this study. Data triangulation occurred during the quantitative and qualitative analyses. For example, the researcher used data triangulation in the quantitative analyses when comparing and combining results from different statistical analyses to answer specific research questions. Further, data triangulation of the qualitative results occurred when the literature review themes were compared with the survey and interview response themes to identify the six emergent qualitative themes of the study. In addition, data and methodological triangulation occurred when the researcher compared the quantitative and qualitative data.

The results from the interviews converged with the quantitative survey data regarding the two main types of educational offerings for teachers about students with MLD. The majority of participants from both the survey and interview reported that they developed a knowledge base for teaching students with MLD through at least one college course on the teaching of mathematics and workshops focused on mathematics teaching. The results from these two 
populations, the survey participants and interviewees, diverged when comparing the percentage of participants who took four or more college courses that addressed students with MLD and the amount of professional development formats attended. Specifically, $24.6 \%$ of surveyed participants took four or more college courses that addressed students with MLD compared to the $40 \%$ of interviewees that reported taking four or more college courses that addressed students with MLD. Further, $70.2 \%$ of survey participants reported attending six or less hours of professional development and $12.3 \%$ reported attending 35 or more hours, compared to the $40 \%$ of interviewees who reported attending six or less hours of professional development and the $20 \%$ who reported attending 35 or more hours.

These divergences lead the researcher to compare the specific demographics of years teaching experience and teaching position of the interviewees to that of the surveyed participants. During this comparison, the researcher looked at the percentage of respondents that taught for the different number of year intervals or the percentage of respondents that were either a general or a special educator. The researcher made this comparison because a large difference existed between these two demographic characteristics of the survey participants as compared to the interviewees. Thus, the researcher found that some findings from the quantitative survey data converged with the qualitative interview data. Specifically, teachers with less teaching experience had more college courses that addressed students with MLD, and those with special education certification had more college courses that addressed students with MLD than those that did not have special education certification. Similar to the quantitative findings, the majority of interviewed special educators $(n=2)$ had more hours of professional development experience as compared to the interviewed general educators. 
The reported use of instructional strategies from the survey results and interview results converged and diverged. Specifically, the majority of survey participants reported using the following literature recommend practices at least once a week: (a) technology, (b) cognitive instructional strategies, (c) explicit instruction, (d) graphic organizers, and (e) peer assisted learning. In contrast, each of these recommended practices were discussed during the interviews but none of the interviewees reported using all five practices regularly. This finding diverges from the survey responses and indicates a varied state of Algebra I instruction for students with MLD. Data from both of these sources indicate that the use of manipulatives and CRA instruction is occurring much less than recommended by the literature. Further, the data from the survey regarding teacher's perceived preparedness converges with this CRA qualitative finding because participants indicated that they were not fully prepared to: (a) develop lessons that provide opportunities for students to actively construct their own mathematical knowledge (b) provide opportunities for students to use manipulatives to verify mathematical reasoning (c) lead a class of students using investigative strategies, and (d) use appropriate techniques for teaching students with MLD.

The quantitative survey results and qualitative interview results converged and diverged regarding the identification of perceived issues when teaching Algebra I to students with MLD. Assessment pressures and availability of in-service opportunities for mathematics teachers are the two biggest perceived issues identified by surveyed participants, as determined by mean responses on the survey; this converged with the interview data. The availability of in-service opportunities for teachers was the interviewees' most frequently noted issue mentioned by all five interviewees. Similarly, divergent results occurred during a comparison of results regarding the availability of appropriate curriculum materials. Four of the interviewees mentioned 
availability of appropriate curriculum materials such as manipulatives as an issue and the survey participants ranked it as the least severe issue. Other divergent results occurred during a comparison of issues regarding instruction of heterogeneously mixed classes. Three interviewees mentioned that they had issues teaching heterogeneously grouped classes while the survey results indicated that the majority of survey participants felt most prepared to teach heterogeneously grouped classes.

\section{Summary}

As expected by the researcher, educators articulated varied experiences and perceptions used to describe the current state of Algebra I instruction for students with MLD in West Virginia. However, the data collected through this study provided enough information to describe Algebra I educators' perceptions of preparation and practice for teaching Algebra I to students with MLD. The quantitative and qualitative data clearly addressed each of the four research questions.

Research question one addressed what types of opportunities Algebra I/Algebra Support educators from West Virginia had to develop knowledge for teaching students with MLD, and the data indicated that (a) participants' knowledge base for teaching Algebra I to students with MLD developed through professional development offerings and higher education courses; and (b) there was a significant difference in the number of college courses taken by special educators, and those certified and "highly qualified" in special education, as compared to those taken by mathematics educators, only certified in mathematics and "highly qualified" in mathematics.

The second research question addressed Algebra I/Algebra Support educators' perceptions regarding how beneficial their educational experiences and opportunities were in helping them develop a knowledge for teaching students with MLD. When asked about their 
preparedness to implement specific instructional practices for teaching Algebra I to students with MLD, the majority of participants felt most prepared to use eight instructional practices when teaching students with MLD (based on survey responses of well prepared and very well prepared). The following are the eight instructional practices: (a) listen and ask questions as students work in order to gauge student understanding, (b) cooperative learning groups, (c) model multiple problem-solving strategies and have students apply what they have learned, (d) consider students' prior understanding when planning curriculum and instruction, (e) variety of assessment strategies to measure students' success, (f) teach heterogeneously grouped classes, (g) teach classes containing students with different learning styles, and (h) encourage classroom participation of students with MLD. In contrast, participants reported not being fully prepared to: (a) develop lessons that provide opportunities for students to actively construct their own mathematical knowledge (b) provide opportunities for students to use manipulatives to verify mathematical reasoning (c) lead a class of students using investigative strategies, and (d) use appropriate techniques for teaching students with MLD. Further, participants' teacher preparation experiences through higher education and professional development sessions varied greatly.

Research question three aimed to identify Algebra I/Algebra Support educators’ instructional practices for students with MLD and the alignment of these practices with the recommended best practices to utilize for students with MLD. Participants reported the using the following literature recommended practices and accommodations daily for teaching Algebra I to students with MLD: (a) demonstrating/modeling, (b) visual and graphic depictions, (c) peerassisted learning, (d) calculator problem solving, (e) review of skills and procedures with step by step prompts, and (f) whole class discussion. A positive correlation between the amount of 
collaborative time and the use of two practices, manipulatives and whole class-discussions, that indicated as the amount of collaborative time increased the facilitation of these practices also increased. Further, the results identified that varied classroom instructional environments existed statewide with limited use of the recommend practices of CRA and manipulatives.

Research question four identified West Virginia's Algebra I/Algebra Support educators' perceived issues with regard to the instruction of algebra to students with MLD. The quantitative data indicated assessment pressures and availability of in-service opportunities for mathematics teachers as the two biggest perceived issues by surveyed participants. Additionally the qualitative data indicated issues with (a) inclusive classroom instruction and (f) challenging student characteristics. Furthermore, the researcher used triangulation of the qualitative analyses results to compare data from different data sources, analyzed differently, to identify the six emergent qualitative themes of (a) varied teacher preparation experiences through higher education, (b) varied teacher preparation experiences through professional development sessions, (c) varied classroom instructional environments, (d) inclusive classroom instruction issues, (e) limited use of CRA and manipulatives, and (f) challenging student characteristics. 


\section{CHAPTER 5: DISCUSSION}

This study examined educators' perceptions of preparation and practice for teaching Algebra I to students with MLD in West Virginia. The purpose of this chapter is to discuss the results of this study, guided by the following research questions:

1. What opportunities have Algebra I/Algebra Support educators from West Virginia had to develop knowledge for teaching students with MLD?

2. What are West Virginia's Algebra I/Algebra Support educators' perceptions regarding how beneficial their educational experiences and opportunities were in helping them develop a knowledge for teaching students with MLD?

3. How do West Virginia's Algebra I/Algebra Support educators' instructional practices for students with MLD align with the recommended best practices to utilize for students with MLD?

a. How do teachers' characteristics (gender, experience, etc.) influence their alignment of their instructional practices with best practices?

4. What are West Virginia's Algebra I/Algebra Support educators' perceived issues with regard to the instruction of algebra to students with MLD?

From the onset of this project, the researcher intended to describe educators' perceptions of preparation and practice for teaching Algebra I to students with mathematical learning disabilities (MLD) in West Virginia and teachers' preparation for this practice. Further, the researcher examined the extent teachers' instructional practices for teaching students with MLD Algebra I aligned with best practices recommended in the research literature. 
Given the research questions and the results of the quantitative and qualitative data analyses, the researcher identified five major conclusions regarding the current state of Algebra I instruction for students with MLD in West Virginia and teachers' preparation for this practice.

Conclusion 1: Educational and professional development opportunities to prepare teachers to teach Algebra I to students with MLD differed in quantity, content, and form. These differences were related to teacher characteristics such as certification, "highly qualified" status, and years teaching experience.

Conclusion 2: Based on the number of college/university courses completed and their perceptions of professional development experiences that addressed mathematics instruction for students with MLD, educators felt most prepared to do the following when teaching Algebra I to students with MLD: (a) listen and ask questions as students work in order to gauge student understanding, (b) cooperative learning groups, (c) model multiple problem-solving strategies and have students apply what they have learned, (d) consider students' prior understanding when planning curriculum and instruction, (e) variety of assessment strategies to measure students' success, (f) teach heterogeneously grouped classes, (g) teach classes containing students with different learning styles, and (h) encourage classroom participation of students with MLD.

Conclusion 3: Educators reported using five research-recommended practices for Algebra I instruction to students with MLD during typical classroom instruction: (a) the use of technology, (b) cognitive instructional strategies, (c) explicit instruction, (d) graphic organizers, and (e) peer assisted learning. The frequent use of lecture with student note-taking during instruction, as reported by educators, indicates that explicit instruction maybe the primary instructional practice used to teach Algebra I concepts to students with MLD. 
Conclusion 4: Educators reported not using manipulatives or CRA as part of their typical Algebra I instruction for students with MLD and do not feel fully prepared to use the key instructional practices of CRA such as (a) develop lessons that provide opportunities for students to actively construct their own mathematical knowledge, (b) provide opportunities for students to use manipulatives to verify mathematical reasoning, and (c) lead a class of students using investigative strategies. However, there is a positive correlation between the amount of collaborative time among general and special educators and educators' reported use of CRA and whole class discussions.

Conclusion 5: The Algebra Support instructional framework for students with MLD varies statewide, which indicates not all counties follow the WVDE recommendations for this course. Regardless of instructional framework used for Algebra Support, educators indicated three major issues including (a) classroom instructional environment issues (e.g class length, class size, etc.), (b) inclusive classroom instruction issues (e.g. curriculum mapping/speed of instruction, support of a special educator, etc.) and (c) challenging student characteristics (e.g. lack of pre-requisite skills, student motivation, etc).

This chapter contains two main sections, (a) descriptions of the major conclusions regarding the current state of Algebra I instruction for students with MLD and teachers' preparation for practice and (b) implications. The first section presents and explains each conclusion in detail, by synthesizing statistical analyses relevant to each conclusion and discussing how the conclusion addresses the research questions. The concluding section discusses the implications for educational practice, future professional developments, and future research. 


\section{Current State of Algebra I Instruction for Students with MLD and Teachers' Preparation}

Based on analysis of the survey and interview responses, the researcher described the current state of Algebra I instruction for students with MLD by the following attributes of Algebra I and Algebra Support teachers: (a) their varied educational and professional development opportunities addressing Algebra I instruction for students with MLD, (b) their perceptions regarding if their educational and professional development experiences' prepared them to teach Algebra I to students with MLD, (c) the alignment of their reported instructional practices to literature recommend practices for teaching Algebra I to students with MLD, (d) what factors affected their use of literature recommended practices, and (e) their perceived issues regarding the instruction of Algebra I to students with MLD, within their school's Algebra Support instructional framework.

\section{Varied State of Educational and Professional Development Opportunities Addressing}

\section{Algebra I Instruction for Students with MLD}

Based on the survey data collected through SIP questions 20-22, responses to SIP question 27, and the interview responses this study identified interesting findings regarding educators' educational and professional development opportunities addressing Algebra I instruction for students with MLD. The only commonality reported among all participants involved educational and professional development opportunities: taking at least one college course that addressed students with MLD or attending one professional development session focused on teaching mathematics and students with MLD.

College courses. As expected by the researcher, a significant difference exists between educators with special education certification and educators with secondary mathematics certification regarding the number of classes taken that address students with MLD. Educators 
with special education certification were more likely to have taken more classes addressing students with MLD than secondary mathematics certified teachers. Similarly, the relationship between "highly qualified" mathematics status and the number of courses taken that addressed students with MLD was significant. Data indicated that teachers who were "highly qualified" in mathematics took fewer courses that addressed students with MLD as compared to those who were not "highly qualified" in mathematics, or "highly qualified" in special education. Furthermore, survey and interview responses indicated that special educators are not as well versed in mathematics as general mathematics educators. Specifically, Teacher D reported taking no mathematics classes during her teacher certification program and Teacher E stated,

The math teacher is there to teach them [the students with MLD] what they need to know and I am there to help them on how they learn. You know, they [general education teachers] teach them what to learn and I teach them how to learn.

These results are similar to findings by Maccini and Gagnon (2006) who found that general mathematics educators have more formal coursework in mathematics and special educators have more formal course work on how to teach mathematics to students with MLD. Given Teacher E's perceived role in his inclusive classroom and the differences in educational experiences of special and general educators, it appears that in West Virginia general educators perceive that it is their responsibility to teach the content and the special educators' responsibility to make accommodations and modifications for students.

Additionally, a negative correlation existed between educators' years teaching experience and the number of classes completed regarding students with MLD. As the years teaching experience of teachers increased the number of college courses taken decreased. These findings could possibly indicate that in recent years, in response to IDEA (2004) and NCLB (2001) teacher preparation programs developed new course requirements of at least one course that 
addresses students with MLD. As described by Teacher A and Teacher B during their interviews, the content of their courses that addressed students with MLD differed greatly. Teacher A's courses focused on classroom interventions and practices, more so at the elementary level than secondary, for students with MLD, and Teacher B's courses focused on student diagnosis and special education law. It appears some teacher preparation programs completed by certified secondary mathematics education teachers in West Virginia address students with MLD. However, the content of these programs regarding students with MLD greatly varies.

Professional development. The majority of participants reported attendance at one workshop on mathematics teaching that addressed students with MLD. Many of the surveyed participants volunteered to be part of this study during the WVDE Algebra Support Conference by providing their email address to the researcher, so it is probable that the workshop on mathematics teaching reported by participants is the Algebra Support Conference. Additionally, the majority $(n=4)$ of all interviewees attended the WVDE Algebra Support Conference, the first statewide WVDE sponsored professional development regarding mathematics instruction for struggling students and students with MLD, where educators learned about a variety of research based instructional practices for teaching Algebra I to students with MLD. The next three highest reported professional development session formats were observation of other teachers teaching mathematics, study group of teachers (Professional Learning Community) on mathematics teaching issues, and attendance at national or state mathematics teacher association meetings. Further, $70.2 \%$ of participants completed six hours or less of professional development regarding students with MLD. This statistic indicates a need for more professional development opportunities that focus on teaching students with MLD. On the 2000 National Survey of Science and Mathematics Education 55\% of all surveyed mathematics teachers 
identified a need for more professional development on teaching students with MLD (Maccini \& Gagnon, 2006). Similarly, survey and interview participants indicated a perceived need for more mathematical co-teaching professional development. This indicates that the professional development opportunities in West Virginia are not typically addressing mathematics coteaching at the secondary level, specifically in Algebra I. Thus, West Virginia educators follow the national trend of a perceived need for more professional development on teaching students with MLD.

\section{Perceptions Regarding Professional Development and Educational Experiences in Regards to Preparedness to Implement Specific Instructional Practices}

The researcher identified participant's perceptions regarding educational and professional development experiences through the survey data collected by SIP question 23, responses to SIP question 27, and the interview responses. Based on professional development experiences, Algebra I and Algebra Support educators felt most prepared to do the following when teaching Algebra I content to students with MLD: (a) listen and ask questions as students work in order to gauge student understanding, (b) cooperative learning groups, (c) model multiple problemsolving strategies and have students apply what they have learned, (d) consider students' prior understanding when planning curriculum and instruction, (e) variety of assessment strategies to measure students' success, (f) teach heterogeneously grouped classes, (g) teach classes containing students with different learning styles, and (h) encourage classroom participation of students with MLD. A positive correlation existed between the number of college/university courses completed regarding mathematics instruction for students with MLD and educators' perceived preparedness to facilitate these instructional practices. 
One explanation for the correlation between these two variables may be that educators who completed more college/university courses regarding mathematics instruction for students with MLD may have been exposed to many of these practices during their college/university courses. For example, many teachers reported having no exposure to CRA or manipulative use so they did not use either as part of their typical instruction. Further, these educators may have a strong mathematical content knowledge and understanding of pedagogical strategies for teaching mathematics based on the number of completed courses. This pedagogical knowledge may influence educators to be more receptive to implementing newly learned instructional practices. According to the National Research Council (2001) in Adding it Up, strong mathematical content knowledge is linked to how educators teach.

\section{The influence of instruction in pedagogical strategies to strengthen the mathematics}

learning of students. Two interviewees with the same secondary mathematics certification shared very different perceptions of their experiences in college courses that addressed students with MLD‘ and different perceptions of the same professional development offering. Teacher A shared that she learned about technology to use for students with MLD and manipulatives for elementary mathematics instruction through her higher education courses, while Teacher B shared that he learned about laws, student characteristics, and policies. Even though they both had different experiences and course structures, they both felt that their teacher preparation program did not prepare them to teach Algebra I to students with MLD.

Following Teacher A's exposure to manipulative use at the WVDE Algebra Support Conference, Teacher A and shared a need for more manipulative exposure through college courses. Specifically Teacher A's stated, "I wish that there were more manipulatives used in college classes. You know if I would have been more familiar with them, I would have used 
them from day one". This teacher had some exposure to manipulatives during her higher education courses and following the Algebra Support Conference, she planned to use manipulatives during her Algebra I instruction for students with MLD. In contrast, Teacher B who had no prior exposure to manipulatives through his higher education courses was not receptive to using manipulatives with his students following the Algebra Support Conference. The difference in the participants' willingness to facilitate a different instructional strategy may be related to their experiences in and the structure and content of the course(s) during their previous higher education teacher preparation program. Educators tend to teach in the manner in which they were previously taught, and for many current Algebra I teachers that manner was very traditional. However, when educators' opportunities to learn about mathematics teaching, through their pre-service programs, help them develop their own knowledge about mathematics and students' thinking about mathematics they are able to a develop a knowledge base for providing instruction that facilitates conceptual understanding for all students (National Research Council, 2001). It appears that Teacher A received some of this type of instruction through her teacher preparation program. Even though this instruction was not focused on secondary mathematics, when she participated in professional development similar to what she learned during her pre-service program but on a secondary mathematics level she was more receptive to using manipulatives as compared to Teacher B who did not receive this type of pre-service instruction.

\section{Reported Instructional Practices Alignment to Recommended Practices}

The researcher identified participants' reported instructional practices and the alignment of these practices to the literature recommended best practices to use for students with MLD through both qualitative and quantitative methods. Through SIP question 24 and interview 
responses educators reported using five research recommended practices for Algebra I instruction to students with MLD during typical classroom instruction: (a) the use of technology, (b) cognitive instructional strategies, (c) explicit instruction, (d) graphic organizers, and (e) peer assisted learning. The frequent use of lecture with student note-taking during instruction, as reported by educators, indicates that explicit instruction maybe the primary instructional practice used to teach Algebra I concepts to students with MLD.

To successfully provide explicit instruction teachers must do more than lecture. Teachers must "tap into prior knowledge, model how to solve problems while thinking aloud, and prompt students when they need assistance in the activity" (Witzel, Smith, \& Brownell, 2001, p. 103). This can be difficult for teachers to do while also teaching the conceptual understanding of mathematics before the abstract, which is recommended for all students but specifically those with MLD, so mathematics does not become a set of memorized meaningless algorithms. CRA instruction provides hands-on experiences that allow students to understand how numerical operations operate on a concrete level, so abstract understanding can develop and make mathematics more accessible to all students (Maccini \& Gagnon, 2000; Witzel et al., 2001). The majority of participants reported using CRA and manipulatives these on a monthly basis or less.

\section{Perceptions regarding professional development experiences and the use of CRA.}

Quantitative and qualitative data indicate that the use of manipulatives and CRA instruction is occurring much less than recommended by the literature. Further, the data from the survey regarding teachers perceived preparedness converges with this CRA qualitative finding because participants indicated that they were not fully prepared to: (a) develop lessons that provide opportunities for students to actively construct their own mathematical knowledge (b) provide 
opportunities for students to use manipulatives to verify mathematical reasoning (c) lead a class of students using investigative strategies, and (d) use appropriate techniques for teaching students with MLD. However, there is a positive correlation between the amount of collaborative time among general and special educators reported use of CRA and whole class discussions. This positive correlation indicate as the amount of collaborative time decreased, the use of the specific practices also decreased, and as the amount of collaborative time increased the use of the specific practices also increased. This finding is similar to findings by Maccini and Gagnon (2006) regarding special educators' implementation of recommended instructional practices. Special educators are more likely to facilitate literature recommend mathematics instruction for students with MLD as compared to general educators.

It is worth emphasizing that manipulative use is not the same as CRA; it is a component of CRA. The use of manipulatives without instruction that facilitates conceptual understanding of mathematical concepts is not productive for students, especially those with MLD (Strickland \& Maccini, 2010). Possible explanations of why educators do not utilize CRA could be that they lack pedagogical knowledge of CRA or they lack a conceptual understanding of some abstract mathematical content. Many teachers teach in the manner they were taught (National Research Council, 2001), so if educators were not instructed using CRA or with instruction that did not promote conceptual understanding then CRA instruction may be difficult for them to facilitate.

\section{Perceived Issues Regarding the Instruction of Algebra I to Students with MLD}

The primary data analyzed to identify participants perceived issues regarding the instruction of Algebra I to students with MLD came from SIP questions 25, 26, 27, and the interview data. The Algebra Support instructional framework for students with MLD varies statewide, which indicates not all counties follow the WVDE recommendations for this course. 
Regardless of instructional framework used for Algebra Support, educators indicated three major issues including (a) classroom instructional environment issues (e.g. class length, class size, etc.), (b) inclusive classroom instruction issues (e.g. curriculum mapping/speed of instruction, support of a special educator, teacher preparation, etc.) and (c) challenging student characteristics (e.g. lack of pre-requisite skills, student motivation, etc). These findings are similar to other research (DeSimone \& Parmar, 2006; Lusk, Thompson \& Daane, 2008; Maccini \& Gagnon, 2006) because educators reported a perceived lack of preparation to teach students with MLD, not enough time to plan for students with MLD, and not enough time to meet all the school district's curriculum goals.

\section{Limitations of the Study}

Two important limitations existed within this study. First, the small sample size and low response rate influence the generalizability of the findings. Not having a central email list with all the names and email address of the 284 Algebra and Algebra Support teachers caused

difficulty when trying to contact the desired population. Further, the number of special educators who participated in this study was much fewer than the number of general educators. The response rate remained low despite reminder emails from the researcher and an extension of the survey completion deadline date. Second, the data only reflects teacher perceptions and not necessarily actual practice, because the researcher did not conduct observations.

\section{Implications}

After reviewing the findings of this study and current research in the field, the researcher identified implications from this study for (a) future research, (b) teacher preparation programs, and (c) professional development offerings. 


\section{Implications for Research}

This study differed from past studies because it specifically addressed general and special education teachers' perceptions of teaching Algebra I to students with MLD and their preparation for this practice. Further, it was conducted in West Virginia, a rural state, where no other similar studies have been conducted. This study makes an important contribution to the research on secondary teachers' perceptions regarding mathematics instruction to students with MLD by emphasizing teachers' perceptions and preparation specifically regarding Algebra I instruction for students with MLD through a mixed methods study design. The study design and Algebra I specification are significant because the majority of similar studies employed a quantitative study design, surveying secondary mathematics teachers of students with MLD.

Future research on this topic needs to include a larger sample size with a greater population of special educator participants. Specific to the methodological design employed by this study, surveys for future studies should include a greater variety of demographic questions, specifically ones that collect ratio and interval data so a variety of analyses are available for the

researcher. Further, case studies of specific teachers could provide greater insight to the types of instruction provided in an Algebra I classroom for students with MLD, what factors influenced their instruction, and the alignment of instructional practices to the recommended instruction by the state education association (SEA).

When describing teacher preparation, this study found that Algebra I educators reported varied experiences in their college courses that addressed students with MLD. Thus, future research should examine specific types of higher education courses (e.g. mathematical methods courses, or pre-service teacher mathematical content courses) to identify how general and special educators are introduced to characteristics and instructional needs of students with MLD. 
Further, future research should examine the relationship between types of pre-service methods courses and instructional practices implemented by educators for Algebra I instruction of students with MLD.

An aspect of the varied state of Algebra I instruction for students with MLD in West Virginia was the types of collaborative mathematical service provided by special educators. Two types of collaborative models (co-teaching and consultation) are used to serve students with MLD in inclusive Algebra I classrooms in West Virginia. Additionally, a positive correlation existed between the amount of collaborative time available to general and special educators and implemented practices for students with MLD, in an inclusive Algebra I classroom. This indicates a need for future research regarding the variations of collaborative models employed for Algebra I instruction of students with MLD and the models' relationship with the types of implemented instruction.

\section{Implications for Teacher Preparation}

This study supports the idea that a need exists for the restructuring of teacher preparation programs in regards to the preparation of pre-service teachers for teaching Algebra I content to students with MLD. Specifically the changes should address general educators' pedagogical preparation for the instruction of Algebra I content to students with MLD and special educators' mathematical content knowledge development.

The number of college courses taken by special educators that addressed students with MLD greatly outnumbered those taken by general educators. The researcher expected this finding, however, only approximately half of the surveyed educators reported daily collaboration between a special educator and general educator. This suggests that some general educators are planning and providing instruction for students with MLD without a strong knowledge base 
regarding characteristics of and recommended practices for students with MLD. General educators who reported taking a course that addressed students with MLD shared varied experiences from their courses. One participant shared that his class focused on policy, law, and student characteristics. While another participant shared that her class focused on the use of manipulatives, at the elementary level but not at the secondary level, and technology for students with MLD. A notable observation about this participant was that even though her exposure was to elementary grades use of manipulatives during her pre-service program she was more receptive to using manipulatives and CRA with her Algebra I students with MLD than the other participant who only reported learning about policy, law and characteristics of students with MLD during his pre-service program. This possibly suggests that exposure to manipulative use during preservice programs may influence the willingness to use manipulatives during instruction for students with MLD.

Further, concern about special educators' mathematical content knowledge by general educators suggests changes need to occur to special education teacher preparation programs to provide more opportunities for mathematical content knowledge development. An interview participant validated this concern by stating that she lacked the mathematical content knowledge to teach Algebra I, but when she was unsure about a concept her general education co-teacher taught her the concept before presenting it to the class.

One of teachers' main classroom responsibilities is to identify how each student in their classroom learns, and teach in a manner that reaches all students. This requires knowledge of instructional practices focused on students learning styles and content knowledge. This suggests that Algebra I and Algebra Support, general and special educators, need courses that address 
characteristics of students with MLD, pedagogical practices recommended for students with MLD, and Algebra I content knowledge.

One approach to restructuring teacher preparation programs in regards to the preparation of pre-service teachers for teaching Algebra I content to students with MLD, would be to integrate more mathematical content and pedagogy into required methods courses. These classes could be co-taught by both a faculty member of a special education department and a mathematics faculty member, or curriculum and instruction faculty member with a specialization in mathematics. Both special education and secondary mathematics education pre-service teachers could be required to complete this co-taught mathematics course. In addition, more dual certification or major programs for mathematics and special education could be offered. This would facilitate more educators who are extensively educated in mathematics content and pedagogical practices that benefit all students. Further, dual certification allows individuals to more efficiently earn both a mathematics and special education degree before becoming an inservice teacher. These suggestions align with the educators needs identified through this study and a study by Maccini and Gagnon (2006) that suggested special educators need more exposure to secondary mathematics content, and secondary mathematics educators need more training in instructional strategies for students with MLD.

\section{Implications for Professional Development}

Through this study, Algebra I and Algebra Support teachers expressed a need for mathematical co-teaching professional development offerings for secondary educators, and reported infrequent use of manipulatives during Algebra I instruction for students with MLD. The use of manipulatives when teaching Algebra I concepts to students with MLD is highly recommended by the literature (Strickland \& Maccini, 2010). Many participants associated the 
use of manipulatives with the CRA instructional strategy, which is also highly recommended by the literature to use for with MLD in an Algebra I class (Strickland \& Maccini, 2010; Witzel, 2005). The minimal use of manipulatives and CRA during Algebra I and Algebra Support instruction reported by the participants supports the need for further professional development focused on the use of manipulatives in a co-taught Algebra I class. The Algebra I and Algebra Support educators who attended the WVDE Algebra Support Conference in October 2010 indicated exposure to multiple classroom resources and practices to use for students with MLD, including manipulatives and CRA but not co-teaching. Further, the positive correlation between the amount of collaborative time with a special educator and the reported use of manipulatives during Algebra I instruction for students with MLD warrants a need for more collaborative time between general and special educators as well as training on what to do during this collaborative time. Thus, a professional development session that addresses co-teaching for students with MLD in Algebra I, or more broadly secondary mathematics, is needed and would be the first of its kind offered statewide by the WVDE.

\section{Conclusions}

The results from this study described the varied state of Algebra I educators' perceptions on instruction for students with MLD and preparation for teaching Algebra I to students with MLD in West Virginia. Algebra I and Algebra Support educators reported the use of five literature recommended practices for Algebra I instruction to students with MLD during typical classroom instruction: (a) the use of technology, (b) cognitive instructional strategies, (c) explicit instruction, (d) graphic organizers, and (e) peer assisted learning. However, Algebra I and Algebra Support educators reported not using manipulatives or CRA as part of their typical classroom instruction, which are two highly suggested practices by the literature to use for 
students with MLD (Strickland \& Maccini, 2010). Further, Algebra I and Algebra Support educators reported the use of lecture with student note-taking as part of typical classroom instruction, either daily or weekly. This practice is a component of explicit instruction, but the literature recommends that it not be the primary mode of mathematics instruction for students with MLD (Gersten et al., 2009). Based on these results, the researcher's general conclusion is that the current state of Algebra I instruction for students with MLD varies greatly statewide, as does, teachers educational and professional development experiences and provided collaborative time between special and general educators.

The most important finding that emerged from this study is the lack of manipulative use and CRA instruction by Algebra I educators. Further, the correlation between manipulative use and the amount of collaborative time with a special educator, combined with the correlation between educators professional development experiences and preparedness to encourage classroom participation of students with MLD, provides a foundation for the WVDE's, and other SEA's, creation of future professional development sessions and instructional recommendations regarding Algebra I instruction for students with MLD. Similarly, Maccini and Gagnon (2006) examined nationwide, secondary mathematics general and special educators use of instructional practices and preparation for this practice and found that special educators were more likely to use concrete objects, manipulatives, during problem-solving than general educators. DeSimone and Parmar (2006) investigated the significance of co-teaching, that including co-planning, for middle school mathematics teachers, special and general educators. They found co-planning a necessity for both general and special mathematics educators because "colleagues are the most important source of support and information regarding effective inclusive practices" (DeSimone 
\& Parmar, p.109, 2006). These studies support, the correlation found in this study, between the amount of collaborative time and the use of manipulatives.

The significance of this research is that it brings to light the question: Is the Algebra I content intended by the WVDE, as outlined through WVDE policies 2510 and 2520, provided for students with MLD given this varied state of instruction and limited use of CRA? Further, the factors of educational opportunities, professional development experiences, teaching certification and amount of collaborative time between general and special educators, identified through this study, that possibly influence this varied state of instruction can now be further investigated in future research. This study supports NCTM's aim, described in the Equity Principle, to ensure that students are treated as individuals, with different needs, yet still have access to the same challenging curriculum. The Equity Principle concludes by emphasizing that all students can learn when offered access to high-quality mathematics instruction. Such instruction should be the norm instead of the exception (NCTM, 2000). To help make highquality mathematics instruction that includes the frequent use of literature recommended practices the norm, future research should continue to explore the state of Algebra I instruction for students with MLD and educators' preparation to teach Algebra I concepts to students with MLD. 


\section{REFERENCES}

Allensworth, E., Nomi, T., Montgomery, N., \& Lee, V. (2009). College preparatory curriculum for all: Academic consequences of requiring algebra and english I for ninth graders in Chicago. Educational Evaluation \& Policy Analysis, 31(4), 367-391. doi:10.3102/0162373709343471.

Allsopp, D. Lovin, L. Green, G., \& Savage-Davis, E. (2003). Why students with special needs have difficulty learning mathematics and what teachers can do to help. Mathematics Teaching in the Middle School, 8(6), 6-16.

Allsopp, D., Kyger, M., Lovin, L., Gerretson, H., Carson, K., \& Ray, S. (2008). Mathematics dynamic assessment: Informal assessment that responds to the needs of struggling learners in mathematics. TEACHING Exceptional Children, 40(3), 6-16. Retrieved from ERIC database.

American Diploma Project Network (2009). Closing the expectations gap: Fourth annual 50state progress report on the alignment of high school policies with the demands of college and careers. New York: Achieve Inc.

Baker, S., Gersten, R., \& Lee, D. (2002). A synthesis of empirical research on teaching mathematics to low- achieving students. Elementary School Journal, 103(1), 51-73. Retrieved from EBSCOhost.

Bottge, B.A., Rueda, E., LaRoque, P.T., Serlin, R.C., \& Kwon, J. (2007). Integrating reformoriented math instruction in special education settings. Learning Disabilities Research \& Practice, 22, 96-109. Retrieved from EBSCOhost. 
Bottge, B.A., Rueda, E., Serlin, R.C., Hung, Y., \& Kwon, J.M. (2007). Shrinking achievement differences with anchored math problems: Challenges and possiblities. Journal of Special Education, 41,31-49.

Brodesky, A.R., \& Gross, F.E. (2009, April). Strategies for Making Middle School Mathematics More Accessible to Students with Learning Disabilities. Presented at the annual meeting of the National Teachers of Mathematics Association, Washington D.C.

Brodesky, A., Gross, F., McTigue, A., \& Tierney, C. (2004). Planning strategies for students with special needs: A professional development activity. Teaching Children Mathematics, 11(3), 146-154. Retrieved from Education Research Complete database.

Burns, M. (2010). Snapshots of student misunderstandings. Educational Leadership, 67(5), 1822. Retrieved from Academic Search Complete database.

Chazan, D.(2008). The shifting landscape of school algebra in the United States. In C.E. Greenes \& R. Rubenstein (Eds.), Algebra and algebraic thinking in school mathematics: Seventieth yearbook (pp. 19-33). Reston, VA: The National Council of Teachers of Mathematics, Inc.

Clark, V., \& Creswell, J. (2007). The mixed methods reader. Los Angeles, California: Sage Publications.

Common Core State Standards Initiative. (2011). About the Standards. Retrieved October 1, 2011, from Common Core State Standards Initiative: http://www.corestandards.org/

DeRidder, C. M. (2007). Standards and curriculum: A view from the nation: A joint report by the national council of teachers of mathematics (NCTM) and the association of state supervisors of mathematics (ASSM). Mathematics Teaching in the Middle School, 12(7), 414. Retrieved from EBSCOhost. 
DeSimone, J., \& Parmar, R. (2006). Middle school mathematics teachers' beliefs about inclusion of students with learning disabilities. Learning Disabilities Research \& Practice (Blackwell Publishing Limited), 21(2), 98-110. doi:10.1111/j.1540-5826.2006.00210.x.

Diversity in Mathematics Education Center for Learning and Teaching (2007). Culture, race, power, and mathematics education. In F. Lester Jr. (Ed.), Second handbook of research on mathematics teaching and learning (pp. 405-433). Charlotte, NC: Information Age Publishing.

Duffy, H. (2007). Meeting the needs of significantly struggling learners in high school: A look at approaches to tiered intervention. National High School Center, Retrieved from Academic Search Complete database.

Eckes, S., \& Swando, J. (2009). Special education subgroups under NCLB: Issues to consider. Teachers College Record, 111(11), 2479-2504. Retrieved from Education Research Complete database.

Education Commission of the States. Projects and Centers: No Child Left Behind. (2005). Retrieved June 20, 2010, from http://nclb2.ecs.org/NCLBSURVEY/nclb.aspx?Target=NG

Ellis, M.W. (2009). Moving from deficiencies to possibilities: Some thoughts on differentiation in the mathematics classroom. In C. Malloy (Ed.), Mathematics for every student: Responding to Diversity (pp. 97-102). Reston, VA: National Council of Teachers of Mathematics.

Fennell, F. (2006). Curriculum Focal Points:What's the Point?. NCTM News Bulletin, Retrieved from http://www.nctm.org/uploadedFiles/About_NCTM/President/2006_10pres.pdf 
Fennell, F. (2008). What algebra? When?. NCTM News Bulletin, Retrieved from http://www.nctm.org/uploadedFiles/About_NCTM/President/Presiden'ts\%20Message_Ja n-Feb\%2008\%20NB.pdf

Ferrini-Mundy, J., \& Floden, R.E. (2007). Educational policy research and mathematics education. In F. Lester Jr. (Ed.), Second handbook of research on mathematics teaching and learning (pp. 1247-1279). Charlotte, NC: Information Age Publishing.

Foegen, A. (2008).Algebra progress monitoring and interventions for students with learning disabilities. Learning Disability Quarterly, 31(2), 65-78. doi:10.2307/20528818

Franke, M.L., Kazemi, E. \& Battey, D. (2007). Mathematics teaching and classroom practice. In F. Lester Jr. (Ed.), Second handbook of research on mathematics teaching and learning (pp. 225-256). Charlotte, NC: Information Age Publishing.

Fuchs, D. \& Fuchs, L.S. (2005) Responsiveness-To-Intervention: A blueprint for practitioners, policymakers, and parents. Teaching Exceptional Children , 38 (1), 57-61. Retrieved from: http://www.advocacyinstitute.org/resources/TEC_RtIblueprint.pdf

Fuchs, L., \& Fuchs, D. (1997). Enhancing students' helping behavior during peer-mediated instruction with conceptual.. Elementary School Journal, 97(3), 223. Retrieved from Academic Search Complete database.

Gagnon, J., \& Maccini, P. (2001). Preparing students with disabilities for algebra. Teaching Exceptional Children, 34(1), 8. Retrieved from Academic Search Complete database.

Gay, L., Mills, G., \& Airasian, P. (2009). Educational research: Competencies for analysis and applications. $\left(9^{\text {th }}\right.$ ed). Columbus, Ohio: Pearson.

Gersten, R., Beckmann, S., Clarke, B., Foegen, A., Marsh, L., Star, J., et al. (2009). Assisting Students Struggling with Mathematics: Response to Intervention (RtI) for Elementary and 
Middle Schools. NCEE 2009-4060. What Works Clearinghouse. Retrieved from ERIC database.

Gersten, R., Chard, D., Jayanthi, M., Baker, S., Morphy, P., \& Flojo, J. (2009). Mathematics instruction for students with learning disabilities: A meta-analysis of instructional components. Review of Educational Research, 79(3), 1202-1242. doi:10.3102/0034654309334431.

Gersten, R., \& Clarke, B. S. (2007). Effective strategies for teaching students with difficulties in mathematics. Retrieved February 11, 2010, from National Council of Teachers of Mathematics: http://www.nctm.org/news/content.aspx?id=8452

Gravetter, F., \& Wallnau, L. (2009). Statistics for the behavioral sciences. Belmont, California: Wadsworth Cengage Learning.

Greene, J.C., Caracelli, V.J., \& Graham, W.F. (1989). Toward a conceptual framework for mixed-method evaluation designs. Educational Evaluation and Policy Analysis, 11(3),255-274. doi:10.3102/01623737011003255

Goldman, S.R., Hasselbring, T. S. \& the Cognition and Technology Group at Vanderbilt. (1997). Achieving meaningful mathematics literacy for students with learning disabilities. Journal of Learning Disabilities, 30, 198-208. doi:10.1177/002221949703000207

Hsieh, H., \& Shannon, S.E. (2005). Three approaches to qualitative content analysis. Qualitative Health Research, 15(9),1277-1288. doi: 10.1177/1049732305276687

Hudson, P., \& Miller, S. (2006). Designing and implementing mathematics instruction for students with diverse learning needs. Boston, MA: Pearson Education, Inc. 
Hutchinson, N.L. (1993). Effects of cognitive strategy instruction on algebra problem solving of adolescents with learning disablities. Learning Disabilities Research \& Practice, 22,109117. doi: $10.2307 / 1511158$

Individuals with Disabilities Education Act of 2004, 20 U.S.C. $§ 1400$ et seq.

Ives, B. (2007). Graphic organizers applied to secondary algebra instruction for students with learning disorders. Learning Disabilities Research \& Practice, 22(2). 110-118. doi:10.1111/j.1540-5826.2007.00235.x

Ketterlin-Geller, L., Chard, D., \& Fien, H. (2008). Making connections in mathematics: Conceptual mathematics intervention for low-performing students. Remedial and Special Education, 29(1). 33-45. doi:10.1177/0741932507309711

Kieran, C. (1992). Learning and teaching of school algebra. In D. Grouws (Ed), Handbook of research on mathematics teaching and learning (pp. 390-419). Reston, Virginia: National Council of Teachers of Mathematics.

Kieran, C. (2007). Learning and teaching algebra at the middle school through college levels: Building meaning for symbols and their manipulation. In F. Lester Jr. (Ed.), Second handbook of research on mathematics teaching and learning (pp. 707-762). Charlotte, NC: Information Age Publishing.

Kilpatrick, J. \& Izsak, A.(2008). A history of algebra in the school curriculum. In C.E. Greenes \& R. Rubenstein (Eds.), Algebra and algebraic thinking in school mathematics: Seventieth yearbook (pp. 3-18). Reston, VA: The National Council of Teachers of Mathematics, Inc. 
Kooy, T. (1992). The effect of graphic advance organizers on the math and science comprehension with high school special education students. B.C. Journal of Special Education, 16(2), 101-11. Retrieved from ERIC database.

Kortering, L.J., deBettencourt, L.U. \& Braziel, P.M. (2005).Improving performance in high school algebra: What students with learning disabilities are saying. Learning Disability Quarterly, 28, 191-203.doi:10.2307/1593658

Kunsch, C., Jitendra, A., \& Sood, S. (2007). The effects of peer-mediated instruction in mathematics for students with learning problems: A research synthesis. Learning Disabilities Research \& Practice (Blackwell Publishing Limited), 22(1), 1-12. doi:10.1111/j.1540-5826.2007.00226.x.

Lange, J.D. (2007). Large-scale assessment and mathematics education. In F. Lester Jr. (Ed.), Second handbook of research on mathematics teaching and learning (pp. 1111-1142). Charlotte, NC: Information Age Publishing.

Loveless, T., \& Brookings Institution, (2008). The Misplaced Math Student: Lost in EighthGrade Algebra. The 2008 Brown Center Report on American Education. Special Release. Brookings Institution, Retrieved from ERIC database.

Lusk, A., Thompson, T. \& Daane, C. J. (2008). Algebra I teachers' perceptions of teaching students with learning disabilities. Journal of Curriculum and Instruction, 2(2), 34-51. doi:10.3776./joci.2008.v2n2p34-51

Maccini, P., \& Gagnon, J. C.(2000). Best practices for teaching mathematics to secondary students with special needs:Implications from teacher perceptions and a review of the literature.Focus on Exceptional Children, 32(5), 1-22. Retrieved from Education Research Complete database. 
Maccini, P., \& Gagnon, J.C. (2002). Perceptions and application of NCTM standards by special and general education teachers. Exceptional Children, 68(3), 325-344. Retrieved from Education Research Complete database.

Maccini, P., \& Gagnon, J. C. (2006). Mathematics instructional practices and assessment accomodations by secondary special and general educators. Exceptional Children, 72 (2), 217-234. Retrieved from Education Research Complete database.

Maccini, P., McNaughton, D., \& Ruhl, K. L. (1999). Algebra instruction for students with learning disabilities: Implications from a research review. Learning Disabilities Quarterly, 22, 113-126.

Maynus, L. (2010, August 10). Personal communication. (S. Lynch, Interviewer)

Mazzacco, M.M. (2007). Defining and differentiating mathematical learning disabilities and difficulties. In D.B. Berch \& M.M. Mazzocco (EDS.), Why is Math so Hard for Some Children? (pp.29-47). Baltimore, MD: Brookes.

Manalo, E., Bunnell, J., \& Stillman, J. (2000). The use of process mnemonics in teaching students with mathematics learning disabilities. Learning Disability Quarterly, 23(2), 137-56. Retrieved from ERIC database.

Miller, S., Butler, F., \& Lee, K. (1998). Validated practices for teaching mathematics to students with learning disabilities: A review of literature. Focus on Exceptional Children, 31(1), 1. Retrieved from Academic Search Complete database.

Miller, S., \& Hudson, P. (2006). Helping students with disabilities understand what mathematics means. TEACHING Exceptional Children, 39 (1), 28-35. Retrieved from Education Research Complete database. 
Moses, R.P., and Cobb, C.E. Radical equations: Math literacy and Civil Rights. Boston: Beacon Press, 2001.

National Center for Education Statistics (2010). Digest of Education Statistics, 2009 (NCES 2009-020), Retrieved June 25,2010, from http://nces.ed.gov/programs/digest/d09/

National Center for Education Statistics (2009). National Assessment of Educational Progress (NAEP), 1996, 2000, 2003, 2005, 2007, and 2009 Mathematics Assessments, Retrieved February 7,2010, from http://nationsreportcard.gov/math_2009/gr8_national.asp?subtab_id=Tab_6\&tab_id=tab1 \#chart

National Center for Learning Disabilties. (2008) Advocacy brief: Understanding the standardsbased individualized education program (IEP). Washington D.C: Author.

National Council of Teachers of Mathematics. (1980). An Adgenda For Action. Reston, Virginia: Author

National Council of Teachers of Mathematics. (1989). Curriculum and evaluation standards for school mathematics. Reston, Virginia: Author

National Council of Teachers of Mathematics. (2000). Executive summary principles and standards for school mathematics. Reston, Virginia: Author

National Council of Teachers of Mathematics. (2006). Curriculum focal points for prekindergarten through grade 8 mathematics. Reston, Virginia: Author

National Council of Teachers of Mathematics. (2009). Focus in high school mathematics:Reasoning and sense making. Reston, Virginia: Author 
National Mathematics Advisory Panel. (2008, March). National Math Panel Archieved Information. Retrieved July 24, 2010, from U.S. Department of Education: http://www2.ed.gov/about/bdscomm/list/mathpanel/report/final-factsheet.html

National Research Council. (2000). How people learn: Brain, mind, experience, and school. J. Bransford, A. Brown, R. Cocking (Eds.) Committee on Developments in the Science of Learning and on Learning Research and Educational Practice, Commission of Behavioral and Social Sciences and Education. Washington DC: National Academy Press.

National Research Council. (2001). Adding it up: Helping children learn mathematics. J. Kilpatrick, J. Swafford, and B. Findell (Eds.) Mathematics Learning Study Committee, Center for Education, Division of Behavioral and Social Sciences and Education. Washington DC: National Academy Press.

No Child Left Behind Act of 2001, 20 U.S.C. $§ 6310$ et seq. (Reauthorization of the Elementary and Secondary Education Act)

Owen, R., \& Fuchs, L. (2002). Mathematical Problem-Solving Strategy Instruction for ThirdGrade Students with Learning Disabilities. Remedial \& Special Education, 23(5), 268. Retrieved from Academic Search Complete database.

Patton, M.Q. (2002). Qualitative research and evaluation methods. Thousand Oaks, California: Sage Publications.

Pennsylvania Council of Teachers of Mathematics. (2009). PCTM position paper: Algebra for all. Retrieved from http://www.pctm.org/AlgebraForAll.html

Riales, J., James, J., Ivy, J. ( 2011, January). Algebra for all: Using TI-Navigator to provide equal opportunities to at-risk students. Paper presented at the Fifteenth Annual Conference of the Association of Mathematics Teacher Educators, Irvine, California. 
Reys, R., Reys, B., Lapan, R., Holliday, G., \& Wasman, D. (2003). Assessing the impact of standards-based middle grades mathematics curriculum materials on student achievement. Journal for Research in Mathematics Education, 34(1), 74-95. Retrieved from Education Research Complete database.

Riccomini, P. (2010). It's not just for reading. Teacher Professional Development Sourcebook, 3(2), 17-18. Retrieved from Education Research Complete database.

Rittle-Johnson, B., \& Alibali, M. W. (1999). Conceptual and procedural knowledge of mathematics: Does on lead to the other? Journal of Educational Psychology, 91, 175189. Retrieved from Education Research Complete database.

Rittle-Johnson, B., \& Star, J. (2007). Does comparing solution methods facilitate conceptual and procedural knowledge? An experimental study on learning to solve equations. Journal of Educational Psychology, 99(3), 561-574. doi:10.1037/0022-0663.99.3.561.

Schiller, K. S., Schmidt, W. H., Muller, C., \& Houang, R. T. (2010). Hidden disparities: How courses and curricula shape opportunities in mathematics during high school. Equity \& Excellence in Education, 43(4), 414-433. doi: 10.1080/10665684.2010.517062

Servilio, K.L. (2009). Mathematics professional development needs of general education and special education teachers. Unpublished doctoral dissertation, West Virginia University, Morgantown, WV. Retrieved May 23,2010, from WVU dissertation database.

Spitzer, J.S., White, D.Y., \& Flores, A. (2009). Help one, help all. In C. Malloy (Ed.), Mathematics for every student: Responding to Diversity (pp. 39-48). Reston, VA: National Council of Teachers of Mathematics. 
Steele, M. (2002). Strategies for helping students who have learning disabilities in mathematics. Mathematics Teaching in the Middle School , 8 (3), 140-143. Retrieved from Academic Search Complete database.

Steele, M. M., \& Steele, J. W. (2003). Teaching algebra to students with learning disabilities. Mathematics Teacher, 96 (9), 622-624. Retrieved from Academic Search Complete database.

Strickland, T. K., \& Maccini P. (2010). Strategies for teaching algebra to students with learning disabilities: Making research to practice connections. Intervention in School and Clinic, 46 (38), 38-45. DOI: $10.1177 / 1053451210369519$

Thurlow, M.L (2000). Standards-based reform and students with disabilties: Reflections on a decade of change. Focus on Exceptional Children, 33, 1-13. Retrieved from Education Research Complete database.

Tomlinson, C.A. (1999). The Differentiated classroom: Responding to the needs of all learners. Alexandria, VA: Association for Supervision and Curriculum Development.

Turnbull, A., Turnbull, R., \& Wehmeyer, M. (2007). Exceptional lives:Special education in today’s schools. Upper Saddle River, NJ: Pearson Education, Inc.

Urban, W. J., \& Wagnor Jr., J. L. (2009). American Education A History. New York, New York: Routledge.

U.S Census Bureau (2009). State and County QuickFacts: Mineral County, West Virginia. Retrieved August 27, 2010, from http://quickfacts.census.gov/qfd/states/54/54057.html

U.S. Department of Education (2001). Twenty-third annual report to Congress. Retrieved February 1, 2010, from http://www.ed.gov/about/reports/annual/osep/2001/index.html 
U.S. Department of Education (2010, March). Teacher shortage areas nationwide listing 199091 through 2009-10. Retrieved on April 1, 2010, from www.ed.gov/about/offices/list/ope/pol/tsa.doc

U.S. Department of Education, Office of Special Education Programs. Idea-building the legacy topic: alignment with the no child left behind act. (2007, February 2). Retrieved January 3, 2010, from http://idea.ed.gov/explore/view/p/\%2Croot\%2Cdynamic\%2CTopicalBrief\%2C3\%2C

van Garderen, D. (2007). Teaching Students With LD to Use Diagrams to Solve Mathematical Word Problems. Journal of Learning Disabilities, 40(6), 540-553. Retrieved from Academic Search Complete database.

Viadero, D. (2010). Early-Algebra Push Seen to Be Flawed. Education Week, 29(21), 1-14. Retrieved from Education Research Complete database.

Walonick, D, S. (1996). Basic research design. Retrieved from http://www.statpac.com/researchpapers/research-proposal.htm

West Virginia State Department of Education. (2006). 21st Century Mathematics Content Standards and Objectives. Retrieved July 1, 2010 from West Virginia Department of Education: http://wvde.state.wv.us/policies/p2520.2.pdf

West Virginia State Department of Education. (2007). West Virginia Mathematics Program Improvement Review [Data file, Inventory, and Scoring Rubric]. Retrieved from http://wvde.state.wv.us/teach21/mpir.html

West Virginia Department of Education. (2008). Assuring the Quality of Education: Regulations for Education Programs (2510). Retrieved November 25, 2008 from West Virginia Department of Education: http://wvde.state.wv.us/policies/p2510.doc 
West Virginia Department of Education. (2009, May). A Study of the National Math Panel Findings Comparision to WV. Retrieved January 2, 2010, from West Virginia Department of Education:

http://wvde.state.wv.us/instruction/documents/AStudyoftheNationalMathPanelFindingsC omparisontoWV.pdf

West Virginia Department of Education. (2010). Regulations for Education of Students with Exceptionalities (2419). Retrieved August 9, 2010 from West Virginia Department of Education: http://wvde.state.wv.us/osp/policy2419.html

West Virginia Education Information System. (2010). West Virginia NCLB Report Card 200809. Retrieved August 27, 2010 from West Virginia Department of Education: http://wveis.k12.wv.us/nclb/pub/rpt0809/cache/pdf999.pdf

White, D. Y. (2004, October). Teaching mathematics to special needs students. Teaching Children Mathematics, 116-117. Retrieved from Academic Search Complete database.

Witzel, B. (2005). Using CRA to Teach Algebra to Students with Math Difficulties in Inclusive Settings. Learning Disabilities -- A Contemporary Journal, 3(2), 49-60. Retrieved from Academic Search Complete database.

Witzel, B.S., Riccomini, P.J., \& Schneider E. (2008, May). Implementing CRA with secondary students with learning disabilities in mathematics. Intervention in School and Clinic, 43(5), 270-276.

Witzel, B.S, Smith, S.W., \& Brownell, M.T. (2001, November). How can I help students with learning disabilities in algebra? Intervention in School and Clinic, 37(2), 101-104. DOI: $10.1177 / 105345120103700205$ 


\section{APPENDICES}


Appendix A

Email Message Inviting Teachers to Complete the Survey of Instructional Practices Implemented by Algebra I General and Special Educators When Educating Students With a MLD (SIP)

\section{Email Title}

Please Respond to a Survey on the Current State of Algebra I Instructional Practices for Students with a Specific Learning Disability in Mathematics

\section{Email Message}

I am a doctoral student in the Department of Curriculum and Instruction at West Virginia University who is conducting research for my dissertation. The research consists of an online survey of educators' perception of how their knowledge base for instructing student with MLD (Mathematical Learning Disability) was developed, and what type of instructional practices general and special educators are implementing for students with MLD. Also, follow-up interviews will be completed with the participants who volunteer to participate in the follow-up interview. I need your help to obtain a better understanding of the current state of Algebra I instruction for students with MLD in West Virginia.

The survey form, which will only take approximately 10 minutes of your time, will be available from . Individuals who take the time to complete the survey can be entered for a chance to win a $\$ 50$ Visa gift card.

Please click the link below to start the survey:

Surveymonkey

If you have any questions feel free to contact me at ssmith71@ mix.wvu.edu or 304.483.0190.

Sincerely,

Sararose Lynch, ABD

West Virginia University

Department of Curriculum and Instruction 
Appendix B

Cover Letter to Teachers Who Complete the Survey of Instructional Practices Implemented by Algebra I General and Special Educators When Educating Students With a MLD (SIP)

\title{
Survey of Instructional Practices Implemented by Algebra I General and Special Educators When Educating Students with a MLD (SIP)
}

\author{
Conducted by \\ Sararose Lynch \\ Co-Principal Investigator \\ Doctoral Student \\ \& \\ Johnna Bolyard \\ Principle Investigator \\ Faculty Supervisor \\ Department of Curriculum and Instruction \\ West Virginia University
}

The purpose of this research study is to describe current instructional practices of Algebra I educators, from West Virginia, and the opportunities they have had to expand their knowledge base for educating students with a specific learning disability in mathematics (MLD). Further, this study will examine to what extent teachers' instructional practices for teaching Algebra I students with MLD align with best practices recommended in the research literature. Results from this study could be utilized to inform the development of future professional development offerings, state and county supported programs, and resources that can address the challenges faced in today's Algebra I classroom.

- Your completion and return of this online survey is considered to reflect your consent to participate in this study. Your participation is completely voluntary. West Virginia University's 'Acknowledgement' for 'Approval' is on file. If you have questions about the survey or your rights as a participant in the study, you may call the staff of the WVU Institutional Review Board for the Protection of Human Subjects at 304.293.7073.

- Your responses to this online survey are confidential, and are only connected to your provided contact information in order to contact you if you are a gift card winner or are selected to participate in a follow-up interview.

- If you do not wish to answer a question, you may choose to not select an indicator or leave the textbox blank.

- If you have any questions about this survey, please contact Sararose Lynch at ssmith71@mix.wvu.edu or 304.483.0190.

- You may also contact my faculty supervisor, Johnna Bolyard, at johnna.bolyard@mail.wvu.edu or 304-293-4724. 
Appendix C

Survey of Instructional Practices Implemented by Algebra I General and Special Educators When Educating Students With a MLD (SIP)

Instructions: I am gathering information to describe the current state of instruction for students with Mathematical Learning Disabilities (MLD) in an Algebra I setting. Please check the appropriate response or complete fill-in the blank where applicable. Thank you in advance for completing this survey.

\section{Professional Background}

1) Do you teach, or co-teach, at least one Algebra I or Algebra I Support class? Yes

No

(If the response is "No" they will be directed out of the survey)

2) What is your current position?

Special education teacher

General education teacher

Neither special educator or general educator

(If the response is "Neither" they will be directed out of the survey)

3) Please provide at least one type of contact information. This information will be kept confidential and will be used to contact you if you win a gift card and/or are selected to participate in a follow-up interview. By providing this information you are in no way consenting to be a participant in an interview. At the time you are contacted to participate in a follow up interview you can accept or decline the invitation.

Email address:

Cell phone number:

Home phone number:

4) Please indicate your gender.

Male

Female

5) Which statement best fits your level of higher education?

I have a doctoral degree in education

I have a master's degree in education

I have a bachelor's degree in education

I have a bachelor's degree in another area with general education certification

I have a bachelor's degree in another area with general education permit

I have a bachelor's degree in another area with special education permit 
Other

6) What is your certification?

Mathematics 5-9

Mathematics 5-Algebra

Mathematics 7-12 or 5-AD

Special education Multi-categorical 5-AD

Other

7) Years Teaching Experience

1-3

4-6

7-10

More than 10

8) Years Experience Teaching Algebra I

1-3 years

4-6 years

$7-10$ years

more than 10

9) Are you "highly qualified" in math (as defined by NCLB)?

Yes

No

10) Are you "highly qualified" in special education (as defined by NCLB)?

Yes

No

11) In which RESA(Regional Education Service Agency) do you work:

I McDowell, Mercer, Monroe, Raleigh, Summers, Wyoming

II Cabell, Lincoln, Logan, Mason, Mingo, Wayne

III Boone, Clay, Kanawha, Putnam

IV Braxton, Fayette, Greenbrier, Nicholas, Pocahontas, Webster

V Calhoun, Jackson, Pleasants, Ritchie, Roane, Tyler, Wirt, Wood

VI Brooke, Hancock, Marshall, Ohio, Wetzel

VII Barbour, Doddridge, Gilmer, Harrison, Lewis, Marion, Monongalia, Preston, Randolph, Taylor, Tucker, Upshur

VIII Berkeley, Grant, Hampshire, Hardy, Jefferson, Mineral, Morgan, Pendleton

12) What is your teaching role in education?

Math teacher in general education setting

Co-teacher in an inclusive classroom

Special Educator in a Self-Contained Classroom

Other 
13) What grade level(s) do you teach?

$5^{\text {th }} 6^{\text {th }} \quad 7^{\text {th }} \quad 8^{\text {th }} 9^{\text {th }} \quad 10^{\text {th }} \quad 11^{\text {th }} \quad 12^{\text {th }}$

14) Approximately how many students graduate each year from your county?

Less than 200 students

200-400 students

401-600 students

601-800 students

Over 800 students

15) How many classes do you teach daily?

1

2

3

4

5

6

More than 6

16) Please indicate what Algebra class you are currently teaching:

Algebra I

Algebra Support

Other

17) The majority of students with MLD in your school receive services through which type of instructional setting?

Inclusive Classroom

Resource Classroom taught by a Special Educator

Other

18) How many students with MLD as their primary disability are in your Algebra class?

$0-5$

6-10

11 or more

19) Please indicate how often you collaborate with special education teacher (if you are a general educator) or a general education teacher (if you are a special educator) about mathematics instruction.

Daily

2-3 times a week 
Once a week

Once every two weeks

Less than twice a month

\section{Professional Development}

20) How many college courses (undergraduate and graduate) have you taken that address the characteristics and needs of students with MLD?

None

One

Two

Three

Four or more

21) In the past three years, how many of hours of professional development have you had in mathematics education for students with MLD?

6 hours or less

7-15 hours

16-35 hours

More than 35 hours

22) If you had professional development related to your mathematics teaching for students with MLD, what was the format? (select all that apply)

-Attendance at a workshop on mathematics teaching -Observation of other teachers teaching mathematics as part of your own professional development (formal or informal)

-Study group of teachers (Professional Learning Community) on mathematics teaching issues

- A formal college/university course in the teaching of mathematics

- A formal college/university mathematics course

- Service as a mentor and/or peer coach in mathematics teaching as part of a formal arrangement that is recognized or supported by the school or district

- Attendance at a national or state mathematics teacher association meeting

- Collaboration on mathematics teaching issues with a group of teachers at a distance using telecommunications (distance learning)

-Other (please specify the format)

23) Reflect on the in-service and other professional development you have received related to your mathematics teaching for students with MLD and evaluate how prepared you feel to do the following: 


\begin{tabular}{|c|c|c|c|c|c|}
\hline & $\begin{array}{c}\text { Not } \\
\text { Well } \\
\text { Prepared }\end{array}$ & $\begin{array}{l}\text { Somewhat } \\
\text { Prepared }\end{array}$ & Prepared & $\begin{array}{c}\text { Well } \\
\text { Prepared }\end{array}$ & $\begin{array}{c}\text { Very } \\
\text { Well } \\
\text { Prepared }\end{array}$ \\
\hline $\begin{array}{l}\text { Develop lessons that } \\
\text { provide opportunities } \\
\text { for students to actively } \\
\text { construct their own } \\
\text { mathematical } \\
\text { knowledge }\end{array}$ & & & & & \\
\hline $\begin{array}{l}\text { Provide opportunities } \\
\text { for students to use } \\
\text { manipulatives to verify } \\
\text { mathematical reasoning }\end{array}$ & & & & & \\
\hline $\begin{array}{l}\text { Use cooperative } \\
\text { learning groups }\end{array}$ & & & & & \\
\hline $\begin{array}{l}\text { Listen/ask questions as } \\
\text { students work in order } \\
\text { to gauge their } \\
\text { understanding. }\end{array}$ & & & & & \\
\hline $\begin{array}{l}\text { Develop students' } \\
\text { conceptual } \\
\text { understanding of } \\
\text { mathematics }\end{array}$ & & & & & \\
\hline $\begin{array}{l}\text { Manage a class of } \\
\text { students engaged in } \\
\text { hands-on project- based } \\
\text { work }\end{array}$ & & & & & \\
\hline $\begin{array}{l}\text { Lead a class of students } \\
\text { using investigative } \\
\text { strategies }\end{array}$ & & & & & \\
\hline $\begin{array}{l}\text { Model multiple } \\
\text { problem-solving } \\
\text { strategies and have } \\
\text { students apply what } \\
\text { they have learned }\end{array}$ & & & & & \\
\hline $\begin{array}{l}\text { Connect math to real- } \\
\text { life contexts and } \\
\text { careers }\end{array}$ & & & & & \\
\hline $\begin{array}{l}\text { Take students' prior } \\
\text { understanding into } \\
\text { account when planning } \\
\text { curriculum and } \\
\text { instruction }\end{array}$ & & & & & \\
\hline Use a variety of & & & & & \\
\hline
\end{tabular}




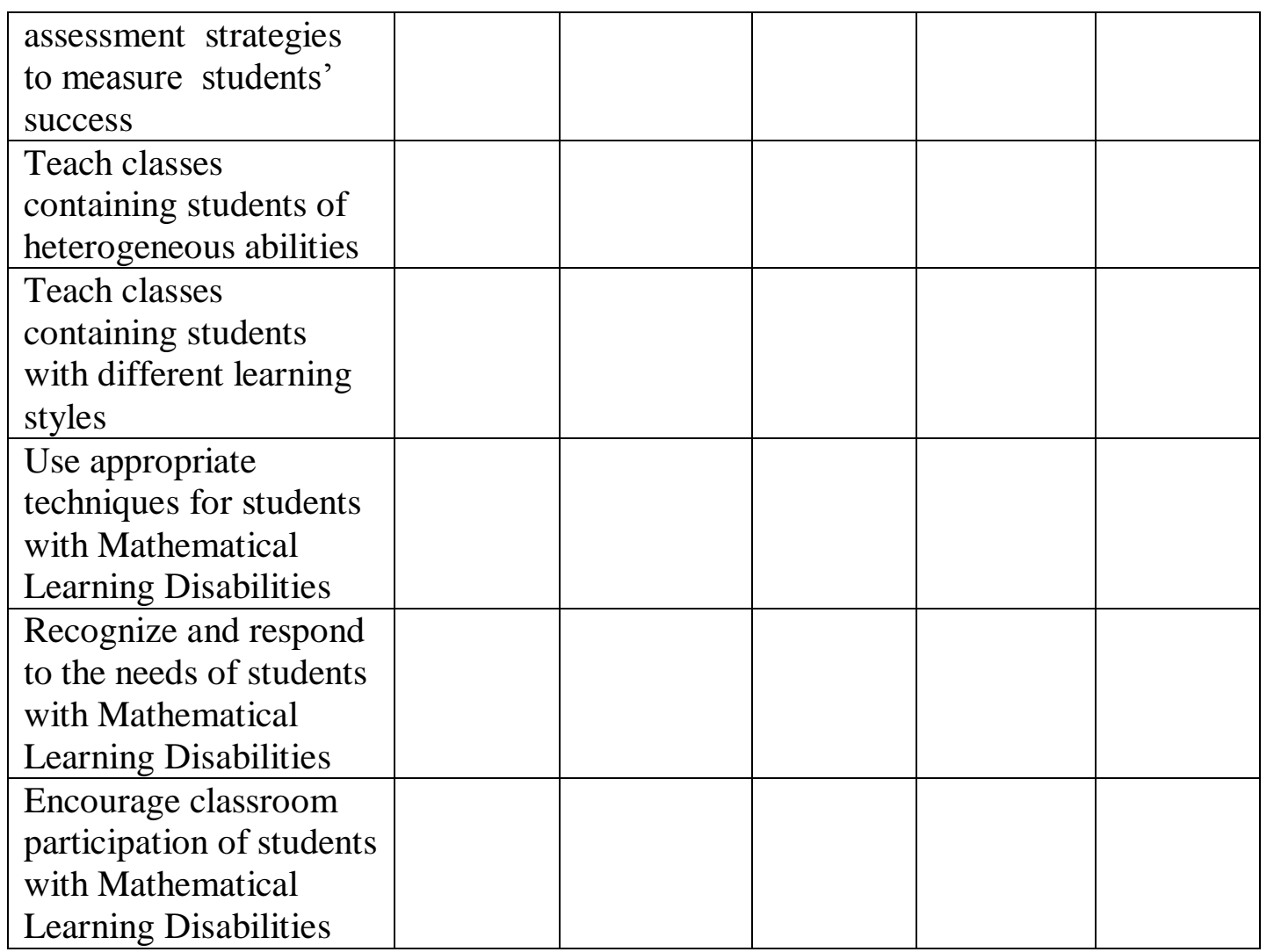

\section{Mathematics Instruction}

24) How often do you use each of the following techniques to teach and/or assess mathematics for students with MLD in your Algebra I class(es)?

\begin{tabular}{|l|l|l|l|l|l|}
\hline & Daily & Weekly & Monthly & Rarely & Never \\
\hline $\begin{array}{l}\text { Students solving real-life } \\
\text { problems }\end{array}$ & & & & & \\
\hline $\begin{array}{l}\text { Mathematical writing } \\
\text { (reflections) }\end{array}$ & & & & & \\
\hline Demonstrating/modeling & & & & & \\
\hline Students using manipulatives & & & & & \\
\hline Visual and graphic depictions & & & & & \\
\hline Student think-alouds & & & & & \\
\hline Peer-assisted learning & & & & & \\
\hline $\begin{array}{l}\text { Formative Assessment Data } \\
\text { provided to teachers and students }\end{array}$ & & & & & \\
\hline $\begin{array}{l}\text { CRA(Conctrete- } \\
\text { Representational-Abstract) }\end{array}$ & & & & & \\
\hline Students in groups or teams & & & & & \\
\hline Calculator problem solving & & & & & \\
\hline $\begin{array}{l}\text { Review of Skills and procedures } \\
\text { with step by step prompts }\end{array}$ & & & & & \\
\hline
\end{tabular}




\begin{tabular}{|l|l|l|l|l|l|}
\hline Whole-class discussion & & & & & \\
\hline Lecture with student note taking & & & & & \\
\hline Student-led discussion & & & & & \\
\hline Individualized assignments & & & & & \\
\hline $\begin{array}{l}\text { Extended time on tests and } \\
\text { assignments }\end{array}$ & & & & & \\
\hline Assessment modifications & & & & & \\
\hline Others (please specify) & & & & & \\
\hline Others (please specify) & & & & & \\
\hline Others (please specify) & & & & & \\
\hline Others (please specify) & & & & & \\
\hline
\end{tabular}

25) Please indicate the item that best describes your perception of the following statement:

Students with MLD are effectively taught mathematics at my school?

-I strongly agree

-I agree

-I do not agree nor disagree

-I disagree

-I strongly disagree

26) To what extent is each of the following a problem that limits students' with MLD mathematical learning in your school?

\begin{tabular}{|l|l|l|l|l|l|}
\hline & $\begin{array}{l}\text { Not a } \\
\text { Problem }\end{array}$ & $\begin{array}{l}\text { Slight } \\
\text { Problem }\end{array}$ & $\begin{array}{l}\text { Moderate } \\
\text { Problem }\end{array}$ & $\begin{array}{l}\text { Significant } \\
\text { Problem }\end{array}$ & $\begin{array}{c}\text { Severe } \\
\text { Problem }\end{array}$ \\
\hline $\begin{array}{l}\text { Availability of funds for } \\
\text { mathematics materials and } \\
\text { supplies }\end{array}$ & & & & & \\
\hline $\begin{array}{l}\text { Availability of appropriate } \\
\text { curriculum materials (texts, } \\
\text { calculators, software, etc.) }\end{array}$ & & & & & \\
\hline $\begin{array}{l}\text { Availability of and access to } \\
\text { computers and other } \\
\text { technology }\end{array}$ & & & & & \\
\hline $\begin{array}{l}\text { Pressure to prepare students } \\
\text { for state assessment }\end{array}$ & & & & & \\
\hline $\begin{array}{l}\text { Availability of in-service } \\
\text { opportunities for math } \\
\text { teachers }\end{array}$ & & & & & \\
\hline $\begin{array}{l}\text { Other(please specify issue and } \\
\text { severity of problem) }\end{array}$ & & & & & \\
\hline
\end{tabular}




\begin{tabular}{|l|l|l|l|l|l|}
\hline & & & & & \\
\hline $\begin{array}{l}\text { Other(please specify issue and } \\
\text { severity of problem) }\end{array}$ & & & & & \\
\hline $\begin{array}{l}\text { Other(please specify issue and } \\
\text { severity of problem) }\end{array}$ & & & & & \\
\hline
\end{tabular}

27) Please describe your perception related to issues involved in Algebra I instruction for students with MLD.

Thank you for participating in this research study. I appreciate your willingness to support this research and the time and thought you put into completing the confidential survey questions. If you win one of the gift cards, and/or are selected as an interview participant you will be contacted through the personal contact information you provided on survey question 2. 
Appendix D

Interview Cover Letter

\section{West VirginiaUniversity}

College of Human Resources and Education

Good morning, good afternoon, or good evening, and thank you for agreeing to meet with me. My name is and I am conducting research under the supervision of Johnna Bolyard, Ph.D., an Associate Professor in the College of Human Resources and Education at West Virginia University. The purpose of this research study is to determine the current state of Algebra I instruction to students with MLD in West Virginia. This study is being conducted in partial fulfillment of my doctoral degree in Curriculum and Instruction. I would like to audiotape this interview in order to accurately represent what you say, may I have your permission to tape this interview? Our interview should last about 15 minutes. Before we begin I want to make sure you understand the following:

- You must be 18 years of age or older to participate.

- Your participation is entirely voluntary, you can choose to stop the interview at any time and you do not have to answer any question you do not want to answer.

- Your responses will be kept as confidential as legally possible. Your name will not be attached to notes from this interview or to transcribed data, and the audio will be erased once transcription is complete. At no time will your name be revealed during reporting.

- Your class job status will not be affected if you decide either not to participate or to withdraw.

- West Virginia's University's Institutional Review Board acknowledgement of this project is on file.

Thank you again for your willingness to participate in this study.

Sincerely,

Sararose Lynch

304.483.0190

ssmith71@mix.wvu.edu

Johnna Bolyard, Ph.D.

304-293-4724

johnna.bolyard@mail.wvu.edu 
Appendix E

Interview Questions

The following are specific questions asked of each interviewee:

- How is Algebra I taught to students with MLD in your school?

- What are your experiences with this delivery system for teaching Algebra I to students with MLD?

- How do you feel about this delivery system for teaching Algebra I to students with MLD?

- Can you share any suggestions for an improvement of your schools, and/or the state departments, delivery system of Algebra I for students with MLD?

- What opportunities have you had to develop knowledge for teaching students with MLD?

- What are any issues you can identify surrounding the instruction of algebra to students with MLD?

The following are specific questions asked of selected interviewees:

Questions asked about use and knowledge of CRA:

- What are your experiences with using CRA to teach Algebra I concepts to students with MLD?

- How would you define CRA and what does it look like when being implemented in a classroom?

- Where or how did you attain this knowledge of CRA?

- How do you feel about using CRA for teaching Algebra I concepts to students with MLD? 
- Can you please describe any other perceptions regarding the use of CRA during instruction of Algebra I to students with MLD?

Questions asked about use and knowledge of peer-assisted learning:

- What are your experiences with using peer-assisted learning to teach Algebra I concepts to students with MLD?

- How would you define peer-assisted learning and what does it look like when being implemented in a classroom?

- Where or how did you attain this knowledge of peer-assisted learning?

- How do you feel about using peer-assisted learning for teaching Algebra I concepts to students with MLD?

- Can you please describe any other perceptions regarding the use of peer-assisted learning during instruction of Algebra I to students with MLD? 


\section{Appendix F}

\section{Coding Chart for Cross Interview Analysis}

Recommended Best Practices for Algebra I Instruction for Students with MLD

\begin{tabular}{|l|l|l|l|l|l|}
\hline & Interview 1 & Interview 2 & Interview 3 & Interview 4 & Interview 5 \\
\hline Explicit Instruction & & & & & \\
\hline $\begin{array}{l}\text { Classwide Peer } \\
\text { Tutoring/Cooperative } \\
\text { Learning }\end{array}$ & & & & & \\
\hline Technology & & & & & \\
\hline Graphic Organizers & & & & & \\
\hline $\begin{array}{l}\text { Graduated } \\
\text { Instructional } \\
\text { Sequence }\end{array}$ & & & & & \\
\hline $\begin{array}{l}\text { Cognitive Strategy } \\
\text { Instruction }\end{array}$ & & & & & \\
\hline $\begin{array}{l}\text { Other-Everyday Life } \\
\text { Applications }\end{array}$ & & & & & \\
\hline
\end{tabular}

Perceived Issues Surrounding Algebra Instruction for Students with MLD

\begin{tabular}{|l|c|c|c|c|c|}
\hline & Interview & Interview & Interview & Interview & Interview \\
& 1 & 2 & 3 & 4 & 5 \\
\hline Teacher Preparation & & & & & \\
\hline Access to Curriculum & & & & & \\
\hline Educational Placement & & & & & \\
\hline
\end{tabular}


Appendix G

\begin{tabular}{|c|c|c|c|c|c|c|c|c|}
\hline \multicolumn{9}{|c|}{$\begin{array}{l}\text { Crosstabulation of "Highly Qualified" in Mathematics and Number of College Courses } \\
\text { Addressing MLD }\end{array}$} \\
\hline & & & \multicolumn{5}{|c|}{$\begin{array}{l}\text { How many college courses (undergraduate and graduate) have } \\
\text { you taken that address the characteristics and needs of students } \\
\text { with MLD? }\end{array}$} & \multirow[t]{2}{*}{ Total } \\
\hline & & & None & One & Two & Three & $\begin{array}{l}\text { Four or } \\
\text { more }\end{array}$ & \\
\hline \multirow{8}{*}{\multicolumn{2}{|c|}{$\begin{array}{l}\text { Are you "highly } \\
\text { qualified" in math } \\
\text { (as defined by } \\
\text { NCLB)? }\end{array}$}} & Count & 14 & 7 & 5 & 6 & 4 & 36 \\
\hline & & $\begin{array}{l}\text { \% within Are you } \\
\text { "highly qualified" } \\
\text { in math (as defined } \\
\text { by NCLB)? }\end{array}$ & $38.9 \%$ & $19.4 \%$ & $13.9 \%$ & $16.7 \%$ & $11.1 \%$ & $\begin{array}{l}100.0 \\
\%\end{array}$ \\
\hline & & $\begin{array}{l}\text { \% within How } \\
\text { many college } \\
\text { courses } \\
\text { (undergraduate and } \\
\text { graduate) have you } \\
\text { taken that address } \\
\text { the characteristics } \\
\text { and needs of } \\
\text { students with } \\
\text { MLD? }\end{array}$ & $87.5 \%$ & $100.0 \%$ & $62.5 \%$ & $75.0 \%$ & $30.8 \%$ & $69.2 \%$ \\
\hline & & $\%$ of Total & $26.9 \%$ & $13.5 \%$ & $9.6 \%$ & $11.5 \%$ & $7.7 \%$ & $69.2 \%$ \\
\hline & & Count & 2 & 0 & 3 & 2 & 9 & 16 \\
\hline & & $\begin{array}{l}\% \text { within Are you } \\
\text { "highly qualified" } \\
\text { in math (as defined } \\
\text { by NCLB)? }\end{array}$ & $12.5 \%$ & $.0 \%$ & $18.8 \%$ & $12.5 \%$ & $56.3 \%$ & $\begin{array}{l}100.0 \\
\%\end{array}$ \\
\hline & & $\begin{array}{l}\% \text { within How } \\
\text { many college } \\
\text { courses } \\
\text { (undergraduate and } \\
\text { graduate) have you } \\
\text { taken that address } \\
\text { the characteristics } \\
\text { and needs of } \\
\text { students with } \\
\text { MLD? }\end{array}$ & $12.5 \%$ & $.0 \%$ & $37.5 \%$ & $25.0 \%$ & $69.2 \%$ & $30.8 \%$ \\
\hline & & $\%$ of Total & $3.8 \%$ & $.0 \%$ & $5.8 \%$ & $3.8 \%$ & $17.3 \%$ & $30.8 \%$ \\
\hline \multirow{4}{*}{\multicolumn{2}{|c|}{ Total }} & Count & 16 & 7 & 8 & 8 & 13 & 52 \\
\hline & & $\begin{array}{l}\% \text { within Are you } \\
\text { "highly qualified" } \\
\text { in math (as defined } \\
\text { by NCLB)? }\end{array}$ & $30.8 \%$ & $13.5 \%$ & $15.4 \%$ & $15.4 \%$ & $25.0 \%$ & $\begin{array}{l}100.0 \\
\%\end{array}$ \\
\hline & & $\begin{array}{l}\text { \% within How } \\
\text { many college } \\
\text { courses } \\
\text { (undergraduate and } \\
\text { graduate) have you } \\
\text { taken that address } \\
\text { the characteristics } \\
\text { and needs of } \\
\text { students with } \\
\text { MLD? }\end{array}$ & $100.0 \%$ & $100.0 \%$ & $100.0 \%$ & $100.0 \%$ & $100.0 \%$ & $\begin{array}{l}100.0 \\
\%\end{array}$ \\
\hline & & $\%$ of Total & $30.8 \%$ & $13.5 \%$ & $15.4 \%$ & $15.4 \%$ & $25.0 \%$ & $\begin{array}{l}100.0 \\
\%\end{array}$ \\
\hline
\end{tabular}




\section{Appendix H}

\begin{tabular}{|c|c|c|c|c|c|c|c|}
\hline \multicolumn{8}{|c|}{$\begin{array}{l}\text { Crosstabulation of "Highly Qualified" in Sp } \\
\text { Addressing MLD }\end{array}$} \\
\hline & & \multicolumn{5}{|c|}{$\begin{array}{l}\text { How many college courses (undergraduate and graduate) have } \\
\text { you taken that address the characteristics and needs of students } \\
\text { with MLD? }\end{array}$} & \multirow[t]{2}{*}{ Total } \\
\hline & & None & One & Two & Three & $\begin{array}{l}\text { Four or } \\
\text { more }\end{array}$ & \\
\hline \multirow{8}{*}{$\begin{array}{l}\text { Are you "highly } \\
\text { qualified" in } \\
\text { special } \\
\text { education (as } \\
\text { defined by } \\
\text { NCLB)? }\end{array}$} & Count & 1 & 0 & 0 & 1 & 10 & 12 \\
\hline & $\begin{array}{l}\% \text { within Are you } \\
\text { "highly qualified" in } \\
\text { special education (as } \\
\text { defined by NCLB)? }\end{array}$ & $8.3 \%$ & $.0 \%$ & $.0 \%$ & $8.3 \%$ & $83.3 \%$ & $\begin{array}{l}100.0 \\
\%\end{array}$ \\
\hline & $\begin{array}{l}\% \text { within How many } \\
\text { college courses } \\
\text { (undergraduate and } \\
\text { graduate) have you } \\
\text { taken that address } \\
\text { the characteristics } \\
\text { and needs of students } \\
\text { with MLD? }\end{array}$ & $6.7 \%$ & $.0 \%$ & $.0 \%$ & $14.3 \%$ & $71.4 \%$ & $23.5 \%$ \\
\hline & $\%$ of Total & $2.0 \%$ & $.0 \%$ & $.0 \%$ & $2.0 \%$ & $19.6 \%$ & $23.5 \%$ \\
\hline & Count & 14 & 7 & 8 & 6 & 4 & 39 \\
\hline & $\begin{array}{l}\% \text { within Are you } \\
\text { "highly qualified" in } \\
\text { special education (as } \\
\text { defined by NCLB)? }\end{array}$ & $35.9 \%$ & $17.9 \%$ & $20.5 \%$ & $15.4 \%$ & $10.3 \%$ & $\begin{array}{l}100.0 \\
\%\end{array}$ \\
\hline & $\begin{array}{l}\text { \% within How many } \\
\text { college courses } \\
\text { (undergraduate and } \\
\text { graduate) have you } \\
\text { taken that address } \\
\text { the characteristics } \\
\text { and needs of students } \\
\text { with MLD? }\end{array}$ & $93.3 \%$ & $100.0 \%$ & $100.0 \%$ & $85.7 \%$ & $28.6 \%$ & $76.5 \%$ \\
\hline & $\%$ of Total & $27.5 \%$ & $13.7 \%$ & $15.7 \%$ & $11.8 \%$ & $7.8 \%$ & $76.5 \%$ \\
\hline \multirow[t]{4}{*}{ Total } & Count & 15 & 7 & 8 & 7 & 14 & 51 \\
\hline & $\begin{array}{l}\text { \% within Are you } \\
\text { "highly qualified" in } \\
\text { special education (as } \\
\text { defined by NCLB)? }\end{array}$ & $29.4 \%$ & $13.7 \%$ & $15.7 \%$ & $13.7 \%$ & $27.5 \%$ & $\begin{array}{l}100.0 \\
\%\end{array}$ \\
\hline & $\begin{array}{l}\% \text { within How many } \\
\text { college courses } \\
\text { (undergraduate and } \\
\text { graduate) have you } \\
\text { taken that address } \\
\text { the characteristics } \\
\text { and needs of students } \\
\text { with MLD? }\end{array}$ & $100.0 \%$ & $100.0 \%$ & $100.0 \%$ & $100.0 \%$ & $100.0 \%$ & $\begin{array}{l}100.0 \\
\%\end{array}$ \\
\hline & $\%$ of Total & $29.4 \%$ & $13.7 \%$ & $15.7 \%$ & $13.7 \%$ & $27.5 \%$ & $\begin{array}{l}100.0 \\
\%\end{array}$ \\
\hline
\end{tabular}




\section{Appendix I}

\begin{tabular}{|c|c|c|c|c|c|c|c|}
\hline \multicolumn{8}{|c|}{$\begin{array}{l}\text { Crosstabulation of RESA of Employment Compared to Hours of Professional Development } \\
\text { Addressing Students with MLD }\end{array}$} \\
\hline & & & \multicolumn{4}{|c|}{$\begin{array}{l}\text { In the past three years, how many of hours of } \\
\text { professional development have you had in } \\
\text { mathematics education for students with MLD? }\end{array}$} & \multirow[t]{2}{*}{ Total } \\
\hline & & & $\begin{array}{l}6 \text { hours or } \\
\text { less }\end{array}$ & $\begin{array}{l}7-15 \\
\text { hours }\end{array}$ & $\begin{array}{l}16-35 \\
\text { hours }\end{array}$ & $\begin{array}{l}\text { More than } \\
35 \text { hours }\end{array}$ & \\
\hline \multirow{16}{*}{$\begin{array}{l}\text { In which } \\
\text { RESA(Regional } \\
\text { Education Service } \\
\text { Agency) do you } \\
\text { work: }\end{array}$} & \multirow[t]{2}{*}{ I } & Count & 3 & 0 & 0 & 0 & 3 \\
\hline & & $\begin{array}{l}\% \text { of } \\
\text { Total }\end{array}$ & $5.9 \%$ & $.0 \%$ & $.0 \%$ & $.0 \%$ & $5.9 \%$ \\
\hline & \multirow[t]{2}{*}{ II } & Count & 4 & 0 & 0 & 1 & 5 \\
\hline & & $\begin{array}{l}\% \text { of } \\
\text { Total }\end{array}$ & $7.8 \%$ & $.0 \%$ & $.0 \%$ & $2.0 \%$ & $9.8 \%$ \\
\hline & \multirow[t]{2}{*}{ III } & Count & 3 & 1 & 0 & 0 & 4 \\
\hline & & $\begin{array}{l}\% \text { of } \\
\text { Total }\end{array}$ & $5.9 \%$ & $2.0 \%$ & $.0 \%$ & $.0 \%$ & $7.8 \%$ \\
\hline & \multirow[t]{2}{*}{ IV } & Count & 2 & 0 & 2 & 0 & 4 \\
\hline & & $\begin{array}{l}\% \text { of } \\
\text { Total }\end{array}$ & $3.9 \%$ & $.0 \%$ & $3.9 \%$ & $.0 \%$ & $7.8 \%$ \\
\hline & \multirow[t]{2}{*}{ V } & Count & 7 & 0 & 0 & 0 & 7 \\
\hline & & $\begin{array}{l}\% \text { of } \\
\text { Total }\end{array}$ & $13.7 \%$ & $.0 \%$ & $.0 \%$ & $.0 \%$ & $13.7 \%$ \\
\hline & \multirow[t]{2}{*}{ VI } & Count & 3 & 1 & 0 & 0 & 4 \\
\hline & & $\begin{array}{l}\% \text { of } \\
\text { Total }\end{array}$ & $5.9 \%$ & $2.0 \%$ & $.0 \%$ & $.0 \%$ & $7.8 \%$ \\
\hline & \multirow[t]{2}{*}{ VII } & Count & 9 & 1 & 0 & 4 & 14 \\
\hline & & $\begin{array}{l}\% \text { of } \\
\text { Total }\end{array}$ & $17.6 \%$ & $2.0 \%$ & $.0 \%$ & $7.8 \%$ & $27.5 \%$ \\
\hline & \multirow[t]{2}{*}{ VIII } & Count & 8 & 1 & 0 & 1 & 10 \\
\hline & & $\begin{array}{l}\% \text { of } \\
\text { Total }\end{array}$ & $15.7 \%$ & $2.0 \%$ & $.0 \%$ & $2.0 \%$ & $19.6 \%$ \\
\hline \multirow{2}{*}{\multicolumn{2}{|c|}{ Total }} & Count & 39 & 4 & 2 & 6 & 51 \\
\hline & & $\begin{array}{l}\% \text { of } \\
\text { Total }\end{array}$ & $76.5 \%$ & $7.8 \%$ & $3.9 \%$ & $11.8 \%$ & $\begin{array}{l}100.0 \\
\%\end{array}$ \\
\hline
\end{tabular}




\section{CURRICLUM VITAE}

Sararose Lynch was born on March 11, 1982 and raised in Parkersburg, West Virginia. She received a Bachelor of Science in Secondary Education (5 $5^{\text {th }}$-Adult) and Mathematics in December of 2004 from West Virginia Wesleyan in Buckhannon, West Virginia. She taught high school mathematics for six months in Buckhannon, West Virginia before enrolling in graduate school. She received a Master of Science in Rehabilitation Counseling in December 2006 from West Virginia University in Morgantown, West Virginia. During her Master's program she was the Graduate Assistant for the Special Education department at West Virginia University, and completed an internship through the Maryland State Department of Education as a transition counselor working with secondary and postsecondary aged students with disabilities, who were enrolled in college. Following the completion of her master's program, in December 2006, she began teaching public school in Cumberland, Maryland at Braddock Middle School as a Special Education Teacher for students with emotional and behavioral disorders.

In August 2007, she accepted a job teaching fifth through eighth grade students Mathematics and Gifted Education at Frankfort Middle School in Ridgeley, West Virginia. The following year she enrolled in the Ed.D. Curriculum and Instruction program with a minor in Mathematics Education at West Virginia University. In addition to teaching at Frankfort Middle School, in August 2008 she began working as an adjunct faculty at Allegany College of Maryland, in Cumberland, Maryland, teaching Mathematics for Elementary Teachers. She also began supervising intern teachers from Frostburg State at Frankfort Middle School as the schools Professional Development School Site Coordinator in August of 2009. In addition to teaching both public school and higher education, she continues to be involved in writing for mathematics journals and presenting research at local and national conferences. 